University of Rhode Island

DigitalCommons@URI

Open Access Dissertations

2012

\title{
Teachers' Perception of Bullying Among Youth: Hindsight Bias in Relation to Victim Responses
}

Karen J. Sherman

University of Rhode Island

Follow this and additional works at: https://digitalcommons.uri.edu/oa_diss

\section{Recommended Citation}

Sherman, Karen J., "Teachers' Perception of Bullying Among Youth: Hindsight Bias in Relation to Victim Responses" (2012). Open Access Dissertations. Paper 1087.

https://digitalcommons.uri.edu/oa_diss/1087

This Dissertation is brought to you for free and open access by DigitalCommons@URI. It has been accepted for inclusion in Open Access Dissertations by an authorized administrator of DigitalCommons@URI. For more information, please contact digitalcommons-group@uri.edu. 
TEACHERS' PERCEPTIONS OF BULLYING AMONG YOUTH:

HINDSIGHT BIAS IN RELATION TO VICTIM RESPONSES

BY

KAREN J. SHERMAN

\section{A DISSERTATION SUBMITTED IN PARTIAL FULFILLMENT OF THE REQUIREMENTS FOR THE DEGREE OF DOCTOR OF PHILOSOPHY}

IN PSYCHOLOGY

UNIVERSITY OF RHODE ISLAND 


\begin{abstract}
Bullying, a common, persistent, and detrimental occurrence in schools, adversely affects the social, emotional, behavioral, and psychological well-being of children and youth. Independent variables that have been studied among children and youth involved in bullying in school settings are delineated, ways that bullying has been assessed and reported are described and critiqued, and the effect of hindsight bias is reviewed. Fortyeight vignettes were constructed by crossing (a) four kinds of social contact (physical aggression, verbal aggression, relational aggression, and non-aggression) with (b) male and female actors, (c) male and female and receivers, and (d) reaction of the receiver (aggressive, passive, and no reaction). Participants gave predictions of how the receiver may react to the scenario, rated vignettes on seven items assessing the seriousness, and gave qualitative responses to how they might intervene. Hindsight bias analyses revealed that when a hindsight bias exists, teachers who read an aggressive reaction by the receiver always gave a higher prediction of the likelihood that the victim would respond aggressively. Analyses of the vignettes revealed that physical aggression was perceived as more serious than any other kind of social contact, and situations that depicted female actors and male receivers were perceived as least serious across all kinds of social contact. The qualitative responses demonstrated that teachers report using different intervention strategies with the actors versus the receivers, and different intervention strategies based on kind of contact. Results are discussed in terms of applied implications for teachers in school settings and in terms of directions for future research.
\end{abstract}




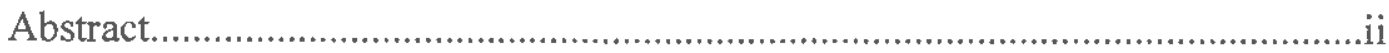

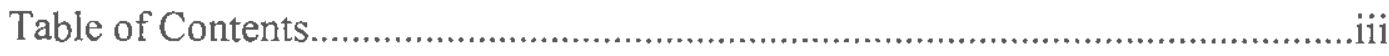

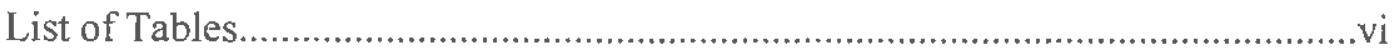

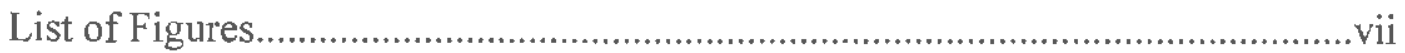

Chapter I: Introduction,

Statement of the Problem............................................................................

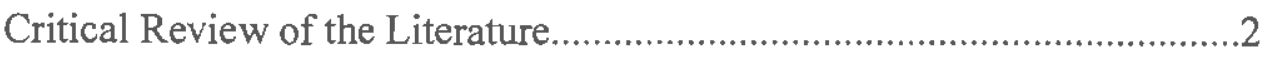

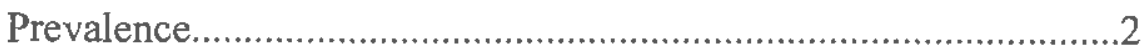

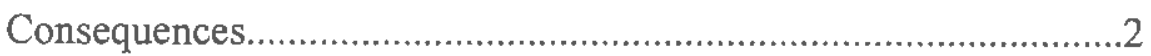

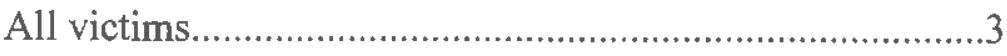

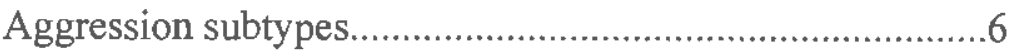

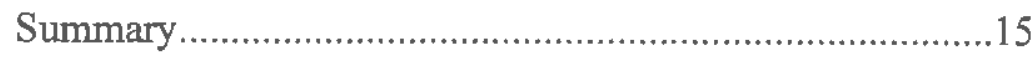

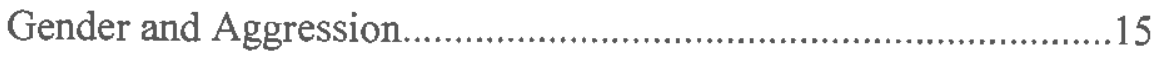

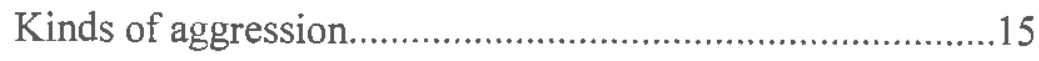

Gender by aggression interactions......................................16

Summary and conclusions.....................................................

Reporting Bullying in Schools......................................................34

Measurement Approaches.................................................................

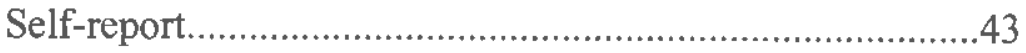

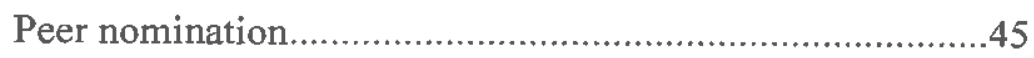

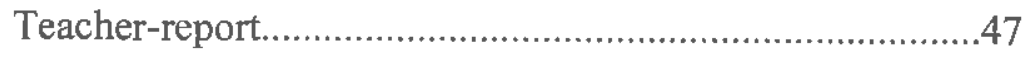


Table of Contents (Continued)

page

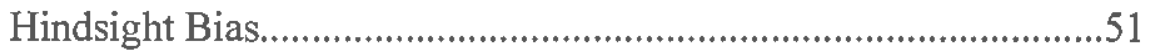

Relevance to teachers.........................................................60

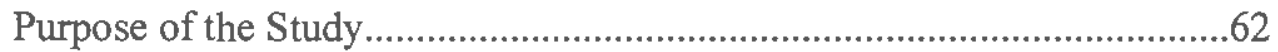

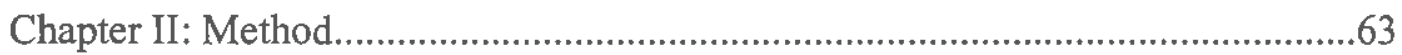

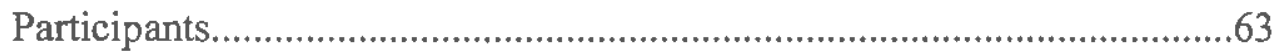

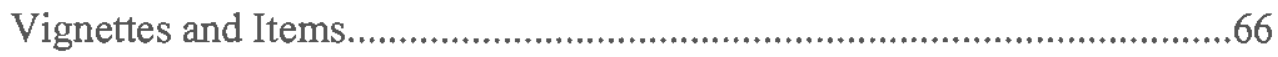

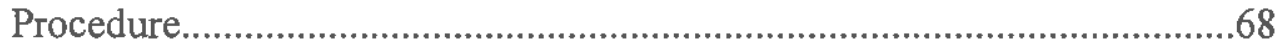

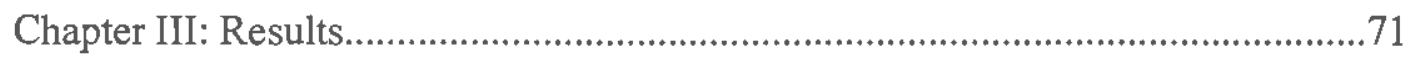

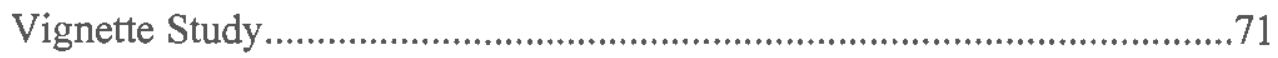

Kind of Aggression x Receiver Reaction Interaction........................75

Gender of Receiver x Receiver Reaction Interaction........................77

Kind of Aggression $x$ Gender of Actor Interaction..........................78

Kind of Aggression x Gender of Receiver Interaction.....................80

Gender of Actor x Gender of Receiver Interaction..........................82

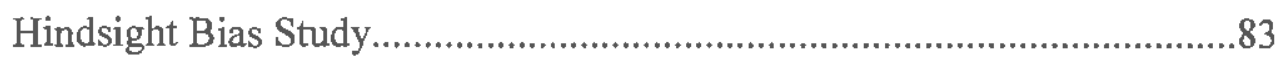

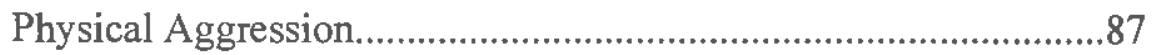

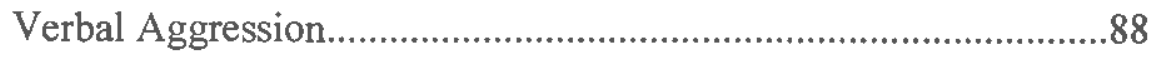

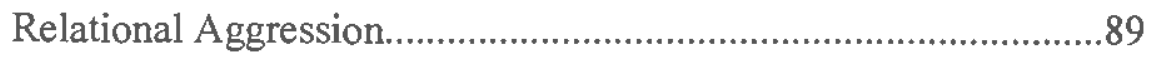

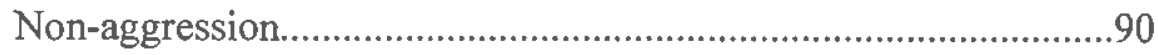

Exploratory Qualitative Study.................................................................90

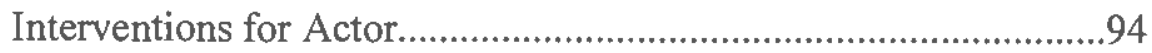


Table of Contents (Continued)

page

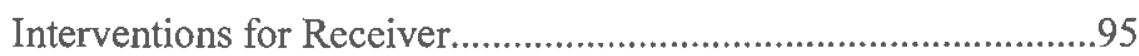

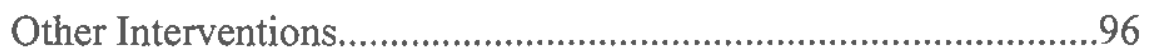

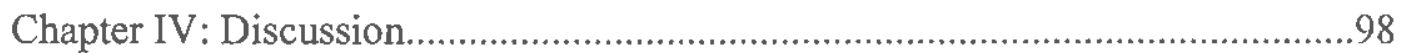

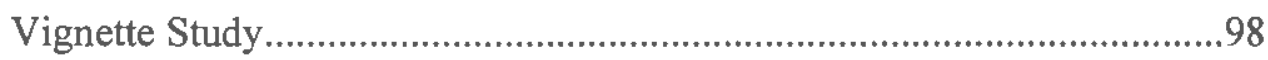

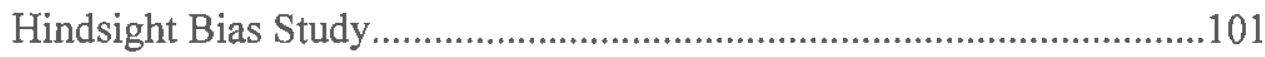

Exploratory Qualitative Study..............................................................103

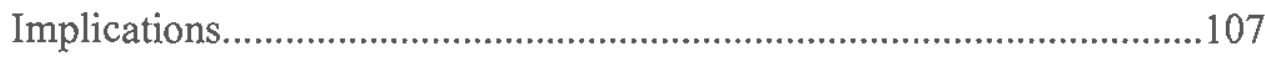

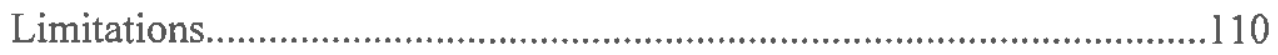

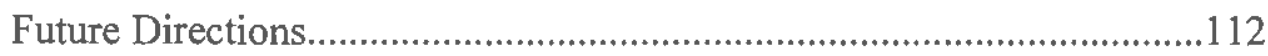

Summary and Conclusions...................................................................114

Appendix A: Directions, Demographic Questionnaire, Vignettes, and Items.....119

Appendix B: Email Invitation to Participate.........................................................169

Appendix C: Informed Consent Form..........................................................170

Appendix D: Debriefing Form...........................................................................172

Appendix E: Sources of Variation in Research Designs.....................................173

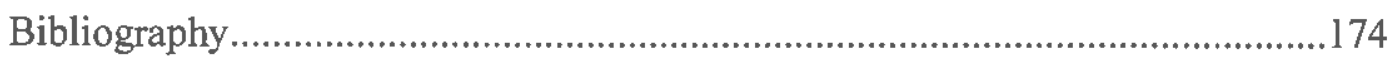




\section{List of Tables}

Table page

1 Social-Psychological Adjustment Variables and Physical Victimization Groups. 30

2 Social-Psychological Adjustment Variables and Relational Victimization Groups. 30

3 Mean Seriousness Ratings for Vignettes.............................................71

4 Mauchly's Test of Sphericity.............................................................73

5 Vignette Study ANOVA Table........................................................... 74

6 Marginal cell means of seriousness ratings for Kind of Aggression $\mathrm{x}$ Receiver Reaction Condition interaction............................................... 75

7 Marginal cell means of seriousness ratings for Gender of Receiver $\mathrm{x}$ Receiver Reaction interaction...............................................................77

8 Marginal cell means of seriousness ratings for Kind of Aggression x Gender of Actor interaction.

9 Marginal cell means of seriousness ratings for Kind of Aggression $\mathrm{x}$ Gender of Receiver interaction.

10 Marginal cell means for seriousness ratings for Gender of Actor $\mathrm{x}$ Gender of Receiver interaction.

11 Mean Probabilities of Aggressive Receiver Reaction.................................84

12 Mauchly's Test of Sphericity............................................................. 85

13 Hindsight Bias Study ANOVA Table.................................................85

14 Frequency of Responses for each Intervention Category..........................91

15 Sum of Intervention Categories for Actor..............................................93

16 Sum of lntervention Categories for Receiver......................................93

17 Sum of Other Intervention Categories................................................99

18 Sources of Variation in Research Designs.............................................. 173 


\section{List of Figures}

Figure page

1 Marginal cell means of seriousness ratings for Kind of Aggression $\mathrm{x}$ Receiver Reaction Condition interaction. .76

2 Marginal cell means of seriousness ratings for Gender of Receiver $\mathbf{x}$

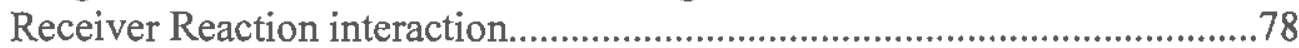

3 Marginal cell means of seriousness ratings for Kind of Aggression $\mathrm{x}$ Gender of Actor interaction.

4 Marginal cell means of seriousness ratings for Kind of Aggression x Gender of Receiver interaction.

5 Marginal cell means for seriousness ratings for Gender of Actor x Gender of Receiver interaction. .83

6 Percent Likelihood of Aggression for Physically Aggressive Vignettes.......88

7 Percent Likelihood of Aggression for Verbally Aggressive Vignettes...........89

8 Percent Likelihood of Aggression for Relationally Aggressive Vignettes.....90 
Chapter I: Introduction

Statement of the Problem

Bullying, a common, persistent, and detrimental occurrence in schools, adversely affects the social, emotional, behavioral, and psychological well-being of children and youth (Nansel et al., 2001). Bullying comprises of a group of behaviors that are aggressive or intended to harm. It occurs repeatedly within the context of an interpersonal relationship characterized by a power imbalance, whereby a person with more perceived power attacks one with less perceived power (Nansel et al., 2001; Olweus, 1993).

A critical review of the literature on bullying reveals a number of inconsistencies among definitions and measurement techniques. Moreover, many variables that potentially are associated with perceptions of the severity of bullying are confounded, which, of course, obfuscates a clear understanding of the phenomenon. Further, different sources of information (e.g., self, peer, and teacher reports) can yield complementary or contradictory information. Indeed, perhaps because multiple factors are involved in various descriptions of bullying (e.g., gender, kind of aggression, context), assessing its frequency and gravity and understanding the antecedents and consequences for its perpetrators and victims in schools is difficult. In order to understand the extent of the problem of bullying, as well as what variables that might be associated with its risk and protective factors, developmental pathways, and outcomes, additional research is needed. This kind of information has the potential to be valuable especially to teachers, who are in regular contact with children experiencing bullying. 


\section{Critical Review of the Literature}

The following critical review focuses on the prevalence and consequences of bullying and victimization, gender differences in kinds of bullying and victim responses, and the reporting of bullying by youth in schools. Next, contemporary measures of bullying and victimization are critiqued, and the development of an alternative measure of perceptions of bullying is reviewed. Finally, the effects of hindsight bias and how they may apply to teachers and bullying situations are discussed.

\section{Prevalence}

In a nationally representative sample of 15,686 students in the $6^{\text {th }}$ through $10^{\text {th }}$ grades, Nansel et al. (2001) found 19.4\% reported moderately to frequently bullying others and $17 \%$ reported experiencing moderate to frequent bullying. Overall, this study found approximately $30 \%$ of students reported some kind of involvement in moderate or frequent bullying, either as bully (13\%), victim (11\%), or a combination of the two roles $(6 \%)$. This study showed no differences in the frequency of being bullied from urban, suburban, town, and rural areas, suggesting that bullying is a widespread issue throughout U.S. schools.

\section{Consequences}

The consequences of bullying and of being victimized by bullies are substantial, and research conducted in this area has begun to identify particular subtype profiles of both victims and bullies. Moreover, the aggressive acts involved in bullying behavior can assume a variety of forms, and those forms appear to interact with the gender of both the bully and the victim. In the following section, the psychological, social, and academic consequences of bullying are critically reviewed. First, the consequences of being 
victimized are examined for all victims as well as a subgroup of victims who respond to being bullied in an aggressive manner. Next, issues associated with gender are identified, with several subtypes of aggression defined and an extensive examination of the literature on how gender and aggression interact.

All victims. Although bullying is sometimes thought to be a normal part of childhood development, the consequences of bullying, both long and short term can be severe. Research has shown that even as adults, individuals who were either bullies or victims in childhood experienced greater loneliness than those adults who were not involved in bullying (Tritt \& Duncan, 1997). This study, involving 206 undergraduate university students, found a negative correlation between level of childhood victimization and current self-esteem, and a positive correlation between level of childhood victimization and current loneliness, as well as a positive correlation between bullying and loneliness. Although this study indicates an interesting correlation between childhood victimization or bullying and adult loneliness or self-esteem, there are several limitations. For example, the sample in this study was limited to undergraduate students of a single university; therefore the sample cannot be thought of as representative of a general adult population. Also, due to the retrospective nature of the study, only possible relationships between childhood bullying and adult psychological well-being can be posited; causality and the direction of the relationships cannot be determined. Longitudinal research on the effects of bullying into adulthood is needed to determine whether the relationships found here are indeed the results of childhood bullying. These findings, however, are consistent with other literature that indicates high rates of psychological distress among both bullies 
and victims (Forero, McLellan, Rissel, \& Bauman, 1999; Kumpulainen, Rasanen, \& Henttonen, 1998).

Victims of bullying are at risk for a variety of school-related and more general psychosocial problems (Juvonen, Nishina, \& Graham, 2001; Pellegrini, 1998). Victims, compared to nonvictims, have been shown to be depressed, be socially anxious, have poor self-esteem, feel disliked by peers, and have problems with concentration and impulsivity (Olweus, 1993). The nationally representative study discussed previously found $6^{\text {th }}$ through $10^{\text {th }}$ grade students who were bullied demonstrated poorer social and emotional adjustment, greater difficulty making friends, poorer relationships with classmates, poorer perceived school climate, and greater loneliness (Nansel et. al., 2001). Victims of bullying have reported increased rates of depression and symptoms related to depression, suicidal ideation, and loneliness (Nansel et al., 2001; van der Wal, de Wit, \& Hirasing, 2003). A longitudinal study of 580 Finnish children assessed at age 8 years and again at age 16 years found that victimization was more persistent than bullying over the eight years, that victimization was strongly associated with internalizing problems, and that a high level of depressive symptoms at age 8 years was associated with both bullying and victimization at age 16 years (Sourander \& Helstela, 2000). These researchers suggested that high ratings of depressive symptoms might reflect low self-esteem, immaturity, loneliness, and poor problem-solving skills, all of which may lead to bullying and victimization. Although these children may have symptoms of depression or be troubled before the onset of bullying, research has shown that victimization leads to more isolation, deeper depression, and further abuse, thereby fostering and exacerbating these problems (Troop-Gordon \& Ladd, 2005). 
A study by Troop-Gordon and Ladd (2005) suggests that these kinds of internalized problems (i.e., feelings of isolation, depression, and low self-esteem) may have a bidirectional relationship to victimization. For example, children who internalize problems may be more likely to be bullied which, in turn, exacerbates the internalized problems. In this study, 399 children were assessed in the spring of fourth grade and again in the spring of sixth grade. The battery of assessments included: (a) a peer nomination assessment of peer victimization, where children were asked to nominate up to three classmates corresponding to specific forms of victimization (physical, verbal, or general), and then to indicate whether they were victimized "sometimes" or "a lot;" (b) a social self-acceptance measure; (c) children's perceptions of the social dispositions of their schoolmates; (d) self-, teacher-, and parent-reports of psychological adjustment; and (e) two peer nomination items assessing physical and verbal aggression against others. Latent growth-curve analyses showed that increased victimization during preadolescence was associated with decreased social self-acceptance and, for boys, with developing less prosocial and more hostile cognitive representations of peers. Examination of the mediated relations between victimization trajectories and changes in adjustment for internalizing problems revealed that the path coefficients from initial self and peer representations to changes in internalizing problems were negative. This suggests that children who had more derogatory self and peer beliefs showed increases in internalizing problems in subsequent years. Also, more negative growth in social self-acceptance and peer beliefs were predictive of concurrent increases in internalizing problems. On average, social perception accounted for $57 \%$ (boys) and $54 \%$ (girls) of the variance in internalizing problems. The extent to which children's harassment from peers changed 
was indirectly associated with changes in internalizing problems through social selfacceptance. Therefore, this study demonstrated that increased victimization was associated with decreased social self-acceptance, and that negative self and peer beliefs were associated with internalizing problems in later years. This study also found that children who held more negative peer beliefs in fourth grade were more likely to show increased externalizing problems in subsequent years. Hence, a decline in positive perceptions of peers showed a parallel increase in antisocial behavior. Again, there was an indirect effect of initial victimization through peer beliefs to changes in externalizing problems, indicating that victimization had an effect on peer beliefs that, in turn, affected externalizing behavior.

One limitation of this study is that agreement among informants for each of the outcome variables was low to moderate. Moreover, for purposes of analyses, the three victimization scores (physical, verbal, and general) were averaged to create a composite victimization score. Researchers potentially lost valuable information on differences between physical, verbal, and what they termed, "general" victimization (p. 1,079); they also neglected to include relational victimization. Therefore, the results of this study cannot be generalized to different or to specific forms of victimization.

Aggression subtypes. Although the detrimental consequences of bullying affect most victims, there is an increasing body of research that suggests that there are two separate kinds of victims: Those who are aggressive and those who are not (Brockenbrough, Cornell, \& Loper, 2002; Olweus, 1993; Pellegrini, Bartini, \& Brooks, 1999; Toblin, Schwartz, Gorman, \& Abou-esseddine, 2005; Unnever, 2005). Of the two groups of victims, the nonaggressive group has been described as passive; displaying 
attitudes and behaviors that are weak, defenseless, submissive; having few friends; showing pain in response to bullying; blaming themselves for being bullied; and, despite feeling close to adults such as teachers and parents, doubting that anyone can help them (Unnever, 2005). On the other hand, aggressive victims have been described as having poor social and problem-solving skills, being disruptive and impulsive, disliked by teachers, punished by parents, and rejected by peers. Unlike bullies who advance to less physical modes of bullying as they mature, aggressive victims continue to engage in physical aggression. They are said to attack other children as well as to be attacked, to insult bullies, and to retaliate, albeit ineffectively (Unnever, 2005). Research has found that aggressive victims are emotionally labile, and that they display a reactive form of aggression whereby they may use aggression after losing control in response to bullying. These aggressive victims are also rejected by nearly all peers and have few, if any, friends, reflecting the loneliness found in victims of bullying (Pellegrini, Bartini, \& Brooks, 1999; Schwartz, Dodge, Petit, \& Bates, 1997). Still more research characterizes aggressive victims as being high in emotional dysregulation and hyperactivity, having poorer social skills, and having lower GPAs when compared to bullies, nonaggressive victims, and students who do not fit within any of the bully or victim profiles (Olweus, 1993; Toblin et al., 2005).

In a study of 8,273 students from $7^{\text {th }}, 9^{\text {th }}, 11^{\text {th }}$, and $12^{\text {th }}$ grades in 12 schools, researchers identified four profiles: (a) aggressive victims, (b) nonaggressive victims, (c) bullies, and (d) normative contrasts (Brockenbrough, Cornell, \& Loper, 2002). The results of this study showed that aggressive victims were more likely to have carried a weapon to school for protection in the past 30 days, and generally more likely to carry a 
knife to school as compared to the other profiles. Moreover this subtype reported the highest level of fighting in school as well as the highest level of gang involvement as compared to any other group. Aggressive victims and bullies reported higher levels of alcohol and drug use, lower academic grades, and less adult support compared to the nonaggressive victims and normative contrasts. This study demonstrates evidence for the possibility of subtypes among bullying victims that may lead to distinct outcomes. For example, victims with more aggressive attitudes may be at greater risk for behaviors such as weapon carrying, involvement in physical fights at school, and drug and alcohol use. Although bullies also demonstrated some behaviors consistent with aggressive victims (i.e., substance use, lower grades, and less adult support), these behaviors and perceptions may have a greater negative effect on those students who are also victimized by their peers. It is important to note that the violent behaviors (e.g., engaging in physical fights) as well as the potentially violent behaviors (e.g., weapon carrying) were displayed by the aggressive victim group more than any other group. These high-risk behaviors and aggressive attitudes may lead to more bullying and continue the cycle of violence, thereby predisposing even more violent behavior and possibly tragic consequences.

There were several limitations of this study. One methodological concern is the manner in which the main construct, aggressive attitudes, was assessed. The researchers used only two items with yes/no response options to assess aggressive attitudes, which they then proposed led to aggressive behaviors. Further research needs to be conducted on the aggressive attitudes using a more reliable and valid scale with a greater breadth of items, perhaps with a continuous versus a dichotomous scale. Students who endorsed three of four items were classified as victims, whereas students who failed to endorse all 
four items were classified as nonvictims. Of course, this method potentially leaves some students who do not fit either of those categories, for example, those students who endorsed one or two of the four items.

Unnever (2005) investigated whether aggressive victims engage in different patterns of behavior and have dissimilar socialization experiences than bullies and nonaggressive victims. This study used a self-report measure with 2,472 middle-school students from a diverse metropolitan area. The sample analyzed in this study included 925 students (37\% of sample): 205 aggressive victims (8\%), 206 bullies (8\%), and 514 nonaggressive victims (21\%). To measure student group affiliations, the Olweus questionnaire was adapted (Solberg \& Olweus, 2003). Students who had been bullied or who had bullied others at least two or three times a month were classified as nonaggressive victims or as bullies, respectively (as defined by Solberg \& Olweus, 2003), and students who had both bullied others and had been bullied themselves at least two or three times a month were classified as aggressive victims. This classification is consistent with other research that defines the aggressive victim group as a combination of bullies and victims (Craig, Henderson, \& Murphy, 2000; Toblin et. al., 2005). Three general kinds of bullying and victimization were examined: (a) physical - involving hitting, shoving, or threatening to use physical force; (b) verbal - involving teasing, and name-calling; and (c) social - involving spreading rumors and influencing peers in order to exclude the victim from social activities with others (Olweus, 1991). Frequency of bullying and victimization were measured separately with response categories of: (a) two or three times a month, (b) about once a week, and (c) several times a week. A measure of reactive and proactive aggression was created by using five items from a previously 
developed scale (Dodge \& Coie, 1987) as well as three new items, and conducting a principal-component factor analysis (PCA) for the eight items. Results of the PCA indicated a two-factor solution, with items identified as indicators of proactive aggression strongly loading on the first factor and items identified as indicators of reactive aggression strongly loading on the second factor. The four items loading on each factor were used as two separate scales, one for proactive aggression and one for reactive aggression, with higher scores indicating greater aggression.

For purposes of the logistic regression analyses reported in this study, two separate analyses were conducted for frequency and kind of bullying. The first analysis examined aggressive victims and bullies. Results indicated that, compared to bullies, aggressive victims were twice as likely to victimize other students physically and about half as likely to victimize other students verbally. Aggressive victims were less aggressive proactively and more aggressive reactively than bullies. In fact, these aggressive victims were nearly one and a half times as likely to show reactive aggression as bullies. Aggressive victims and bullies did not differ on their general frequencies of bullying or perceived relative strengths. The second logistic regression analysis examined aggressive and nonaggressive victims. Results of this analysis revealed that, although aggressive victims were not bullied more frequently than nonaggressive victims, they were more likely to be bullied physically, and were almost twice as likely to bully others physically. Aggressive victims were more than three times as likely to display proactive aggression and almost one and a half times as likely to report low self-control as nonaggressive victims. 
Although these results show some clear associations between aggressive victims versus bullies and between aggressive versus nonaggressive victims, by constructing the data into dichotomous groups to fit the logistic regression analyses, the researchers possibly lost some interesting information about potential differences among all three groups. For example, aggressive victims may or may not be as distinguishable from bullies if nonaggressive victims were to be included in the analysis. Because this is a fairly new area of research, however, the exploratory nature of this study can be used to provide an argument for the need for more research comparing students in all three groups, (i.e., bullies, aggressive victims, nonaggressive victims) as well as to students not involved in any bully or victim group.

In another study, Toblin and colleagues (2005) asked 240 children, $(M$ age $=9.5$ years) from two elementary schools to respond to five scenarios that described ambiguous peer provocations. Children were assessed on their global evaluation of an aggressive response to the scenarios, positive outcome expectancy, and efficacy of beliefs regarding an aggressive response to the scenarios, as well as depression, loneliness, and dissatisfaction with peer relationships. Peer nominations were used to assess aggression and victimization, friendship, social behavior, and social adjustment. Teachers provided information about the children's social behavior and adjustment, and their capabilities for emotional self-regulation. Academic functioning was measured by grades and achievement-test scores (Stanford Achievement Test-Ninth Edition). Children high on both aggression and victimization were classified as aggressive victims (14 boys, 5 girls); children high on victimization and low on aggression were classified as nonaggressive victims (11 boys, 7 girls); children high on aggression and low on victimization were 
classified as bullies ( 16 boys, 2 girls); and children low on both aggression and victimization were classified as normative contrasts ( 48 boys, 82 girls).

Analyses revealed that aggressive victims had higher ratings for emotional dysregulation and hyperactivity, lower scores on social preferences, and lower grades than any of the other groups. Compared to bullies and normative contrasts, aggressive victims had higher depression and loneliness scores, and lower assertivenessprosociability scores. Bullies had higher scores on aggression-related social information processing, meaning they endorsed the use of aggressive behaviors more often than normative contrasts and aggressive victims. Bullies had lower scores on hyperactivity and emotional regulation than aggressive victims, and also displayed lower scores on submissiveness-withdrawal compared to either nonaggressive victims or aggressive victims. Nonaggressive victims were generally better adjusted than aggressive victims. Nonaggressive victims, however, did have higher scores on submissiveness-withdrawal, hyperactivity, depression, and emotional dysregulation as well as lower grades, social preference, assertiveness-prosociability, loneliness, and efficacy beliefs for engaging in aggression than normative contrasts. These findings suggest that children who demonstrate proactive aggression seem to be characterized by social-cognitive biases toward aggressive behavior, whereas children who demonstrate more reactive aggression are more likely to exhibit hyperactivity and impaired regulation of emotions (including anger).

A limitation of this study is related to the measure that was used to classify bully and victim status, which is consistent with a limitation of much of the bullying research reviewed thus far. A small number of items were used to assess bullying and 
victimization, with two items each assessing physical aggression, relational aggression, physical victimization, and relational victimization. A rather strict cutoff was then imposed of .75 as the upper limit for high aggression or victimization and .25 as the lower limit for low aggression or victimization. The physical and relational aggression and victimization groups were combined to produce the four groups. This classification system is limited in number of items, and by combining kinds of bullying and victimization. Also, by imposing the strict upper- and lower-limit criteria, researchers may have misclassified some bullies and victims as normative contrasts, and have correctly classified only the most severe students. This process identified very small numbers of students in the three victim and bully groups, in contrast to the disproportionately large number of normative contrasts. Therefore, caution should be used when generalizing these results gleamed from small samples within groups and uneven group sizes.

A study by Pellegrini, Bartini, and Brooks (1999) also sought to find specific factors relating to group affiliation (bully, victim, or aggressive victim) and victimization in early adolescence. This study assessed 154 students in the fifth grade and their teachers on measures of peer nominations of bullying other students, physical and relational victimization, aggressive victimization, and negative attitudes toward bullying, using the Senior Questionnaire (Olweus, 1989; unpublished manuscript as cited in Pellegrini, Bartini, \& Brooks, 1999); temperament measured by activity and emotionality; and the Teacher Check List Aggressive/Reactive, Aggressive/Proactive, and Dominance subscales (Dodge \& Coie, 1987). Youth were categorized as bullies, victims, or aggressive victims if their total scores on the items of the Senior Questionnaire 
corresponding to each group were $0.8 S D$ above the mean for their classrooms; all others were classified as controls. Summary statistics showed that $14 \%$ were classified as bullies, $19 \%$ as victims, $5 \%$ as aggressive victims, and $61 \%$ as controls. The bully group had more boys than girls. This study found that scores on bully and aggressive-victim scales related negatively to peer status and positively to aggression; that is, as bully or aggressive-victim nominations increased, peer status decreased and aggression increased. Emotionality was positively correlated with both bullying and with aggressivevictimization scores, demonstrating that these are aggressive and highly emotional groups. Bullies were typically identified as liked by other bullies; however, popularity within the bully group was positively correlated with proactive aggression, activity, and emotionality, demonstrating that those children who were more popular with other bullies were also higher on proactive aggression. Victims were also more likely to be nominated as liked by their same peer group, other victims. Victim popularity with each other, however, was negatively related to proactive aggression and emotionality; those demonstrating more proactive aggression and emotionality (likely the aggressive victims) were less well liked than their other victim peers. The small sample size within each bully group is a limitation of this study, especially the aggressive victim group that comprised only $5 \%$ of the sample. A larger sample is also needed to explore possible gender differences as well as differences in physical versus relational kinds of bullying. This study employed a common technique in which children's bully, victim, and aggressivevictims scores were derived from the subscales of the Senior Questionnaire (Olweus, 1989; unpublished manuscript as cited in Pellegrini, Bartini, \& Brooks, 1999) for bullying other students, exposure to physical and relational victimization, and classified 
as bullies, victims, or a combined group. This technique of group assignment, however, again does not consider gender or kind of aggression displayed by bullies and victims.

Summary. A substantial proportion of students in the U.S. are involved in some form of moderate to frequent bullying, either as bully, victim, or a combination of the two roles (Nansel et al., 2001). The review of literature presented here has shown deleterious consequences for the victims of bullying (e.g., Juvonen, Nishina, \& Graham, 2001; Nansel et al., 2001; Olweus, 1993; Pellegrini, 1998; Toblin et al., 2005; Unnever, 2005; van der Wal, de Wit, \& Hirasing, 2003). Research also suggests that there are two separate kinds of victims, those who are aggressive and those who are not (Brockenbrough, Cornell, \& Loper, 2002; Olweus, 1993; Pellegrini, Bartini, \& Brooks, 1999; Toblin et al., 2005; Unnever, 2005). Next is a review of the limited research on the role gender plays on victim subtype, kind of aggression engaged in or received, and the consequences of bullying.

\section{Gender and Aggression}

Kinds of aggression. When gender has been studied, kind of aggression naturally arises. Three kinds of bullying or victimization have been delineated throughout the literature; physical, verbal, and relational. Physical bullying is engaging in behaviors that harm others through physical damage or through the threat of physical or property damage. Verbal bullying is expressing unkind statements or names with the intent of harm. Relational bullying is manipulating or controlling social relationships (e.g., threatening to end a friendship, social exclusion, rumor spreading).

Literature on victim profiles suggests there is a 3:1 ratio of males to females among the aggressive-victim groups; this is consistent with findings of the representation 
of males in the bully group as well (Juvonen \& Graham, 2001; Olweus, 1993). Past research on childhood aggression as well as school bullying, however, has focused largely on the study of physical aggression. Research on physical aggression has demonstrated a higher representation of males, which, in turn, has lead to the majority of research on aggression and bullying focusing on males displaying physical bullying behaviors (Crick, 1997; Crick \& Grotpeter, 1995; Olweus, 1993). Increasingly, research has begun to explore relational aggression (Crick \& Grotpeter, 1995). This research has demonstrated that victims of relational aggression exhibit higher levels of anxiety, loneliness, psychological distress, social avoidance, and poor school functioning compared to their non-victimized peers (Crick \& Grotpeter, 1995; Hoglund, 2007).

Gender by aggression interactions. Crick and Grotpeter (1995) suggested that, when attempting to inflict harm on peers (bullying), children do so in ways that best damage the goals that are valued by their respective peer groups. In support of this suggestion, research has consistently shown that males tend to harm others through physical and verbal aggression. These behaviors are consistent with the kinds of goals that have been shown to be important to males within the peer-group context, specifically physical dominance. In contrast to males, however, females are more likely to focus on relational issues during social interactions, and therefore females may tend to harm others through relational aggression more than physical aggression, which would be consistent with their peer-group goals. For example, Crick and Grotpeter studied 491 students in the third through sixth grades and found that the physically aggressive group consisted primarily of males ( $16 \%$ males vs. $0.4 \%$ females), the relationally aggressive group consisted primarily of females ( $17 \%$ females vs. $2 \%$ males), and the combined physically 
and relationally aggressive group consisted of both males and females, although twice as many were males ( $9 \%$ males vs. $4 \%$ females). Contrary to prior research on bullying, these findings suggest that aggressive males and females may be identified with almost equal frequency ( $27 \%$ males, $22 \%$ females) when relational as well as physical forms of aggression are assessed. This research suggests that past research may have been missing a key feature of the nature of aggression displayed by females within the definitions of bullying and aggressive behavior.

An early study of relational aggression and gender did reveal the tendency for girls to engage in relational aggression more than boys do, and also supports Crick and Grotpeter's (1995) position that this difference in kind of aggression may be due to goals valued by peer groups (Lagerspetz, Bjorkqvist, \& Peltonen, 1988). These researchers conducted interviews with 89 students in the fifth grade that focused on behavior when angry and on the meaning or importance of friendships. They collected written self-report measures of behavior of each child when angry with a same-sex peer, frequency of anger, and friendship patterns in the class. After pooling the responses of behaviors when angry, factor analysis revealed a three-factor structure for kinds of behaviors: Factor 1 reflected relational means of aggression, Factor 2 reflected physical means of aggression, and Factor 3 reflected peaceful means of responding. Further analyses revealed Factors 1 and 3 were more typical for girls, and Factor 2 was more typical for boys. When analyzing responses to friendships, the size of friendship groups was generally larger for boys than for girls. Here, more pair relationships were mentioned by girls than boys, whereas boys were more likely to identify groups with more than four members than girls were. Generally, interviews confirmed the belief that relational aggression was used by girls 
and that, for them, friendships were of greater emotional significance than for boys. This study also found that the duration of anger was longer for girls than for boys, which suggests that relational means of aggression may be associated with a longer period of aggressive feelings by the aggressor. Future research should assess the impact of duration of aggression on both the aggressor and the victim. Although this research offered early evidence of the differences among kinds of aggression engaged in by girls and boys, and the possibility of children deciding on aggressive behavior by how to hurt members of their peer group the most, it has several limitations. First, it should be noted that this study did not assess bullies or victims, so these results cannot be generalized to schoolbullying situations. The items also instructed children to think only of same-gender peers, and so these results are limited to aggression experienced within same-gender peers. This research also relied on self-report by interview or open-ended questions, and therefore the reliability or validity of the items or method of analysis has not been studied or replicated. So, although this study is important in that it suggested initial reasons to explore the area of kind of aggression on gender and friendships, its results should be interpreted with caution.

Another study investigating relational aggression asked 234 students in the fourth, seventh, and tenth grades to read 12 vignettes that described 6 physical and 6 relational attacks between same-gender peers (Galen \& Underwood, 1997). The students were then asked to imagine these situations happening to them and to respond to two questions for each vignette: "How hurt would you be if this happened to you?" and "How often does something like this happen in the group of people you hang around with?" on a 5-point scale ranging from not at all to very much. Overall, this study found that children rated 
physical aggression as more hurtful than relational aggression, and girls rated any kind of aggression as more hurtful than boys did. Girls also rated relational aggression as more hurtful than did boys, and only boys viewed physical aggression as more hurtful than relational aggression (girls rated relational and physical aggression as equally hurtful). There were no differences between boys' and girls' ratings of frequencies of physical or relational aggression in the fourth and seventh grades. In the tenth grade, however, girls reported more relational aggression than boys. Overall, for boys, ratings of frequency tended to decrease with age in contrast to girls, who reported that the frequency of relational aggression increased with age. Although overall boys and girls rated physical aggression as more hurtful than relational aggression, this study again demonstrated a difference between how boys and girls experience relational aggression. Girls found relational aggression more hurtful than did boys. This supports the idea that girls use relational means of aggression as a way to hurt their same-gender peers effectively. Although this study also gives reason to study further the relationship between kind of aggression and gender, it again is limited in the measure of kind of aggression, which was assumed by the nature of the vignettes, and the limited assessments of one item each for hurtfulness and for frequency.

More recent research on adolescent aggressors and victims further exemplifies the need to include relational forms of aggression in bullying research (Prinstein, Boergers, \& Vernberg, 2001). In a study of 566 adolescents, data demonstrated that males reported higher levels of physical aggression and victimization than females. Males and females reported comparable levels of relational aggression and victimization, and both males and females reported relational aggression and victimization with greater frequency than 
physical victimization. Although males reported the use of physical and relational forms of aggression at comparable frequency, females reported the use of relational aggression more than physical aggression. This study also found gender differences in the outcomes of victimization by kind of aggression. For males, relational victimization contributed to the prediction of internalizing adjustment problems (i.e., depression, loneliness, selfesteem). For females, relational victimization explained more than twice the variability in concurrent loneliness and self-esteem compared to physical victimization. Data indicated that relational victimization contributed more distinctly to internalizing problems whereas physical aggression and victimization related more to externalizing problems.

Interestingly, this study also found that regardless of gender, adolescents who were victims of both relational and physical aggression had higher levels of depression, externalizing behavior, and loneliness compared with adolescents who were victims of either only relational or only physical aggression, followed by adolescents who were not victimized at all. This finding suggests that relational victimization may exacerbate the detrimental effects of physical victimization.

Results of this study offer preliminary evidence to support relational and physical victimization as important contributors to adolescent psychological adjustment, and also highlight possible gender differences. These results, however, are based of self-report measures of one sample at one time. It is important that future research investigate these findings using multiple sources of information and using a longitudinal design in order to assess the direction of effect between physical and relational aggression/victimization and social-psychological adjustment. 
In a study of 337 adolescents in the sixth and seventh grades, Hoglund (2007) also found differential effects of kind of aggression on school functioning by gender. This study used Crick and Grotpeter's (1995) Social Experiences Questionnaire to measure peer victimization from self-reported episodes of relational and physical victimization. Additional measures included school achievement based on grades; school engagement based on teacher-reported attitude and effort on final report cards and absences; internalizing problems of self-reported depression, anxiety, stress, and loneliness in interpersonal relationships; and teacher-reported aggression and hyperactivity. This research found that, for females, both physical and relational victimization related to poorer school engagement, whereas physical but not relational victimization contributed to lower school achievement. For males, physical, but not relational, victimization related to lower school engagement whereas relational, but not physical, victimization related to poorer school achievement. Although demonstrating clear effects of kind of aggression and gender on school engagement, these results also show that gender non-normative victimization (i.e., males who are victims of relational aggression and females who are victims of physical aggression) is related to poorer school achievement for both males and females. Although this study again relies on one self-report measure of victimization, these results beg the question of whether gender normative versus gender non-normative victimization may produce different effects on other victim outcomes.

Paquette and Underwood (1999) examined gender differences in 76 middleschool students in the seventh and eighth grades in their experiences of relational and physical aggression. Students completed a self-report measure of perceived competence in scholastic competence, social acceptance, athletic competence, physical appearance, 
job competence, romantic appeal, behavioral conduct, close friendship, and global selfworth, as well as a slightly revised version of the Social Experience Questionnaire selfreport (Crick \& Grotpeter, 1995). Interviews were also conducted with each student to elicit narrative responses regarding one previous experience of being victimized by social aggression and one account of being victimized by physical aggression.

Results of this study showed no gender differences in the frequency of experiencing relational aggression; however, boys reported experiencing more physical aggression from their peers than did girls, and girls reported experiencing more prosocial behavior than did boys. When examining the variable of the gender of the aggressor, data demonstrated that relational aggression most commonly took place for both boys and girls within same-gender peer groups. For boys, physical aggression most commonly occurred within same-gender peer groups ( $96 \%$ of reported episodes). A significant number of girls (47\%), however, described physical aggression in which boys were the perpetrators. Researchers also examined how the adolescents coped with the different kinds of aggression as victims. For relational aggression, there was a trend for gender differences. Here, girls were more likely to confront their aggressor verbally. In contrast, boys were just as likely to ignore their aggressors as to confront them. Not one girl reported that she would use physical aggression in response to an aggressor, but $20 \%$ of boys reported that they would respond to aggression with a physical attack. For acts of physical aggression, male victims tended to be more likely than female victims to respond with a physically aggressive act in return, and girls tended to use verbal confrontation more than boys. Analyses revealed that there was no difference between boys' reported negative affect following relational and physical aggression; however, 
girls reported more negative affect following relational aggression than following physical aggression.

Results of the self-perception variables showed that, for boys, a negative correlation occurred between the frequency of experiencing either kind of aggression and perceptions of close friendships. For girls, the frequency of experiencing relational aggression was negatively correlated with athletic competence, physical appearance, romantic appeal, behavioral conduct, close friendships, and global self-worth. The frequency of experiencing physical aggression was negatively correlated perceptions of close friendships, physical appearance, and behavioral conduct. The frequency of experiencing prosocial acts was positively correlated with perceptions of close friendships. These data clearly demonstrate that boys and girls are affected differently by both kinds of aggression, relational and physical. This research, however, again relied on self-report data alone. Also, although this research analyzed data based on different kinds of aggression as well as gender of aggressor and victim, gender was not identified when analyzing differences in self-perception variables. Although it was found that relational aggression mostly occurs in same-gender peer groups, and boys more often experience physical aggression from other boys, nearly half of the girls reported experiencing physical aggression from boys. The difference in how girls experience physical aggression when the aggressor is a boy versus a girl would be interesting as well as if the aggressor's gender elicits a different reaction to the bullying. Although this research also relies on a modest sample size, it does enhance our knowledge of victims' reactions to different kinds of aggression. This is also one of the few studies to date to reveal gender differences in kinds of aggression experienced, reactions to different kinds of aggression 
by gender, and self-perceptions of either gender associated with the frequency of aggression experienced.

A study of 4,721 students in seventh and eighth grade conducted in Amsterdam examined psychosocial health among victims and offenders of physical and relational bullying (van der Wal, de Wit, \& Hirasing, 2003). Participants responded to a self-report questionnaire of bullying developed for Amsterdam school systems, a short depression inventory for children, two items on suicidal ideation, and a self-report questionnaire of delinquent behavior. For boys and girls, depression and suicidal ideation were more common among children who reported sometimes or frequently being bullied physically compared to children reporting being bullied physically almost never or never. After multivariate analyses were conducted, however, these results only held true for girls. Here, odds ratios (OR) showed girls who reported sometimes experiencing physical bullying were one and a half times more likely to report depression $(\mathrm{OR}=1.50)$ and suicidal ideation $(\mathrm{OR}=1.72)$ compared to girls almost never or never experiencing physical bullying. Girls who reported frequently experiencing physical bullying were three times as likely to report depression $(\mathrm{OR}=3.29)$ and more than twice as likely to report suicidal ideation $(\mathrm{OR}=2.62)$ as compared to girls who did not report experiencing these frequencies of physical bullying.

Depression and suicide ideation were also associated with being bullied relationally. For boys who reported sometimes being bullied relationally, odds ratios demonstrated that they were over three times more likely to report depression $(\mathrm{OR}=3.4)$, and twice as likely to report suicide ideation $(\mathrm{OR}=2.1)$ compared to boys reporting being bullied relationally less frequently or not at all. For boys who reported frequently 
being bullied relationally, odds ratios demonstrated that they were 11 times more likely to report depression $(\mathrm{OR}=11.1)$ and more than five times as likely $(\mathrm{OR}=5.6)$ to report suicidal ideation compared to boys experiencing less frequent relational bullying. For girls who reported sometimes being bullied relationally, odds ratios demonstrated that they were over three times more likely to report depression $(\mathrm{OR}=3.5)$, and nearly twice as likely to report suicide ideation ( $O R=1.8)$ compared to girls reporting being bullied relationally less frequently or not at all. For girls who reported frequently being bullied relationally, odds ratios demonstrated that they were 9 times more likely to report depression $(\mathrm{OR}=8.9)$ and more than 3 times as likely $(\mathrm{OR}=3.6)$ to report suicidal ideation compared to girls experiencing less frequent relational bullying.

Delinquent behavior was far more common in children who sometimes or frequently bullied other children physically compared to children who did not report this frequency of physically bullying other children. For children who reported sometimes physically bullying others, boys were four times as likely to engage in delinquent behavior (OR $=4.2)$ and girls were three and a half times as likely (OR 3.6). For children who reported frequently physically bullying others, boys were 15 times as likely to engage in delinquent behaviors $(\mathrm{OR}=15.3)$ and girls were nearly 11 times as likely to engage in delinquent behavior $(\mathrm{OR}=10.8)$.

The results of this study demonstrate some profound effects of physical and relational bullying on depression and suicidal ideation for both boys and girls. Again, this study relied on a single self-report measure of bullying, and no causal direction of the associations found can be made because of the cross-sectional nature of the study. Still, the results of the impact of physical and relational bullying on the psychosocial health of 
victims and delinquent behavior of bullies provide further evidence for the need to include different kinds of aggression in research on the effects of bullying and victimization.

In a study by Caims et al. (1989) 220 students in four public elementary schools were assessed annually from fourth through seventh grades. Measures included interpersonal competence of aggression (i.e., "gets in trouble at school," "fights a lot," and "always argues;" p. 321), popularity, and academic competence (measured by teacher and self reports). Peer nominations assessed conflict instigation, and school nominations assessed extreme aggression. Teachers and principals were asked to name every child in the fourth grade who was extremely aggressive, and a child was identified as high risk if he or she was nominated by two or more teachers or administrators. Interviews were conducted to assess recent conflicts. Participants were asked to identify the peers in the school who bothered them or caused them trouble (same and different gender) and to describe two recent conflicts with peers (one same-gender and one different-gender conflict).

This study found that in fourth grade, boys reported more physical aggression in conflicts with boys than with girls; in seventh grade these effects were even stronger. In fourth grade, girls reported more physical aggression in conflicts with boys than girls. In seventh grade, girls reported few instances of physical aggression overall. For reports of social alienation, in fourth grade only $10 \%$ of girls' same-gender themes were social alienation; however, by seventh grade, over $30 \%$ of the same-gender conflicts among girls involved social alienation. Social alienation was rarely reported by boys as compared to girls in either grade. These findings suggest that, overall, boys engage in 
physical means of aggression versus relational regardless of gender of the victim. Girls' reports of instances of physical aggression declined with age, but their reports of social alienation increased with age.

When looking at developmental themes across time by teacher reports, a decline in rates of aggression was found in both boys and girls, and this decline was greater for boys than for girls. When comparing these data to the self-report data, the aggressive scores self-reported by girls were consistently higher than those assigned to them by teachers, whereas the aggressive scores self-reported by boys were within the same range as those assigned to them by teachers. One possible explanation for this result is that teachers may be assessing boys' aggression accurately, but that they may be underestimating girls' aggressive behaviors. This is consistent with past research that suggests that boy's physical aggression is acknowledged more often than aggression of girls, which may be more social or relational and less obvious. This study used both teacher- and self-report measures of aggression, and although the two different reporters were not always consistent, results demonstrated the need to examine different groups' perceptions of bullying and adults' recognition of children's perceptions of bullying.

In a study assessing relational and physical forms of peer victimization by using multiple informants, Crick and Bigbee (1998) found several interesting differences in kind of aggression, gender, and informant. This study examined 383 students in the fourth and fifth grades from four public elementary schools. The research used a large battery of measures including: the Social Experience Questionnaire-Self-Report (SEQS); the Social Experience Questionnaire-Peer Report (SEQ-P); peer reports of adjustment: rejection, acceptance, and submissiveness; a peer nomination on the 
Submissiveness Behavior scale; and self-reports of adjustment: loneliness, social anxiety, avoidance, emotional distress, and self-restraint. Scores from the peer-report victimization measure were used to identify groups of victimized and nonvictimized children. Specifically, children with victimization scores one $S D$ above the sample $M$ for either relational or physical aggression were considered victimized; the remaining children were considered nonvictimized. Four groups were identified: (a) relationally victimized, (b) physically victimized, (c) relationally plus physically victimized, and (d) nonvictimized. Those who were relationally victimized were primarily girls ( $12 \%$ girls vs. $4 \%$ boys), whereas those who were physically victimized ( $9 \%$ boys vs. $1 \%$ girls) and those who were relationally and physically victimized were primarily boys ( $12 \%$ boys vs. $4 \%$ girls). To assess frequency of physical bullying uniquely, relational victimization was controlled and it was found that boys were more physically victimized than girls. After controlling for physical victimization, it was found that girls were more relationally victimized than boys. The majority of aggressive and victimized children were either aggressive or victimized, but not both. When analyzing peer nominations of "liked least" and "liked most," a social-preference score was derived and standardized according to procedures from past research (Coie \& Dodge, 1983). These procedures identified a group of children labeled as rejected ( 24 girls, 28 boys). Results showed that $65 \%$ of rejected children were physically aggressive, physically victimized, or both. When adding relational victimization and aggression to these analyses, an additional $17 \%$ of rejected children were identified, for a total of $83 \%$ of the rejected children classified as physically aggressive, relationally aggressive, physically victimized, relationally victimized, or a combination. These findings provide support for the need to include 
relational forms of aggression and victimization in studying aggression and for understanding rejected sociometric status.

Hierarchical multiple regression analyses were conducted to assess victimization, aggression, and social-psychological adjustment variables. For both boys and for girls, both physical and relational victimization were negatively related to peer acceptance, and positively related to rejection, submissive behavior, social avoidance, and feelings of loneliness and distress. For girls, relational victimization was also negatively related to self-restraint. Relational victimization provided additional information about socialpsychological adjustment beyond that provided by physical and relational aggression and by physical victimization for both boys and girls. For boys, relational victimization added unique information to the prediction of peer rejection, submissive behavior, social avoidance, and feelings of loneliness and distress. For girls, relational victimization added unique information to the prediction of peer acceptance, peer rejection, and selfrestraint.

Another way this study enhanced the literature on victimization was by examining peer- versus self-reports of victimization and social-psychological adjustment. Four victim groups were identified from the peer and self-reports for physical victimization and also for relational victimization: (a) self identified only, (b) peer identified only, (c) both self and peer identified, and (d) neither self nor peer identified, or non victims. Tables 1 and 2 show how each of these groups compared across the social-psychological adjustment variables that were studied. Self- and peer-identified groups fared the worst compared to self-identified only or peer-identified only groups for both physical and relational victimization. 
Table 1. Social-Psychological Adjustment Variables and

Physical Victimization Groups

\begin{tabular}{llll}
\hline $\begin{array}{l}\text { Adjustment } \\
\text { Variable }\end{array}$ & \multicolumn{2}{c}{ Group } \\
\cline { 2 - 4 } Rejection & Self and Peer Identified & $\begin{array}{l}\text { Self Identified Only } \\
\text { groups }\end{array}$ & \multicolumn{1}{c}{ Peer Identified Only } \\
Submissive & & $\begin{array}{l}\text { More than self- } \\
\text { identified only and non } \\
\text { victims }\end{array}$ \\
Loneliness & $\begin{array}{l}\text { More than non } \\
\text { victims }\end{array}$ & $\begin{array}{l}\text { More than all other } \\
\text { groups }\end{array}$ \\
groups & $\begin{array}{l}\text { More than peer- } \\
\text { identified only and } \\
\text { Distress }\end{array}$ & $\begin{array}{l}\text { Mon victims } \\
\text { groups }\end{array}$ & More than non victims \\
\hline
\end{tabular}

Table 2. Social-Psychological Adjustment Variables and Relational Victimization Groups

\begin{tabular}{|c|c|c|c|}
\hline \multirow{2}{*}{$\begin{array}{l}\text { Adjustment } \\
\text { Variable }\end{array}$} & \multicolumn{3}{|c|}{ Group } \\
\hline & Self and Peer Identified & Self Identified Only & Peer Identified Only \\
\hline Rejection & $\begin{array}{l}\text { More than self- } \\
\text { identified only and non } \\
\text { victims }\end{array}$ & & $\begin{array}{l}\text { More than self- } \\
\text { identified only and non } \\
\text { victims }\end{array}$ \\
\hline Submissive & $\begin{array}{l}\text { More than all other } \\
\text { groups }\end{array}$ & & $\begin{array}{l}\text { More than self- } \\
\text { identified only and non } \\
\text { victims }\end{array}$ \\
\hline Loneliness & $\begin{array}{l}\text { More than peer- } \\
\text { identified only and non } \\
\text { victims }\end{array}$ & $\begin{array}{l}\text { More than peer- } \\
\text { identified only and } \\
\text { non victims }\end{array}$ & More than non victims \\
\hline $\begin{array}{l}\text { Emotional } \\
\text { Distress }\end{array}$ & $\begin{array}{l}\text { More than peer- } \\
\text { identified only and non } \\
\text { victims }\end{array}$ & & More than non victims \\
\hline $\begin{array}{l}\text { Self- } \\
\text { restraint }\end{array}$ & Less than non victims & $\begin{array}{l}\text { Less than non } \\
\text { victims }\end{array}$ & Less than non victims \\
\hline
\end{tabular}

This study used multiple informants, multiple measures, and assessed different kinds of bullying and victimization. It is clear from these results that both physical and 
relational victimization and aggression have deleterious effects on psychosocial outcomes of youth. Moreover, relational aggression and victimization added to the effects that can be explained by physical aggression and victimization measured alone. It was also found that peer acceptance and perceptions of peer acceptance were associated with different outcomes on psychosocial variables, and that these effects might be mediated by the kind of victimization experienced.

Another study that examined the effects of physical and relational victimization through multiple informants was conducted by Cullerton-Sen and Crick (2005). This study assessed 119 students in the fourth grade using self-, peer-, and teacher-reports of aggression and victimization: the Social Experience Questionnaire-Self-Report (SEQ-S); the Social Experience Questionnaire-Peer Report (SEQ-P); the Social Experience Questionnaire-Teacher Report (SEQ-T); peer reports of adjustment; and teacher reports of internalizing and externalizing problem behaviors. Correlation coefficients were computed to assess associations among these variables. The results found low to moderate correlations among teacher-, peer-, and self-reports of both relational and physical victimization with all correlation coefficients ranging from $r \mathrm{~s}=.21$ to .34 . There were no differences in informant agreement across the multiple forms of the SEQ (teacher, peer, and self-reports of victimization).

When examining gender differences in the kind of victimization, interactions emerged for teacher and peer reports. Teacher-reported victimization showed an effect of victimization for girls only, with girls more relationally than physically victimized. Peer reports of victimization, however, showed effects of victimization for girls and boys. According to peers, girls were more relationally than physically victimized; boys were 
more physically than relationally victimized. One possible reason for the difference in teacher and peer reporting for boys is that boys may not wish to report frequent relational victimization because it has been suggested that relational victimization is more gendernormative for girls than it is for boys.

A series of hierarchical multiple regression analyses were conducted to examine unique information provided by teacher reports of relational victimization about adjustment beyond that accounted for by reports of physical victimization. These analyses were conducted separately for boys and girls. For boys, when teachers' reports of physical victimization were entered at step 1 , teacher reports of relational victimization (entered at step 2) improved the accuracy of predicting teacher-reported internalizing and externalizing behaviors. For girls, teacher reports of relational victimization, added to their reports of physical victimization, improved the accuracy of predicting peer-reported peer acceptance and rejection, as well as teacher-reported externalizing problems. For both boys and girls, when teacher reports of relational victimization were entered at step 1 , teacher reports of physical victimization (entered at step 2) added unique information and improved the accuracy of predicting externalizing behaviors only.

Next, the same hierarchical multiple-regression equations were again calculated but this time including teacher, peer, and self-reports of victimization. Peer and selfreports of relational and physical victimization were entered at step 1, teacher reports of physical victimization at step 2, and teacher reports of relational victimization at step 3 . This analysis revealed that teacher reports of physical victimization contributed to the prediction of externalizing behaviors and adding teacher reports of relational victimization improved the accuracy of predicting peer rejection and externalizing and 
internalizing behaviors beyond that provided by peer and self-reports of relational and physical victimization and teacher reports of physical victimization. The hierarchical regression analyses discussed here reveal that teacher reports of both physical and relational victimization help to account for the variance in the findings of peer rejection, and internalizing and externalizing problems identified among victims.

Summary and conclusions. Boys engage in more physical kinds of bullying and victimization than girls do (Cairns et al., 1989; Crick \& Bigbee, 1998; Crick \& Grotpeter, 1995; Lagerspetz, Bjorkqvist, \& Peltonen, 1988). The frequency of relational bullying and victimization reported by boys versus girls, however, is less clear. Some studies report that girls engage in more relational bullying and victimization as compared to boys (Crick \& Bigbee, 1998; Crick \& Grotpeter, 1995; Galen \& Underwood, 1997; Lagerspetz, Bjorkqvist, \& Peltonen, 1988), whereas other studies suggest that boys and girls engage in relational bullying and victimization with equal frequencies (Paquette \& Underwood, 1999; Prinstein, Boergers, \& Vernberg, 2001). Research does reveal that physical and relational forms of bullying have different effects depending on gender. Although both boys and girls rate physical as more hurtful than relational aggression, girls rate relational aggression as more hurtful than boys do (Galen \& Underwood, 1997). It has also been found that relational victimization contributes more to internalizing problems whereas physical aggression or victimization contribute more to externalizing problems (Prinstein, Boergers, \& Vernberg, 2001).

Overall, research has demonstrated the need to study different kinds of bullying and its effects by gender. At the present time, there has been limited literature on the effects of bullying by gender; the research that has been published has focused only on 
relational versus physical forms, and has not included verbal forms of bullying. Understanding how bullying affects youth, and particularly how different kinds of bullying affect boys versus girls is important in recognizing bullying as well as considering when and how to intervene. Because adults may misestimate the frequencies of bullying and victimization (perhaps, for example, due to the fact that they are not always present to witness bullying when it occurs, or that they do not consider relational or covert forms of aggression as bullying), it is also important to understand the relevance and consequences of bullying that is reported by children and their peers. Reporting Bullying in Schools

Given the substantial consequences of bullying for both its victims and perpetrators, some epidemiological research has begun to accrue focusing on the assessment of bullying, particularly in school settings. Such information has addressed not only gender-by-aggression interactions, but also comparisons of reports of occurrence and perceptions of severity by those involved in bullying versus adults who are likely to witness it or to have it reported to them.

For example, Fekkes, Pijpers, and Verloove-Vanhorick (2005) used the Olweus Bully/Victim Questionnaire (Olweus, 1991) to assess 2,766 children from 32 Dutch elementary schools on general bullying and victimization behavior. This study found that $16 \%$ of the sample were bullied regularly (several times a month or more), and $7 \%$ were bullied several times a week. In regards to bullies, $6 \%$ of children bullied others several times a month or more and $32 \%$ bullied others at least once during the current term. Of the victims, in the past 4 weeks, $31 \%$ experienced name-calling, $25 \%$ experienced spreading of rumors, $17 \%$ were ignored or not allowed to participate, and $15 \%$ were 
kicked, hit, or pushed. Girls were more likely to experience spreading of rumors, being ignored, or not allowed to participate, whereas boys were more likely to experience physical forms of bullying. For bullies, boys reported more bullying than girls, particularly more name-calling, kicking, hitting or pushing, and making fun of other children. When victims were asked about telling others about the bullying they experienced, $53 \%$ of the regularly bullied children told their teacher that bullying took place. According to the children, in attempts to stop bullying, teachers were successful $49 \%$ of the time. Of the children who regularly bullied others, $52 \%$ said teachers talked to them about their behavior.

This large-scale study demonstrates that the majority of children who are victims of bullying tell their teachers; however, teachers may be successful at stopping the victimization less than half of the time. This study used a child self-report measure to assess bullying as well as their teachers' reactions to bullying, so caution should be taken when interpreting results in that these are only the child's perceptions. Results of how often children tell teachers about bullying and how successful teachers are in intervening have not yet been reported separately according to kind of aggression and, therefore, valuable information about particular kinds of bullying behaviors may be excluded from the literature all together. This study demonstrates a need for a reliable and valid way for teachers to assess bullying as well as a way to assess teacher knowledge about how to intervene effectively.

Craig, Henderson, and Murphy (2000) conducted a study on prospective teachers' attitudes toward bullying and victimization. The sample comprised 82 female and 34 male students $(M$ age $=26$ yrs. $)$ enrolled in a University Teachers College who were 
surveyed on the Bullying Attitudes Questionnaire (BAQ). The BAQ was designed for this study to assess participants' definitions of bullying, perceived seriousness of bullying, and likelihood of intervention. This study used 18 vignettes that varied by the kind of aggression used by the bully (physical, verbal, relational) and teachers witnessing or not witnessing the bullying. Results revealed that whether or not the teacher witnessed the event had no effect on labeling bullying as physical or verbal aggression but did have an effect for labeling bullying as relational. Witnessing the event did increase perceived seriousness for physical, verbal, and relational aggression. Witnessing the event also increased the likelihood of intervention for all three kinds of bullying. Regardless of whether or not the event was witnessed, physical was more likely than relational aggression to be labeled as bullying; however, there was no difference in labeling physical versus verbal aggression as bullying. Physical aggression was more likely than both verbal and relational aggression to be perceived as serious and to elicit intervention. Verbal aggression was more likely than relational aggression to be labeled as bullying, to be perceived as serious, and to elicit intervention. The results of this study demonstrate the need to define different kinds of bullying for teachers clearly, and to develop a measure to help teachers in assessing different kinds of bullying and the seriousness or need for intervention in each situation. Although teachers may not be present to witness all instances of bullying in schools, their contact with students provides opportunities to witness or to receive reports about such events more frequently than most other adults. In another study that used the BAQ, Yoon and Kerber (2003) examined 94 elementary teachers' attitudes toward bullying and intervention strategies. This study found teacher attitudes were different in response to the three bullying situations (verbal, 
physical, relational) for seriousness, empathy, and likelihood to intervene. Teacher ratings were lower for seriousness, empathy, and likelihood of intervention for relational bullying than for verbal and physical bullying. There were no differences in verbal and physical bullying for ratings of empathy or likelihood of intervention; however, teachers rated physical bullying as more serious than verbal bullying. Teachers were also more likely to intervene in physical or verbal bullying than in relational bullying. Follow-up analyses indicated that only $10 \%$ of teacher responses for relational bullying involved disciplining the perpetrators, whereas about $50 \%$ of teacher responses for verbal and physical bullying involved disciplining the perpetrators.

Bauman and Del Rio (2006) showed 82 students in an education program the same six vignettes as in the Yoon and Kerber (2003) study, which were based on physical, verbal, or relational bullying with gender-neutral bullies and victims. In a survey of perceptions of the seriousness of each bullying scenario and likelihood of intervention, results again demonstrated that the preservice teachers considered relational bullying to be less serious than physical or verbal bullying. They also had less empathy for victims of relational bullying, were less likely to intervene in relational bullying, and reported that they would take less severe actions toward relational bullies and victims than for physical or verbal bullies and victims. These results mimic those found in the report by Yoon and Kerber (2003) in demonstrating that teachers and preservice teachers perceive relational bullying as less serious than either physical or verbal bullying scenarios and, therefore, are potentially less likely to intervene in relational bullying situations. 
In a similar study by Sherman (2009), pre-service teachers were asked to rate the severity of 16 different vignettes, which differed on the kind of social contact (physically aggressive, verbally aggressive, relationally aggressive, non-aggressive), the gender of the bully (male or female), and the gender of the victim (male or female). Results revealed that, regardless of the gender of the actor or the receiver, pre-service teachers perceived vignettes depicting physical aggression as more serious than any other kind of social contact, non-aggressive contact as less serious than any kind of aggressive contact, and no difference in seriousness of verbal and relational aggression.

When examining how gender interacts with kind of aggression, it was found that physical aggression was perceived as more severe when perpetrated by a male than by a female bully. This may indicate that pre-service teachers are more likely to be concerned about or to intervene with physical aggression when the bully is male compared to when the bully is female. Participants perceived verbal and relational aggression equally serious whether perpetrated by a male or a female. Pre-service teachers also considered physical and relational aggression more serious when there was a female victim compared to when there was a male victim. Consistent with previous research showing that females report relational bullying as being more serious than males do (Galen \& Underwood, 1997; Paquette \& Underwood, 1999), these data suggest that pre-service teachers may also perceive relational bullying as more harmful to females than to males.

Finally, when the bully was male, both same- and other-gender interactions were perceived as equally serious. In contrast, when the bully was female, other-gender interactions (i.e., female bully-male victim) were perceived as less serious than samegender situations (i.e., female bully-female victim). When the victim was portrayed as 
male, pre-service teachers perceived same-gender social interactions as more serious than other-gender interactions. In contrast, for female victims, both same- and other-gender interactions were perceived as equally serious. These differential perceptions could lead to less reporting or intervening in female bully-male victim situations, despite findings that relational bullying is as detrimental to males as females (Hoglund, 2007; Prinstein, Boergers, \& Vernberg, 2001).

In a recent study, Naylor and colleagues (2006) explored how both teachers and students define bullying. This study assessed 225 teachers and 1,820 students aged 11 to 14 years ( 881 boys, 939 girls) from 51 UK secondary schools. It is important to consider that if teachers' definitions of bullying differ significantly from students' definitions, this may have serious consequences for students' perceptions on whether or not teachers effectively intervene.

Results demonstrated that, overall, $35.5 \%$ of students and $10.2 \%$ of teachers restricted their definitions of bullying to include only physical kinds of aggression (Naylor et al., 2006). The relatively high percentage of students conceptualizing bullying as purely physical aggression may reflect students' perceptions that physical bullying is the most harmful, and most frequent, as typically found throughout the literature (Galen \& Underwood, 1997). Although the percentage of teachers conceptualizing bullying as purely physical aggression was low, it is still disheartening that $10 \%$ of teachers failed to recognize verbal or relational forms of bullying considering the detrimental consequences of these kinds of aggression. When looking at any mention of each of the three kinds of bullying, the majority of respondents referred to physical bullying (66.4\%) and/or verbal bullying $(59.5 \%)$ in their definitions, whereas only $6.1 \%$ made reference to relational 
bullying. Significantly more teachers $(75.6 \%)$ than students $(65.2 \%)$ referred to physical aggression, but there were no differences between females (66.9\%) and males (65.7\%). When referring to verbal aggression, there was no difference between the percentage of teachers $(59.1 \%)$ and students $(59.6 \%)$; however, more females $(64.2 \%)$ than males (54.1\%) mentioned verbal aggression. Although the overall percentage of participants who mentioned relational aggression in their definition of bullying was quite small, more teachers $(12.9 \%)$ than students $(5.3 \%)$ as well as more females $(8.1 \%)$ than males $(3.8 \%)$ conceptualized relational aggression as a form of bullying. These findings demonstrate that both teachers and students define bullying most frequently as physical aggression, and very infrequently as relational aggression, suggesting that students may not perceive relational aggression as harmful as physical; similarly teachers may also not consider relational aggression as a high-priority problem.

Weinke, Tortura, Green, Karver, and Gesten, (2009) assessed 1,442 students in the $6^{\text {th }}, 7^{\text {th }}$, and $8^{\text {th }}$ grades as well as 57 of those students' teachers to examine identification agreement of bullies and victims. Results revealed that, in general, agreement between self- and teacher-ratings of bullying status were low. Teachers identified more bullies and combination bully/victims than students did; however, more students perceived themselves as victims compared to teacher reports. This finding suggests that observation of bullying may be more salient to teachers, whereas perception of victimization may be more salient to students. Social desirability, however, must be considered in that it is less socially desirable for students to admit to bullying others and teachers may be more likely to identify bullying as it is disruptive to school climate. If teachers are not identifying or perceiving students as victims, however, they may be 
missing opportunities to stop frequent or less obvious (e.g., relational) bullying as well as opportunities to help victims deal with the bullying situations and combat the negative effects.

Given the harmful effects of prolonged bullying, prevention efforts are key in helping students avoid any involvement in bullying. In an effort to discover teachers' perceptions of bullying as well as practices regarding prevention, Dake and colleagues (2003) surveyed 359 elementary school teachers throughout the U.S. Of those surveyed, only $32 \%$ received some form of violence-prevention training, and $31 \%$ received bullying-prevention training prior to the survey. Several variables typically found in bullying-prevention programs were assessed, including involvement of students in creating classroom rules around bullying, having serious talks with either bullies or victims, setting aside time for discussions about bullying, and general perceptions regarding bullying and level of violence. Teachers' perceptions of three kinds of bullying interventions were also assessed: (a) post-bullying interventions (e.g., talking to bully), (b) environmental bullying interventions, and (c) improved student supervision.

When asked about involvement of students in creating classroom rules, $29 \%$ had not thought seriously about involving students in creating rules against bullying, citing the largest barriers as students' lack of knowledge regarding bullying, bullying being low priority relative to other issues, bullying not being a problem to create rules for, and students not taking responsibility seriously (Dake, Price, Telljohann, \& Funk, 2003). Eighty-six percent of teachers did say that they currently talked with both bullies and victims when bullying occurred. In allocating time for discussions about bullying, $66 \%$ of teachers did not regularly set aside time and $36 \%$ found it to be overly time consuming 
and of low priority relative to other problems. When asked to rate their confidence in their ability to effectively deal with student bullying situations, teachers generally indicated that they felt moderately confident. Reporting being only moderately confident in dealing with bullying is interesting given the general belief that bullying is not a high priority at their schools, and the serious consequences bullying can have on students. Teachers who report greater confidence in intervening may be more likely to intervene when bullying situations arise.

This research reveals that only about half of children being bullied tell a teacher and, of that group, only about half report that the teacher intervened effectively (Fekkes, Pijpers, \& Verloove-Vanhorick, 2005). Also, teachers may be more likely to perceive bullying as serious and to intervene if they witness the event (Craig, Henderson, \& Murphy, 2000). Of course, youth often engage in undesirable behaviors such as bullying when adults are not present in order to avoid being punished. Both physical and verbal aggression are more likely to be labeled bullying, to be perceived as serious, to elicit empathy, and to elicit intervention than relational aggression (Craig, Henderson, \& Murphy, 2000; Yoon \& Kerber, 2003).

The results from these studies are particularly disturbing in light of the literature reviewed that overwhelmingly finds relational bullying to be a significant predictor of poor psychosocial outcomes and a common occurrence for boys and girls. Teachers need to be aware of the seriousness of relational forms of bullying and to be equipped with how to assess and respond to all instances of bullying. Teachers also need to be aware of how often and effectively they intervene with bullying situations when they arise. The issue of assessment is addressed next. 


\section{Measurement Approaches}

In the literature reviewed here, three primary kinds of measures have been used to assess bullying and victimization in school settings: self-reports, peer nominations, and teacher reports of bullying and victimization. This section reviews some of the most widely used measures of each kind and identifies their strengths and weaknesses.

Self-report. Self-report measures of bullying and victimization ask students themselves to report on the degree to which they have bullied or have been victimized, and sometimes how they feel about it as well. Issues related to social desirability of responses and fear of retaliation from bullies may inhibit honest disclosure. By using selfreport measures, however, practitioners and researchers can gain valuable information about bullying that may be occurring without the witness of an adult, as well as youths' perceptions of bullying or being victimized.

Olweus's Bully/Victim questionnaires for children and adolescents are probably the most commonly used self-report measures in studies of bullying and victimization (Solberg \& Olweus, 2003). These measures can be used in an anonymous format. Respondents are asked to rate themselves on a number of questions, such as, "Have you been bullied by one or more students?" "How often have you been bullied?" and "How often do other students say nasty and unpleasant things to you?" The Revised Olweus Bully/Victim Questionnaire is completed anonymously by the students. It consists of approximately 40 questions measuring a number of aspects related to being a bully or victim, such as being exposed to various forms of bullying/harassment, various forms of bullying other students (e.g., physical, verbal, relational, racial, sexual), where the 
bullying occurs, and pro-bully and pro-victim attitudes. There are two slightly different versions of the questionnaire, one for use in Grades 3 through 5 and one for Grades 6 through 10 or higher. In a "General Information" section of a form developed for the purpose of ordering the instrument, Olweus (2001) states that the psychometric properties of the Questionnaire are "generally quite good," although data are not reported. Olweus (1991) does provide reliability estimates derived from the students' own reports of being bullied or bullying others that are in the $r \mathrm{~s}=.60$ to .70 range; however, the author also states that many studies of psychometric properties of this instrument have not yet been published. The fact that this questionnaire has remained the most commonly used assessment of bullying for many years, and yet no psychometric properties have been published, of course, is cause for concern.

Crick and Grotpeter's (1995) Social Experiences Questionnaire--Self-Report (SEQ-S) is another commonly used measure. The SEQ-S can be used with students of ages 9 to 11 years, or in fourth and fifth grades. The SEQ-S comprises three subscales (i.e., Relational Victimization, Physical Victimization, and Receipt of Prosocial Acts) each of which contains five items. The Relational Victimization scale measures children's reports of the frequency with which peers attempt or threaten to harm their peer relationships (e.g., "How often does another kid say they won't like you unless you do what they want you to do?"). In contrast, the Physical Victimization scale assesses children's reports of the frequency with which other children attempt or threaten to harm their physical well-being (e.g., "How often do you get hit by another kid at school?"). The Receipt of Prosocial Acts scale assesses the frequency with which children are the targets of peers' caring acts (e.g., "How often does another kid give you help when you 
need it?"). Responses to the items on each scale range from 1 (never) to 5 (all the time). The internal consistency reliability coefficients were $r \mathrm{~s}=0.77$ to 0.80 . Criterion validity data have not yet been reported.

In an attempt to address construct validity, however, Crick and Bigbee (1998) conducted a principle components analysis (PCA) of self reports on the SEQ-S in order to assess whether Relational Victimization, Physical Victimization, and Receipt of Prosocial Acts would emerge as separate factors. This analysis yielded the three predicted factors. Cronbach's alpha coefficients (i.e., internal consistency estimates) ranged from $\alpha \mathrm{s}=.89$ to .91 for the three scales. The Relational- and Physical-Victimization scales correlated $r$ $=.69$, and both correlated negatively with the Receipt-of-Prosocial-Acts scale, $r \mathrm{~s}=-.35$ and -.34 , respectively.

Peer nomination. Another widely used method of measuring bullying in youth is peer nomination. Like self-reports, peer-nomination measures yield information that may be hidden from adults, such as which students are bullying or being victimized, and can also be administered to large groups at a time. Peer nominations are typically administered by giving students class rosters and asking them to nominate peers who meet a specified criterion, for example, "What are the names of three students who are victimized?" The benefits of using peer nominations are that in a relatively short period of time, investigators can gain knowledge about the status of individuals among peers, which may differ from that individual's own perception of his or her peer status. Unlike self-reports, however, peer nominations require students to identify peers in both positive and negative ways, which raises ethical concerns and may make children, teachers, and parents alike uncomfortable. 
One commonly used peer-report measure is the Social Experience Questionnaire-Peer Report (SEQ-P), developed by Crick (1997) and validated by Crick and Bigbee (1998). The SEQ-P can be used with students of ages 9 to 11 years old, or in fourth and fifth grades. The SEQ-P assesses peer perceptions of children's positive and negative treatment by peers. This instrument consists of three scales: (a) Victims of Relational Aggression (six items; e.g., children who are ignored by classmates when someone is mad at them), (b) Victims of Physical Aggression (six items; e.g., children who are beat up a lot by their classmates), and (c) Recipients of Caring Acts (five items; e.g., children who get a lot of help from others when they need it). The items included in this instrument were generated based on those used in the SEQ-S. Children are provided with a class roster and asked to nominate up to three classmates of either gender who fit each item descriptor. Both aggression subscales have been shown to be highly reliable ( $\alpha \mathrm{s}=.82$ to .89 for the Relational-Aggression scale and $\alpha \mathrm{s}=.94$ to .97 for the PhysicalAggression scale; Crick, 1997). The psychometric properties of this scale were tested in a study by Crick (1997) using 1,166 students in third through sixth grades from 12 elementary schools. A factor analysis was first conducted on children's scores for each item. This yielded the three predicted factors, Physical Aggression, Relational Aggression, and Prosocial Behavior. Loadings ranged from .70 to .90 and cross loadings were all below .43. Cronbach's alphas for this sample were $\alpha=.96$ for the PhysicalAggression scale and $\alpha=.88$ for the Relational-Aggression scale. In a later study, a PCA of peer reports assessed whether Relational Victimization, Physical Victimization, and Receipt of Prosocial Acts would emerge as separate factors (Crick \& Bigbee, 1998). This analysis yielded the three predicted factors. Cronbach's alpha values were $\alpha=.86$ (five 
items) for the Relational-Victimization scale, $\alpha=.93$ (five items) for the PhysicalVictimization scale, and $\alpha=.77$ (five items) for the Receipt- of-Prosocial-Acts scale. Relational and Physical Victimization correlated $r=.68$, and both correlated negatively with receipt of Prosocial Acts, $r \mathrm{~s}=-.43$ and -.40 respectively.

Crick and Bigbee (1998) also reported correlations between the SEQ-S and SEQP. Self- and peer-reports of physical victimization correlated $r=.31$ for girls and $r=.39$ for boys. Although these associations provide initial evidence for the convergent validity of the peer-report measure of relational and physical victimization, the correlation between the self- and peer-report forms is relatively low, accounting for only about $9 \%$ to $16 \%$ of the variance. This suggests that self-perceptions of bullying and victimization frequently fail to correspond with perceptions by peers.

Teacher-report. Teacher assessments are often easier and faster to administer than peer nominations, and can help reduce anxiety about students giving and receiving negative peer nominations. In addition, teacher reports of student behaviors can facilitate the monitoring and evaluation of intervention efforts in the classroom.

The SEQ measurement series also includes a teacher-report form, the Social Experience Questionnaire-Teacher Report (SEQ-T), which consists of six items that assess teachers' perceptions of children's physical- and relational-victimization experiences. Using a five-point Likert scale of "never" to "almost always," items assess information about the extent to which each child was a target of physically aggressive acts (3 items) and relationally aggressive acts ( 3 items), Cullerton-Sen and Crick (2005) conducted a study using the SEQ-S, SEQ-P, and the SEQ-T and found there were no differences in informant agreement across the multiple forms of the SEQ (teacher, peer, 
and self-reports of victimization). For the SEQ-T Cronbach's alphas were $\alpha=.82$ for relational victimization and $\alpha=.93$ for physical victimization (Cullerton-Sen \& Crick 2005). Although this instrument has been found to be acceptably valid and reliable, teacher-reports in general were not found to be used very frequently throughout the bullying literature.

A study by Sherman (2009) used generalizability theory (G theory) to develop a measure to assess pre-service teachers' perceptions of the severity of different bullying scenarios. G theory attributes error to multiple sources, which allows one to estimate how much variation arises from several variables of the measure (Cronbach, Gleser, Nanda, \& Ragaratnam, 1972). Having estimates of several variance components allows an investigator to understand how unwanted variation arises, and therefore to plan an efficient design for collecting future data (Cronbach et al., 1972). In Sherman (2009), 29 undergraduate education majors were asked to read 16 vignettes, which differed on kind of bullying depicted, gender of the actor, and gender of the receiver. Participants rated the seriousness of each vignette on five items, from "not at all" to "extremely." $\mathrm{G}$ theory was used to examine the reliability of pre-service teacher's ratings of the seriousness of different bullying vignettes, with vignettes serving as the main effect of interest and items and readers as the secondary facets.

Overall, ratings of the vignettes accounted for the most substantial proportion of the variance among severity ratings $(70 \%)$. That is, differences in the vignettes accounted for most of the variance in the ratings by the readers. A small proportion of variance was also accounted for by the readers (10\%) demonstrating consistency among ratings by individual readers. Almost no variance was accounted for by items (1\%), indicating the 
items were consistently rated across the vignettes. This finding is important because it demonstrates a high degree of homogeneity or internal consistency among items, thereby suggesting that they measure a similar construct. Little variance was accounted for by the interactions of vignette by reader (7\%) and item by reader (3\%), showing that the vignettes and items both were rated fairly consistently across readers. All together, results suggested that items and readers did identify differences among the vignettes, with little variance due to individual items or readers.

This measurement strategy (the 16 vignettes rated on 5 items by 29 readers) demonstrated a high degree of reliability, with a $\mathrm{G}$ coefficient of .995 (analogous to reliability coefficients $\left(\mathrm{r}_{\mathbb{H}}\right)$ in classical test theory). This finding suggests an exceptionally high degree of reliability with the levels of each of the facets used in the design. It is unlikely, however, that any real-world bullying situation will be observed and assessed by 29 readers. Therefore, reliability estimates were estimated for hypothesized levels of each facet. These results revealed that the optimal number of items would be five to seven in order for this measurement strategy to demonstrate an acceptable degree of reliability with only one reader ( $\mathrm{G}$ coefficients $=.78$ and .83 , respectively).

Overall, this measurement strategy was found to have internal consistency, high reliability, and to be a feasible strategy to implement in a school, where bullying is likely to occur. Considering time, budget, and resource constraints in school systems, being effective as well as efficient are important attributes of a measure to be used in the school setting. There are, however, several limitations that remain to be addressed. Even though $\mathrm{G}$ theory allows us to consider multiple facets of a measurement design, there are still several assumptions made about the data. $\mathrm{G}$ theory uses generalizability coefficients from 
one set of measurement conditions and assumes that they apply to other predicted conditions in order to estimate the reliability of the measurement under hypothesized conditions. Despite its strengths, $G$ theory derives predicted values as opposed to obtained values, and therefore must be considered tentative. Further, the measure development was conducted with pre-service teachers serving as the participants as opposed to certified teachers who are currently working in schools. Finally, although the reliability of the measure was evaluated in some detail within one particular population, issues of validity remain to be addressed. That the raters evaluated the seriousness of the non-aggressive versus the physical-, verbal-, and relational-aggression vignettes markedly differently is a promising indication of the construct validity of the measure. Other studies of validity remain to be conducted in order to establish its value, particularly as it might apply to school settings.

In summary, relatively few measures have been developed to assess bullying and victimization in school settings. Those that are most frequently used have been limited to two groups of researchers, and psychometric information is readily available for only one of those groups. Clearly, there is a need for school personnel, who are in contact with school-aged youth, and therefore observers and recipients of information about bullying situations, to be able to assess the severity of these situations effectively and efficiently. Such a measure should be valid, reliable, and theory based. Although Sherman (2009) developed such a measure, and initial analyses demonstrated high reliability, future research is needed to assess the generalizability of the measure with current teachers. 


\section{Hindsight Bias}

Clearly, it is important for teachers be able to accurately assess the severity of different kinds of bullying situations. Moreover, it also is important to be able to consider potential outcomes or consequences of those situations because such perceptions are likely to affect responses. For example, Sherman (2009) found that preservice teachers perceived a vignette about a female bully using relational aggression against a male victim as neither particularly serious nor in need of intervention. It has also been shown that teachers may respond differently to bullying scenarios based on the reaction of the victim (Yoon, 2004). For example, they may be more or less likely to consider the bullying to be serious or to intervene on the basis of their prediction of the response of the victim. Unfortunately, simply discussing bullying situations with teachers and asking them to reflect on how they might have reacted or how serious they believed the situation might have been may result in what is known as hindsight bias.

Hindsight differs from foresight in that hindsight judges possess outcome knowledge that foresight judges do not. Hindsight bias refers to the tendency of people to overestimate the likelihood that they would have predicted an event's outcome correctly after the event has already occurred (Arkes, Faust, Guilmette, \& Hart, 1988). For example, a teacher might evaluate the severity of a situation in which a female bully uses relational aggression against a male victim as low and be unlikely to intervene (see Sherman, 2009). If, however, the teacher later were to learn (in hindsight) that the victim reacted with physical aggression against the bully, that initial (foresight) evaluation might change dramatically. Indeed, it consistently has been shown that telling people that an event has occurred (in hindsight) increases their perception of the probability that they 
would have predicted that event (in foresight; see Fischhoff, 1975; Fischhoff, 1977; Fischhoff \& Beyth, 1975). Moreover, individuals find it difficult to assess how their judgments of an event might have changed due to attaining outcome knowledge (Fischhoff \& Beyth, 1975). Thus, an unfortunate result of hindsight bias is that because people overestimate the extent to which they would have predicted a given outcome, they have no need to learn from experience.

In a classic study, Fischhoff and Beyth (1975) tested this hypothesis by asking a group of participants to estimate the probability of a number of events whose outcomes were unknown, but would be known in the near future. From 2 weeks to 6 months later, the same participants were asked to reconstruct their original predictions as accurately as possible and to indicate whether they knew the actual outcome. A separate group of participants who had not yet participated were also asked to report probabilities that they would have given prior to the event occurring. Results showed that outcome knowledge was associated with biases in prediction. Overall, participants assigned higher postdictive than predictive probabilities when they believed events had occurred; likewise they assigned lower postdictive than predictive probabilities when they believed events had not occurred. Again, one of the dangers of remembering prior predictions inaccurately after hearing about actual outcomes, is that learning about one's predictive abilities is less likely to occur and confidence in predictive accuracy is more likely to be inflated unrealistically.

Through a series of three experiments, Fischhoff (1975) examined differences in hindsight and foresight, as well as how these conditions affected the perceived relevance of presented data. Participants were randomly assigned to one of five groups: a foresight 
group having no outcome, three hindsight groups receiving outcomes that were false, and one hindsight group receiving an outcome that was true. All participants were asked to estimate the likelihood of each of the possible outcomes, as well as to evaluate the relevance of each piece of information in the event's description.

Results showed that reporting an outcome increased its perceived likelihood of occurrence across all variations of participant group, event description, reported outcome, and truth of outcome. In hindsight, particular pieces of information were perceived as more or less relevant based on current knowledge. This finding indicates that participants changed their perceptions of an event after gaining outcome information. That is, reporting an outcome's occurrence increased its perceived likelihood and altered the perceived relevance of data describing the situation.

Fischhoff (1975) also explored how aware participants were of the effect of outcome knowledge on their perceptions. Here, participants were presented materials identical to the previously described hindsight groups, but were asked to respond as if they had not known the outcome. Results indicated that the predictions of these participants closely resembled those of the corresponding hindsight groups, demonstrating an inability to recognize the effects that outcome knowledge had on the evaluation of information.

Thus, Fischoff (1975) convincingly demonstrated that, first, receiving outcome knowledge affects judgments as predicted by the hindsight bias hypothesis. Second, judges are either unaware that outcome knowledge has any effect on their perceptions, or they are aware but unable to ignore the effect. Finally, Fischoff examined the assumption that judges are able to clearly perceive how others view situations before receipt of 
outcome knowledge (which underlies most second guessing of decisions). Here, participants were again presented with the same materials, but this time were asked to respond like other judges who did not know the true outcomes. Once again, results showed that these participants were unable to ignore the effects of the outcome knowledge. Instead, these participants expected others who previously predicted the outcome in foresight to have perceived the same relevance of the data as they, themselves, saw in hindsight. Moreover, these participants felt more confident and believed that they saw the relevant information more clearly than foresight participants. Thus, knowing what happened seemed to facilitate knowing what to look for and what to accept as reasons for the outcome. This study revealed that not only does hindsight bias affect impressions of what individuals believe they would have known (without outcome knowledge), but also what they believe others should have known or seen as relevant in foresight.

A few years after these studies, Fischoff (1977) conducted another series of two experiments to better understand when hindsight bias shows its greatest effects as well as what can be done to prevent this bias. In one experiment, participants were asked 75 difficult general-knowledge questions. An hour later, some of these participants were asked a subset of 25 of those original questions again, whereas others were asked 25 new questions. Participants were assigned to one of three groups: (a) reliability, who were asked the subset of original questions, then were asked to recall their original predictions, (b) memory, who were asked the subset of original questions, were told the correct answers to those questions, and then were asked to recall their original predictions; and (c) hypothetical, who were told the correct answers to all new questions and then were 
asked to respond as if they had not been told the answers. Results showed that those in the reliability group correctly remembered their original predictions $66 \%$ of the time, whereas those in the memory group correctly remembered fewer predictions (53\%). This indicated that being told the correct answer interfered with memory. Moreover, those in the memory group recalled assigning a higher likelihood to correct answers than they actually had; they had difficulty remembering how they could ever have found particular answers incorrect. Those in the hypothetical group (who were told the answers before ever making predictions) substantially overestimated how much they would have known without being told the answer, believing they would have assigned higher probabilities to correct answers than the other participants. Therefore, although the hour wait between the two phases of this study increased memory errors for all groups (reliability group included), the biasing effects were only seen in the memory and hypothetical groups who had been told the correct answers, and not in the reliability group who received no additional information. These results are consistent with the previous studies discussed (Fischhoff, 1975; Fischhoff \& Beyth, 1975).

A second experiment (Fischhoff, 1977) included strategies to counteract hindsight-bias effects. Here one group was treated exactly the same as the hypothetical group in the previous experiment. A second group, the warning group, was given the same manipulation but asked to devote as much attention as they could to the task and reminded of the importance of their responses to the study. A third group, the debiasing group, was told about the hindsight bias effect and was given an example of how the overestimation of probability occurs; they were also asked to devote their attention to the task and reminded of its importance. Results revealed that all three groups were affected 
by the hindsight bias, regardless of attempts to thwart its effects; neither manipulation (warning or debiasing) had any effect. This study adds to the previous literature in demonstrating the robust effects of the hindsight bias.

More recently, a meta-analysis was conducted on the research on hindsight bias (Guilbault, Bryant, Brockway, \& Posavac, 2004). In this meta-analysis, including 252 independent effect-size estimates, found that the hindsight-bias effect is pervasive across disciplines and populations, with a small to medium effect size of 0.39 (Cohen, 1988). This demonstrates that the participants involved in those studies had a tendency to increase their reported probabilities of an event's occurrence retrospectively. This analysis of the literature also found four moderator variables that affected the outcomes of hindsight bias: (a) subjective versus objective probability estimates, (b) kind of event or task, (c) positive versus negative outcome, and (d) manipulation to reduce or increase hindsight bias. Although not one of these variables completely negated the findings of hindsight bias, they did provide some ameliorating effects.

Thus, the research on hindsight bias demonstrates that outcome knowledge influences the way that people retrospectively perceive information. Research conducted by Carli (1999) was designed to explore this phenomenon further. For example, when recalling previously encoded information, do people perceive that information differently in the presence versus the absence of outcome knowledge? Moreover, is previously encoded information recalled as being more consistent with activated schemas in the presence versus the absence of outcome knowledge? If so, hindsight bias effects could be potentiated. These were questions investigated in research conducted by Carli. A second goal of this research was to determine whether hindsight bias, if affected by 
memory reconstruction, affects derogation of a victims and perpetrators after a negative outcome is known.

In the one study (Carli, 1999), participants read a story about a man and a woman that either had no ending or ended with the man raping the woman. Participants then completed questionnaires measuring hindsight bias, memory of actual events of the story, and memory of events that were not actually present but are stereotypically associated with rape. This study found that participants in the rape condition reported more rape antecedents than did those in the no-ending condition, demonstrating that knowing the outcome of rape, these participants falsely remembered more stereotypical rape behaviors than did those who did not know that the outcome was rape. Participants in the rape condition gave lower ratings of both the woman's character and behaviors compared to the no-ending condition, indicating they disapproved of her behaviors and character more when they believed the outcome was rape than when they didn't know the outcome. This finding demonstrates that the victim was derogated in hindsight given a negative outcome. Moreover, regression analyses revealed that memory for rape antecedents mediated the effect of condition on the hindsight bias, rather than hindsight mediating the effect of condition on memory. This finding suggests that knowing an outcome may have lead to the reconstruction of memories that were less accurate and more stereotypical than when the outcome was unknown.

A second study (Carli, 1999) was conducted to replicate the findings of the first, as well as to determine whether the same results would be found for positive rather than negative outcomes. In this study, participants read a similar story about a man and a woman but this time it ended with either the negative outcome (where the man rapes the 
woman), or a positive outcome where the man proposes marriage to the woman. Here, participants in the rape condition reported more inaccurate but stereotypical information than did those in the proposal condition. Likewise, participants in the proposal condition reported more proposal antecedents than did those in the rape condition. Again, results were consistent with the hypothesis that memory of the stereotypical antecedents mediated the relation between the outcome condition and the hindsight bias. Similar to previous findings, the woman's behaviors were seen as more positive or more negative depending on the positive or negative outcome, respectively. The woman's character, however, was not evaluated more positively or negatively, demonstrating that these participants did not make inferences from the behaviors or information given in the story about the character traits of the woman, regardless of the positive or negative outcome. The man's behaviors as well as his character were evaluated differently depending on the outcome; however, overall it was the hindsight bias rather than stereotypical memories that best predicted the ratings of both the man and the woman.

The results of these two studies suggest that the hindsight bias involves reconstructing memories and information to make the outcome seem more plausible or even inevitable. Participants' memories of antecedent events may become altered to be stereotypically consistent with their outcome knowledge. The regression analyses indicated that this reconstruction of memory contributed to the hindsight bias, not that hindsight bias contributes to misremembering of events. Therefore, the addition of stereotypical antecedents resulted in strengthening of hindsight bias effects. Also, compared to the no-outcome and positive-outcome conditions, knowledge of a negative outcome lead to more negative perceptions of the actors in the story. 
This finding, that people make negative evaluations based on outcome information, has important implications for what people conclude when learning about different situations or from experiences. Collectively, the results of these studies indicate that observers' reconstructions of events leading up to an outcome involve both adding new stereotypical antecedents and reinterpreting the actors' behaviors as causal antecedents to that outcome. These processes then combine to reinforce and strengthen the hindsight bias, leading to a greater belief in the outcome's inevitability. The hindsight bias, in turn, may lead observers to evaluate the behaviors of both the perpetrator and the victim negatively.

Blank, Musch, and Pohl (2007) have suggested that hindsight bias is a particularly problematic phenomenon because: (a) it is everywhere, (b) it is hard to avoid, and (c) it has potentially detrimental consequences in applied settings. The effects of hindsight bias have been demonstrated in a variety of domains including, but not limited to, historical and political situations and settings, medical diagnoses, economic, judicial, and everyday decision-making. Attempts at reducing this bias, however, have found only limited success. It has been demonstrated that simply telling people that hindsight bias exists and asking them to consider it before making decisions does not reduce its effects (Fischoff, 1977). Some success has been found for debiasing using counterfactual reasoning, where people are asked to consider reasons or arguments for alternative options (Arkes, Faust, Guilmette, \& Hart, 1988; Koriat, Lichtenstein, \& Fischhoff, 1980). Even given the possibility of using counterfactual reasoning, however, it is clear that it is difficult to eliminate hindsight bias. Finally, hindsight bias may have dangerous effects on people's perceptions of events seeming more foreseeable than they actually are, as well as limiting 
the ability to learn from experience. For all of these reasons, hindsight bias is an important part of decision-making in everyday life, and should be considered when making judgments on whether or not to intervene or to take seriously a potentially harmful event such as bullying among youth.

Relevance to teachers. Most of the empirical research associated with hindsight bias that has been conducted with teachers involves the issue of effective teaching. In a review of this research, Yates (2005) noted that when clear and informative research findings on known, effective, teaching practices are presented, teachers generally report that they already know this information or that it is obvious. Despite a substantial research base that demonstrates effective teaching practices and the fact that teachers report being aware of those practices, however, those practices are used with substantial variability (Yates, 2005).

Consistent with hindsight bias, Yates argued that best teaching practices might appear obvious only in retrospect. For example, a study by Wong (1995) examined the ability of educators to identify which of two opposing claims of best teaching practice was indeed true. This research also examined how obvious these claims appeared to the educators. Results indicated that, when asked which of the two claims was the true research finding, across 12 items only $45 \%$ of educators chose correctly. Of course, these results indicate that participants were not able to distinguish actual research findings from their opposites consistently. Moreover, when the educators were provided with a claim labeled as true and accompanied by an explanation, they rated that claim as more obvious than the opposing claim even when the claim that was labeled as true was actually false. Thus, providing an explanation of a claim increased the educators' ratings of the 
obviousness of that claim, for both true and false claims. Again, consistent with the hindsight-bias effect, these findings suggest that those practices that teachers describe as obvious and known actually may be only retrospectively labeled through outcome knowledge. Once again, a detrimental effect of such a process is that it may lead to a diminished ability to profit from performance feedback.

As applied to bullying, it may seem obvious to teachers that they would have predicted a particular outcome of a bullying incident and would have reacted with a particular intervention only after being informed of that outcome. In foresight, however, that outcome and resulting intervention might not have been as clear. The finding that hindsight bias increases derogation of the victim also is an important factor in assessing teachers' perceptions of bullying among youth, particularly when considering reactions of the victims. As noted previously, many victims of bullying react in an aggressive manner to provocation (Brockenbrough, Cornell, \& Loper, 2002; Olweus, 1993; Pellegrini, Bartini, \& Brooks, 1999; Toblin et. al., 2005; Unnever, 2005). Following predictions based on hindsight-bias research, for example, if a teacher perceives a situation in which a victim is bullied and then that teacher observes an outcome in which the victim reacts aggressively, then that teacher may be more likely to place blame on (or derogate) the victim in future bullying situations. This process may serve to increase the negative consequences of the bullying, such as helplessness and isolation, felt by the victim. Therefore, if hindsight bias occurs when teachers learn the outcomes of a bullying situation, whether the outcome is a passive or aggressive reaction on part of the victim, knowing how this bias affects the teacher's response to the situation and future 
evaluations of the situation can help to discover potentially important factors in how bullying prevention programs need to be targeted toward teachers.

$$
\text { Purpose of the Study }
$$

This study explored the severity of different kinds of bullying situations (physical, verbal, and relational) based on teachers' perceptions in relation to gender of both the bully and the victim, as well as the response of the victim (aggressive or passive). Potential hindsight biases were examined to discover whether knowledge of victim responses to bullying (outcome) influenced the way teachers rated their confidence in predicting those outcomes. Additionally, relationships between different kinds of bullying situations and teachers' intents to intervene with the bully or victim as well as kind of intervention chosen were explored. 


\section{Chapter II: Method}

\section{Participants}

Participants were 208 current teachers throughout the United States. Teachers were recruited via email invitations distributed to teaching listservs, email-distribution lists, and personal contacts. This procedure was modified from a study in which Bauman, Rigby, and Hoppa (2008) successfully recruited a nationally representative sample of teachers and school counselors to respond to an Internet survey. The current research attempted to examine the issue of bullying from the perspective of teachers throughout the United States, although it is recognized that some cultures may perceive different kinds of aggression as more or less serious (Smith, Cowie, Olafsson, \& Liefooghe, 2002; Smorti, Menesini, \& Smith, 2003).

In order to reach a large sample, the questionnaire was hosted on a survey website, Qualtrics (2010). There are several benefits to using an Internet-based survey, namely, the nationwide reach, minimal expense, less time per participant, format flexibility, instant data entry, and ease of execution (Granello \& Wheaton, 2004). There are also some limitations of conducting Internet-based research, including concerns about the representativeness of the sample, response rates, measurement errors, and technical difficulties (Granello \& Wheaton, 2004). Although access to the Internet remains unequally distributed throughout the U.S. population (Granello \& Wheaton, 2004), most school districts throughout the U.S. provide teachers with email addresses to communicate internally; therefore, this limitation was not a concern in this study. Response rates may be affected by concerns over anonymity when using emails and Internet-based surveys to reach participants. Data for this study, however, were collected 
anonymously; teachers neither responded via email nor provided any identifying information. When transferring surveys from paper-based format to electronic format there may be issues in measurement error based on the possibility for different response option formats and scrolling. In this study, however, all response options were either typed by the teacher (similar to writing in paper-based formats) or were fully visible on the screen at one time (i.e., no drop-down response options or scrolling to expose all options).

Before launching this survey, the format was tested on several different Web browsers and versions (i.e., Internet Explorer, Safari, FireFox), as well as computing platforms (i.e., Windows, Mac). After the initial survey launch, there were two instances where the survey-hosting site (Qualtrics) was unavailable for access due to updating their technology, leaving the survey unavailable to teachers for several hours in each instance. During this time, if teachers attempted to access the survey they received a message stating the survey was currently unavailable and to check back later. Although potential responses may have been lost due to these issues, because of the random assignment procedure there is no concern over biasing in the sample based on this limitation.

The population of teachers was of interest given the high frequency with which they may encounter bullying situations during their work in schools. The sample size was selected in consideration of the anticipated analyses. There were a total of 48 surveys, with 16 vignettes in each of three receiver-reaction conditions (Foresight, Hindsight: Aggressive [A], and Hindsight: Passive [P]). To deal with potential order effects, within each of these three conditions, the order of administration of the vignettes was determined by a 16 by 16 Latin square balanced for carryover effects (Williams, 1949). A 
minimum of four teachers completed the vignettes in the order specified by a unique row in the Latin square in each condition. Thus, administration order of the vignettes was balanced across conditions. The survey website was programmed to randomize the presentation of the 48 surveys systematically as teachers logged onto the site. Each of the 16 surveys was programmed to allow for a maximum of six teachers to be randomized to the individual survey. As teachers were randomized to each survey, the program recorded the entry to that survey, and then randomized new teachers to surveys with fewer entries based on the individual survey's quota. This process ensured randomization as well as an approximately equal distribution of teachers to conditions.

Data collected from 15 teachers were excluded due to (a) not living in the United States, (b) not being a current teacher, (c) a potential response bias that could render the ratings invalid (i.e., rating each item on each vignette identically), and (d) indicating in qualitative responses that the data were not valid (i.e., "not serious about this anymore"). The final sample comprised 193 teachers, (61 in the Foresight, 71 in the Hindsight: A, and 61 in the Hindsight: $P$ conditions), $156(80.8 \%)$ females and $37(19.2 \%)$ males, of which $4.7 \%$ were Hispanic/Latino, $89.6 \%$ were White, $4.1 \%$ were African American, $0.5 \%$ were Asian, and $1 \%$ were Native Hawaiian/Other Pacific Islander; $2.6 \%$ endorsed "two or more of the above," and $2.1 \%$ wrote in responses to "other" ("Ethnically Jewish decent," "human race," and "Filipino"). Teachers ranged in age from 23 to 68 years old, with the mode being 32 years and the median being 44 years $(M=43.8, S D=11.4$ years). Three teachers' ages could not be included in those descriptions because they answered "50+," "over 40," and "N/A." The majority of teachers reported that their highest level of education was a Master's degree (64.8\%), with 23.3\% holding a Bachelor's degree, 3.1\% 
an Educational Specialist degree, $7.8 \%$ a Doctoral degree, and 1\% reporting "other" (i.e., "NBCT," "Rank I"). The teachers ranged in years of teaching experience from 1 to 45 years, with the mode being 15 years and the median being 13 years $(M=15.3, S D=9.6$ years); one teacher responded " $5+$." The teachers taught at all three school levels $(40.4 \%$ in Elementary School, $16.6 \%$ in Middle School, and 43.0\% in High School), and ranged from teaching Pre-Kindergarten through $12^{\text {th }}$ grade. Teachers reported living across 33 states in the United States. Based on the U.S. Census Bureau Regions (2012), 25.9\% reported living in the Northeast (CT, MA, ME, NJ, NY, PA, RI), 29.1\% in the Midwest (IA, IL, IN, MI, MN, MO, OH, WI), 26.3\% in the South (AR, DE, FL, GA, KY, MS, NC, $\mathrm{OK}, \mathrm{SC}, \mathrm{TN}, \mathrm{TX}, \mathrm{VA})$, and $17.6 \%$ in the West (AZ, CA, CO, ID, NM, OR, WA); $1 \%$ reported living in the U.S.

\section{Vignettes and Items}

Forty-eight bullying vignettes were developed based on a $4 \times 3 \times 2 \times 2$ matrix for the kind of aggression (Physical, Verbal, Relational, or Nonaggressive) by the reaction of the victim (Physically Aggressive Reaction, Passive Reaction, No Reaction Specified) by the gender of the bully (i.e., actor; Male, Female) by the gender of the victim (i.e., receiver; Male, Female). Names used in each vignette were unique so that the teachers would not equate a particular name as being a bully or victim. Names were chosen based on the most popular baby names in the year 1997, which is consistent with the birth year of current middle school students (Social Security Administration, 2010). Popular names reflecting students currently in middle school were chosen because the instructions prior to the vignettes directed teachers to think of the situation as occurring in a middle school. The vignettes were focused around one age group to improve consistency of perspective 
in consideration of developmental changes across school levels. Middle school was chosen given the high prevalence of bullying during those years (Olweus, 1993; Sawyer, Bradshaw, \& O'Brennan, 2008). Gender-specific names were selected in consideration of frequency of occurrence (within the top 100 most popular names for the desired gender). Names that appeared in the top 500 most popular names for the other gender, and names that were culturally specific were omitted.

In a previous study (Sherman, 2009), the researcher used $\mathrm{G}$ theory to examine the reliability of pre-service teachers' ratings of the seriousness of different bullying vignettes. Overall, the measurement strategy developed demonstrated a high degree of reliability, with a $\mathrm{G}$ coefficient of .995 when including 16 vignettes (based on a $4 \times 2 \times 2$ matrix for the kind of aggression by the gender of the actor by the gender of the receiver) rated on 5 items measuring severity of the vignettes, by 29 readers. Reliability estimates were then determined for hypothesized levels of each facet (number of items and number of readers). Results revealed that the optimal number of items would be five to seven in order for this measurement strategy to demonstrate an acceptable degree of reliability with only one reader. Based on these findings, the measure was adapted for the current research to include seven items to be completed by each reader for an estimated reliability $\mathrm{G}$ coefficient of .83 . Each of these items was rated on a 5 -point Likert scale from 1 ("not at all") to 5 ("extremely"). The two items added for this research were reverse-scored to guard against acquiescence response bias. Teachers also provided probabilities that they would (or would not) have predicted the outcome of each vignette, with the predictions summing to $100 \%$. Although only one probability rating was needed for parametric statistical procedures, teachers were asked to record both probabilities to 
increase the likelihood that they would consider both possibilities more thoroughly. Each teacher recorded probabilities for each outcome, and the survey was programmed to generate the total probability and produce an error message if the total did not equal $100 \%$. The survey would not allow the teacher to continue if the sums did not equal $100 \%$. All items in the survey were programmed as mandatory to answer before continuing, with the exception of the qualitative questions, which were optional. The vignettes and items appear in Appendix A.

\section{Procedure}

The researcher sent an email to each listserv or contact inviting current teachers to participate in the research (see Appendix B). The email stated that the researcher was seeking volunteers to complete an online survey that would take about 20 to 30 minutes, and that would help to understand bullying situations in schools more fully. The email also explained that anyone who was interested in volunteering to participate should follow the link at the end of the email by either clicking on the link, or by copying the link and pasting it into their Internet web browser. This link brought the teacher to the survey site, and directly to one of the 48 surveys.

Teachers who volunteered to participate first read an informed-consent screen, which explained that by continuing to the next screen they were indicating consent to participate (see Appendix C). This screen explained the purpose of the investigation as a study of teachers' assessments of bullying scenarios, and described the informed-consent process. Teachers had the opportunity to print or to save this screen for their records.

Once the informed-consent procedure was completed, the teacher continued to the survey screens, which appear in Appendix A. Each teacher completed a brief 
demographics survey, and then read and responded to 16 vignettes, each of which was immediately followed by the two prediction probability items, the seven severity assessment items, and lastly three open-ended questions.

The demographics survey solicited information about age, gender, race/ethnicity, highest level of education, years teaching experience, grade level currently taught, previous grade levels taught, and U.S. state of current residence. Next, the vignettes were presented. As noted, the presentation order of the vignettes was randomized for each teacher to guard against potential order effects and response bias. Teachers in the Foresight group read each of the 16 vignettes with no outcome given. Teachers in the Hindsight: A group read the 16 vignettes identical to those read by the Foresight group except with the addition of the outcome stating that the receiver reacted to the situation in a physically aggressive manner (e.g., "Christopher reacts by shoving Matthew hard."). Teachers in the Hindsight: $\mathrm{P}$ group also read the 16 vignettes identical to those read by the Foresight group except with the addition of the outcome stating that the receiver reacted to the situation in a passive manner (e.g., "Christopher reacts by ignoring Matthew.").

Each vignette had instructions printed on the top of the screen asking the teacher to read it carefully and then to provide probabilities for each of the two possible outcomes, with the predictions summing to $100 \%$. Teachers then answered each of the seven items rating severity of the vignette by choosing one response option for each. Finally, teachers were asked to type in an open-ended qualitative response to the questions "As a teacher, if you would respond to this situation, how would you respond to (name of the actor specific to each vignette)? How would you respond to (name of the 
receiver specific to each vignette)?" and "Is there anything else you would do in this situation?"

After teachers completed the survey they were thanked for their participation and viewed a written explanation of the study for debriefing purposes (see Appendix D). All teachers were treated in a manner consistent with ethical guidelines of the American Psychological Association (2002), the National Association of School Psychologists (2010), and the Institutional Review Board of the University of Rhode Island (2010). 


\section{Chapter III: Results}

Three sets of analyses were conducted: (a) a vignette study, (b) a hindsight bias study, and (c) an exploratory study of the qualitative responses.

\section{Vignette Study}

The vignette study was conceptualized as a $3 \times(2 \times 2 \times 4)$ factorial design with receiver reaction ( 3 ; Foresight - no reaction given, Hindsight: A - aggressive reaction by the receiver given, Hindsight: $\mathrm{P}$ - passive reaction by the receiver) as a between-subjects independent variable, and gender of the actor ( 2 ; Male or Female), gender of the receiver (2; Male or Female), and kind of aggression (4; Physical, Verbal, Relational, Nonaggressive) as within-subjects independent variables. Approximately one-third (36.79\%) of the teachers independently rated the 16 aggressive-reaction vignettes, onethird (31.61\%) independently rated the 16 passive-reaction vignettes, and one-third (31.61\%) independently rated the 16 vignettes with no reaction given on each of the seven items, for a total of 112 ratings per teacher. For this study, the dependent variable was the mean rating across the seven items for each vignette for each reader. A mixed $3 \mathrm{x}$ ( $2 \times 2 \times 4)$ ANOVA was computed; appropriate follow-up tests (e.g., simple-effects analyses and paired comparison post-hoc tests) were used to explore significant main effects and interactions, and $\eta^{2}$ values and effect sizes were calculated for these sources of variation.

Table 3. Mean Seriousness Ratings for Vignettes

\begin{tabular}{lllccc}
\hline $\begin{array}{l}\text { Kind of } \\
\text { Aggression }\end{array}$ & $\begin{array}{c}\text { Gender of } \\
\text { Actor }\end{array}$ & $\begin{array}{c}\text { Gender of } \\
\text { Receiver }\end{array}$ & Foresight & $\begin{array}{c}\text { Hindsight: } \\
\text { Aggressive }\end{array}$ & $\begin{array}{c}\text { Hindsight: } \\
\text { Passive }\end{array}$ \\
\hline \multirow{2}{*}{ Physical } & Male & Male & 4.48 & 4.40 & 4.26 \\
\cline { 2 - 6 } & Female & Female & 4.57 & 4.47 & 4.34 \\
\hline
\end{tabular}




\begin{tabular}{|c|c|c|c|c|c|}
\hline $\begin{array}{l}\text { Kind of } \\
\text { Aggression }\end{array}$ & $\begin{array}{l}\text { Gender of } \\
\text { Actor }\end{array}$ & $\begin{array}{l}\text { Gender of } \\
\text { Receiver }\end{array}$ & Foresight & $\begin{array}{l}\text { Hindsight: } \\
\text { Aggressive }\end{array}$ & $\begin{array}{l}\text { Hindsight: } \\
\text { Passive }\end{array}$ \\
\hline & & Female & 4.49 & 4.38 & 4.26 \\
\hline \multirow{4}{*}{ Verbal } & \multirow{2}{*}{ Male } & Male & 3.96 & 4.19 & 3.77 \\
\hline & & Female & 3.87 & 4.12 & 3.79 \\
\hline & \multirow{2}{*}{ Female } & Male & 3.87 & 4.13 & 3.72 \\
\hline & & Female & 3.93 & 4.16 & 3.82 \\
\hline \multirow{4}{*}{ Relational } & \multirow{2}{*}{ Male } & Male & 3.59 & 4.09 & $3 . \overline{49}$ \\
\hline & & Female & 3.56 & 4.06 & 3.51 \\
\hline & \multirow{2}{*}{ Female } & Male & 3.59 & 4.07 & 3.45 \\
\hline & & Female & 3.62 & 4.06 & 3.56 \\
\hline \multirow{4}{*}{$\begin{array}{l}\text { Non- } \\
\text { aggression }\end{array}$} & \multirow{2}{*}{ Male } & Male & 2.15 & 3.93 & 2.18 \\
\hline & & Female & 2.03 & 3.83 & 2.17 \\
\hline & \multirow{2}{*}{ Female } & Male & 2.01 & 4.00 & 2.18 \\
\hline & & Female & 2.07 & 3.92 & 2.20 \\
\hline
\end{tabular}

An important assumption underlying the analysis of a factorial design concerns equality of variance. In particular, for a within-subjects (or repeated-measures) ANOVA, in order for the $F$-test to produce valid results, the variability of differences between pairs of treatment conditions should be homogenous. This is known as the sphericity assumption, and it can be assessed using Mauchly's W (Mauchly, 1940). If a chi-squared $(\chi)$ test of Mauchly's $W$ is significant, then the assumption of sphericity has been violated and a correction should be applied to the ANOVA results for the affected sources of variation. Three such corrections are: (a) the Greenhouse-Geisser correction (1959); (b) the Huynh-Feldt correction (1976); and (c) a lowest-possible (or lowerbound) correction. In all cases, these procedures adjust (i.e., lower) degrees of freedom associated with sources of variation, thereby requiring a relatively larger $F$-ratio in order to achieve significance. Girden (1992) suggested that if estimates of sphericity are epsilon $(\varepsilon)<.75$ (indicating a higher degree of correlation among difference scores), the Greenhouse-Geisser correction should be used because it is a relatively more 
conservative correction (and therefore less likely to result in Type I error); if not, and the estimates are $\varepsilon \geq .75$ (indicating a lower degree of correlation among difference scores), then the Huynh-Feldt correction (a more liberal correction) should be used. The lowerbound correction is seldom used because it may result in an overly conservative correction.

Estimates of Mauchly"s $W$ are presented in Table 4 for all sources of variation in the vignette study involving more than one pair of difference scores. Results indicated that the assumption of sphericity was violated for the Kind of Aggression $(\chi(5, N=193)$ $=56.73, p<.001, \varepsilon=.85)$, Kind of Aggression $\mathrm{x}$ Gender of Actor interaction $\left(\chi^{2}(5, N=\right.$ 193) $=12.36, p<.05, \varepsilon=.99$ ), Kind of Aggression $\times$ Gender of Receiver interaction $(\chi 2(5, N=193)=23.31, p<.001, \varepsilon=.95)$, and the Kind of Aggression $x$ Gender of Actor $\mathrm{x}$ Gender of Receiver interaction $(\mathcal{X}(5, N=193)=13.84, p<.05, \varepsilon=.96)$. Thus, the Huynh-Feldt correction is reported for each interaction. It should be noted, however, that no decisions to reject null hypotheses (at $p<.05$ ) were affected by the type of correction applied.

Table 4. Mauchly's Test of Sphericity

\begin{tabular}{lccccccc}
\hline $\begin{array}{l}\text { Within } \\
\text { Subjects Effect }\end{array}$ & $\begin{array}{c}\text { Mauchly's } \\
W\end{array}$ & $\chi$ & $d f$ & $p$ & $\begin{array}{c}\text { Greenhouse- } \\
\text { Geisser }\end{array}$ & $\begin{array}{c}\text { Huynh- } \\
\text { Feldt }\end{array}$ & $\begin{array}{c}\text { Lower- } \\
\text { bound }\end{array}$ \\
\hline $\begin{array}{l}\text { Kind of } \\
\text { Aggression (K) }\end{array}$ & .74 & 56.73 & 5 & .00 & .83 & .85 & .33 \\
$\begin{array}{l}\text { K x Gender of } \\
\text { Actor (A) }\end{array}$ & .94 & 12.36 & 5 & .03 & .96 & .99 & .33 \\
$\begin{array}{l}\text { K x Gender of } \\
\text { Receiver (R) }\end{array}$ & .88 & 23.31 & 5 & .00 & .92 & .95 & .33 \\
K x A x R & .93 & 13.84 & 5 & .02 & .96 & .99 & .33 \\
\hline
\end{tabular}


The ANOVA table for the Vignette Study is presented in Table 5.

Table 5. Vignette Study ANOVA Table

\begin{tabular}{|c|c|c|c|c|c|c|}
\hline Source of Variation & $\begin{array}{l}\text { Sum of } \\
\text { Squares }\end{array}$ & $d f$ & $\begin{array}{l}\text { Mean } \\
\text { Square }\end{array}$ & $F$ & $p$ & $\eta^{2}$ \\
\hline Kind of Aggression (K) * & 1133.71 & 2.54 & 446.67 & 413.20 & .00 & .69 \\
\hline Error: $\mathrm{K}^{*}$ & 521.31 & 482.25 & 1.08 & & & \\
\hline K x Receiver Reaction (RR) & 332.57 & 6 & 55.43 & 60.61 & .00 & .39 \\
\hline Gender of Actor (A) & .23 & 1 & .23 & 1.97 & .16 & .01 \\
\hline Error: A & 22.43 & 190 & .12 & & & \\
\hline$A \times R R$ & .17 & 2 & .08 & .71 & .50 & .01 \\
\hline Gender of Receiver (R) & .19 & 1 & .19 & 1.66 & .20 & .01 \\
\hline Error: $\mathrm{R}$ & 21.34 & 190 & .11 & & & \\
\hline$R \times R R$ & .79 & 2 & .40 & 3.52 & .03 & .04 \\
\hline $\mathrm{K} \times \mathrm{A}^{*}$ & 1.13 & 2.96 & .38 & 3.32 & .02 & .02 \\
\hline Error: $\mathrm{K}$ x A* & 64.61 & 562.28 & .12 & & & \\
\hline $\mathrm{K} \times \mathrm{A} \times \mathrm{RR}$ & .50 & 6 & .08 & .74 & .62 & .01 \\
\hline $\mathrm{K} \times \mathrm{R}^{*}$ & 1.31 & 2.84 & .46 & 5.93 & .00 & .03 \\
\hline Error: $\mathrm{K}$ x R* & 42.02 & 539.44 & .08 & & & \\
\hline $\mathrm{K} \times \mathrm{R} \times \mathrm{RR}$ & .16 & 6 & .03 & .35 & .91 & .00 \\
\hline$A \times R$ & .73 & 1 & .73 & 6.17 & .01 & .03 \\
\hline Error: A x R & 22.56 & 190 & .12 & & & \\
\hline
\end{tabular}




$\begin{array}{lrrrrrr}\mathrm{A} \times \mathrm{R} \times \mathrm{RR} & .30 & 2 & .15 & 1.26 & .29 & .01 \\ \mathrm{~K} \times \mathrm{A} \times \mathrm{R}^{*} & .33 & 2.95 & .11 & 1.25 & .29 & .01 \\ \text { Error: Kx A x R* } & 49.94 & 561.22 & .09 & & & \\ \mathrm{~K} \times \mathrm{A} \times \mathrm{R} \times \mathrm{RR} & .24 & 6 & .04 & .45 & .85 & .01\end{array}$

*Huynh-Feldt correction.

Note: $\sum \eta^{2} \neq 1$ because separate error terms were used for each effect.

Results showed a significant $(p<.01)$ main effect for Kind of Aggression, and significant $(p \leq .03)$ interactions for Kind of Aggression $\mathrm{x}$ Receiver Reaction, Gender of Receiver x Receiver Reaction, Kind of Aggression x Gender of Actor, Kind of Aggression x Gender of Receiver, and Gender of Actor x Gender of Receiver. Simple effects analyses, therefore, were conducted for each of the significant interactions. Kind of Aggression x Receiver Reaction Interaction

In order to analyze the Kind of Aggression x Receiver Reaction interaction, the severity ratings across the three receiver-reaction groups (i.e., Foresight, Hindsight: A, Hindsight: P) were examined separately for each of the four kinds of aggression (i.e., Physical, Verbal, Relational, Non-aggression). Marginal cell means for this interaction are presented in Table 6 and are graphically depicted in Figure 1.

Table 6. Marginal cell means of seriousness ratings for Kind of Aggression $\mathrm{x}$ Receiver Reaction Condition interaction

\begin{tabular}{lccc}
$\begin{array}{l}\text { Kind of } \\
\text { Aggression }\end{array}$ & Foresight & $\begin{array}{c}\text { Hindsight: } \\
\text { Aggressive }\end{array}$ & $\begin{array}{c}\text { Hindsight: } \\
\text { Passive }\end{array}$ \\
\cline { 2 - 4 } & 4.48 & 4.41 & 4.25 \\
\hline Physical & & & \\
\hline
\end{tabular}

Receiver Reaction 


\begin{tabular}{llll}
\hline Verbal & 3.91 & 4.15 & 3.77 \\
\hline Relational & 3.59 & 4.07 & 3.50 \\
\hline Non-aggression & 2.06 & 3.92 & 2.18 \\
\hline
\end{tabular}

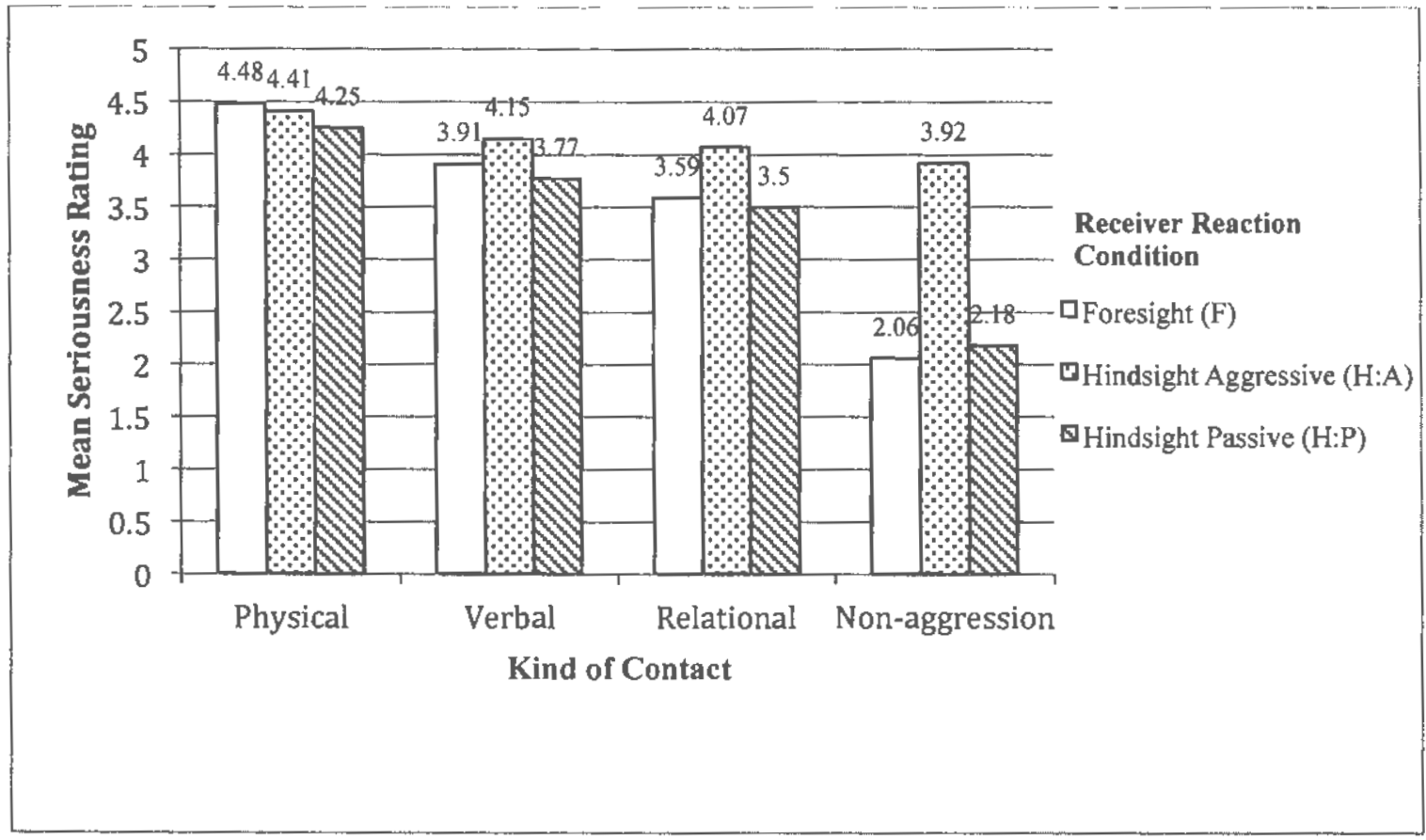

Figure 1. Marginal cell means of seriousness ratings for Kind of Aggression $x$ Receiver Reaction Condition interaction

Results demonstrated that for physical aggression, teachers in the Foresight group $(M=4.48)$ rated vignettes as more serious than teachers in the Hindsight: $\mathrm{P}$ group $(M=$ $4.25 ; p<.05)$. Severity ratings by teachers in the Foresight group did not differ from those in the Hindsight: A group $(M=4.41)$ group, nor did they differ between the two Hindsight groups. That is, for physical aggression, $F>H: P, F=H: A$, and $H: A=H: P$.

For verbal aggression, teachers in the Hindsight: A group $(M=4.15)$ rated vignettes as more serious than teachers in the Hindsight: $\mathrm{P}$ group $(M=3.77 ; p<.01)$. Severity ratings by teachers in the Foresight group $(M=3.91)$ did not differ from those in the Hindsight: A group ( $M=4.41)$ group, nor did they differ from the Hindsight: $\mathrm{P}$ group. 
That is, for verbal aggression, $\mathrm{H}: \mathrm{A}>\mathrm{H}: \mathrm{P}, \mathrm{F}=\mathrm{H}: \mathrm{A}$, and $\mathrm{F}=\mathrm{H}: \mathrm{P}$.

For relational aggression, teachers in the Hindsight: A group $(M=4.07)$ rated vignettes as more serious than teachers in either the Foresight $(M=3.59)$ or the Hindsight $\mathrm{P}(M=3.50)$ groups $(p s<.001)$. Severity ratings by teachers in the Foresight group did not differ from those in the Hindsight: $\mathrm{P}$ group. That is, for relational aggression, $\mathrm{H}: \mathrm{A}>$ $F, H: A>H: P$, and $F=H: P$.

Finally, for non-aggression, teachers in the Hindsight: A group $(M=3.92)$ rated vignettes as more serious than teachers in either the Foresight $(M=2.06)$ or the Hindsight: $\mathrm{P}(M=2.18)$ groups $(p s<.001)$. Severity ratings by teachers in the Foresight group did not differ from those in the Hindsight: $\mathrm{P}$ group. That is, for non-aggression, $\mathrm{H}: \mathrm{A}>\mathrm{F}, \mathrm{H}: \mathrm{A},>\mathrm{H}: \mathrm{P}, \mathrm{F}=\mathrm{H}: \mathrm{P}$.

\section{Gender of Receiver $x$ Receiver Reaction Interaction}

In order to analyze the Gender of Receiver $x$ Receiver Reaction interaction, the severity ratings across the three receiver-reaction groups (i.e., Foresight, Hindsight: A, Hindsight: P) were examined separately for each gender of receiver (i.e., Male, Female). Marginal cell means for this interaction are presented in Table 7 and are graphically depicted in Figure 2.

Table 7. Marginal cell means of seriousness ratings for Gender of Receiver $x$ Receiver Reaction interaction

\begin{tabular}{lccc}
\hline & \multicolumn{3}{c}{ Receiver Reaction } \\
\cline { 2 - 4 } $\begin{array}{l}\text { Gender of } \\
\text { Receiver }\end{array}$ & Foresight & $\begin{array}{c}\text { Hindsight: } \\
\text { Aggressive }\end{array}$ & $\begin{array}{c}\text { Hindsight: } \\
\text { Passive }\end{array}$ \\
\hline Male & 3.50 & 4.15 & 3.40 \\
\hline Female & 3.52 & 4.13 & 3.45 \\
\hline
\end{tabular}




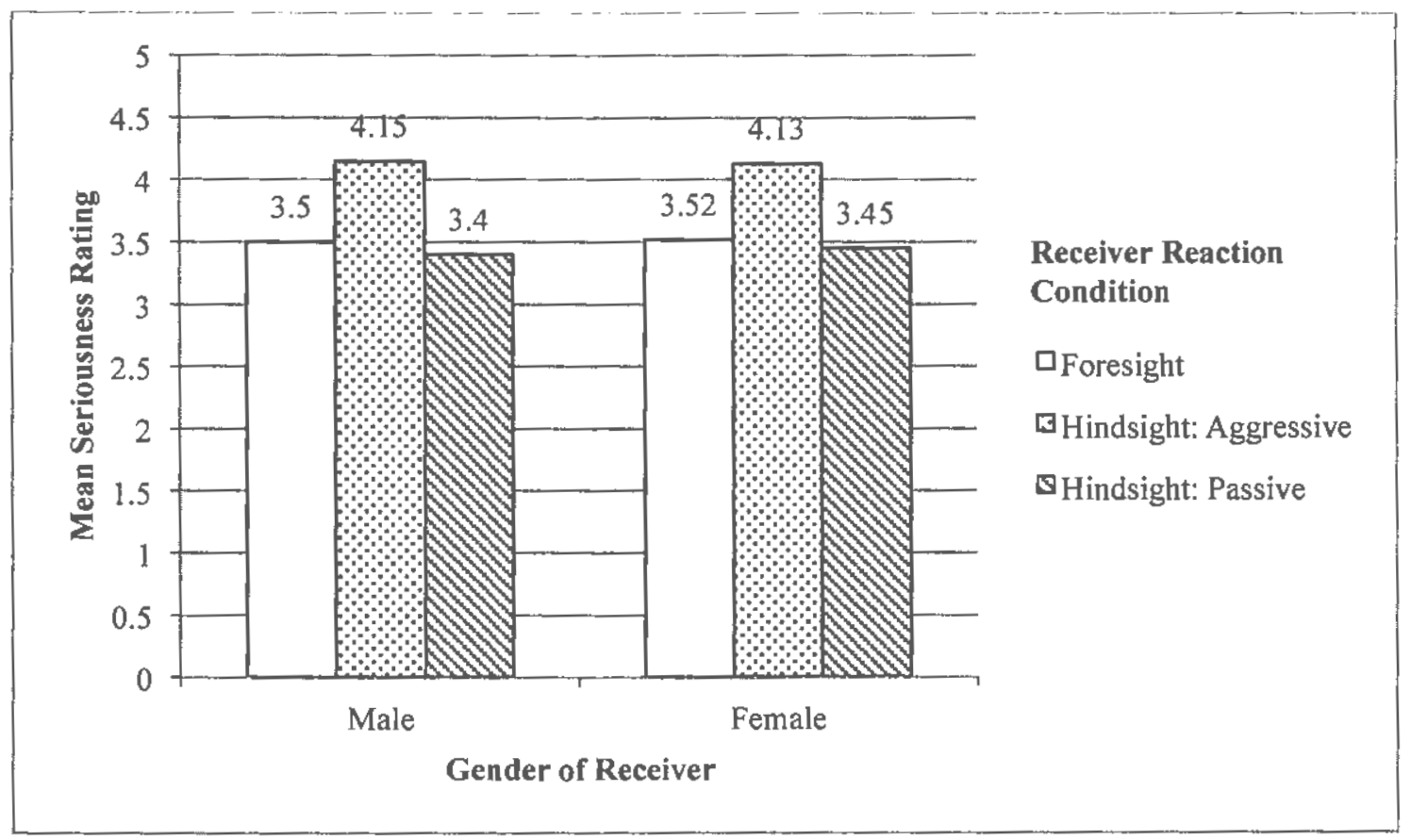

Figure 2. Marginal cell means of seriousness ratings for Gender of Receiver $x$ Receiver Reaction Condition interaction

Results demonstrated that for male receivers, teachers in the Hindsight: $\mathrm{A}(M=$ 4.15) group rated vignettes as more serious than teachers in either the Foresight ( $M=$ 3.50) or Hindsight: $\mathrm{P}(M=3.40)$ groups ( $p s<.001)$. Severity ratings by teachers in the Foresight group did not differ from those in the Hindsight: $\mathrm{P}$ group. That is, for male receivers, $\mathrm{H}: \mathrm{A}>\mathrm{F}, \mathrm{H}: \mathrm{A}>\mathrm{H}: \mathrm{P}, \mathrm{F}=\mathrm{H}: \mathrm{P}$.

Despite the interaction, for female receivers, the pattern was the same. Teachers in the Hindsight: A group $(M=4.13)$ rated vignettes as more serious than teachers in either the Foresight $(M=3.52)$ or Hindsight: $\mathrm{P}(M=3.45)$ groups ( $p s<.001)$. Again, severity ratings by teachers in the Foresight group did not differ from those in the Hindsight: $\mathrm{P}$ group. That is, for female receivers, $\mathrm{H}: \mathrm{A}>\mathrm{F}, \mathrm{H}: \mathrm{A}>\mathrm{H}: \mathrm{P}, \mathrm{F}=\mathrm{H}: \mathrm{P}$. Kind of Aggression x Gender of Actor Interaction

In order to analyze the Kind of Aggression $\mathrm{x}$ Gender of Actor interaction, the 
severity ratings across the four kinds of aggression (i.e., Physical, Verbal, Relational, Non-aggression) were examined separately for each gender of actor (i.e., Male, Female). Marginal cell means for this interaction are presented in Table $\mathbf{8}$ and are graphically depicted in Figure 3.

Table 8. Marginal cell means of seriousness ratings for Kind of Aggression x Gender of Actor interaction

\begin{tabular}{lcc} 
& \multicolumn{2}{c}{ Gender of Actor } \\
Kind of \\
Aggression & Male & Female \\
\cline { 2 - 3 } & 4.42 & 4.34 \\
\hline Physical & 3.96 & 3.95 \\
\hline Verbal & 3.74 & 3.74 \\
\hline Relational & 2.77 & 2.79 \\
\hline Non-aggression & \\
\hline
\end{tabular}

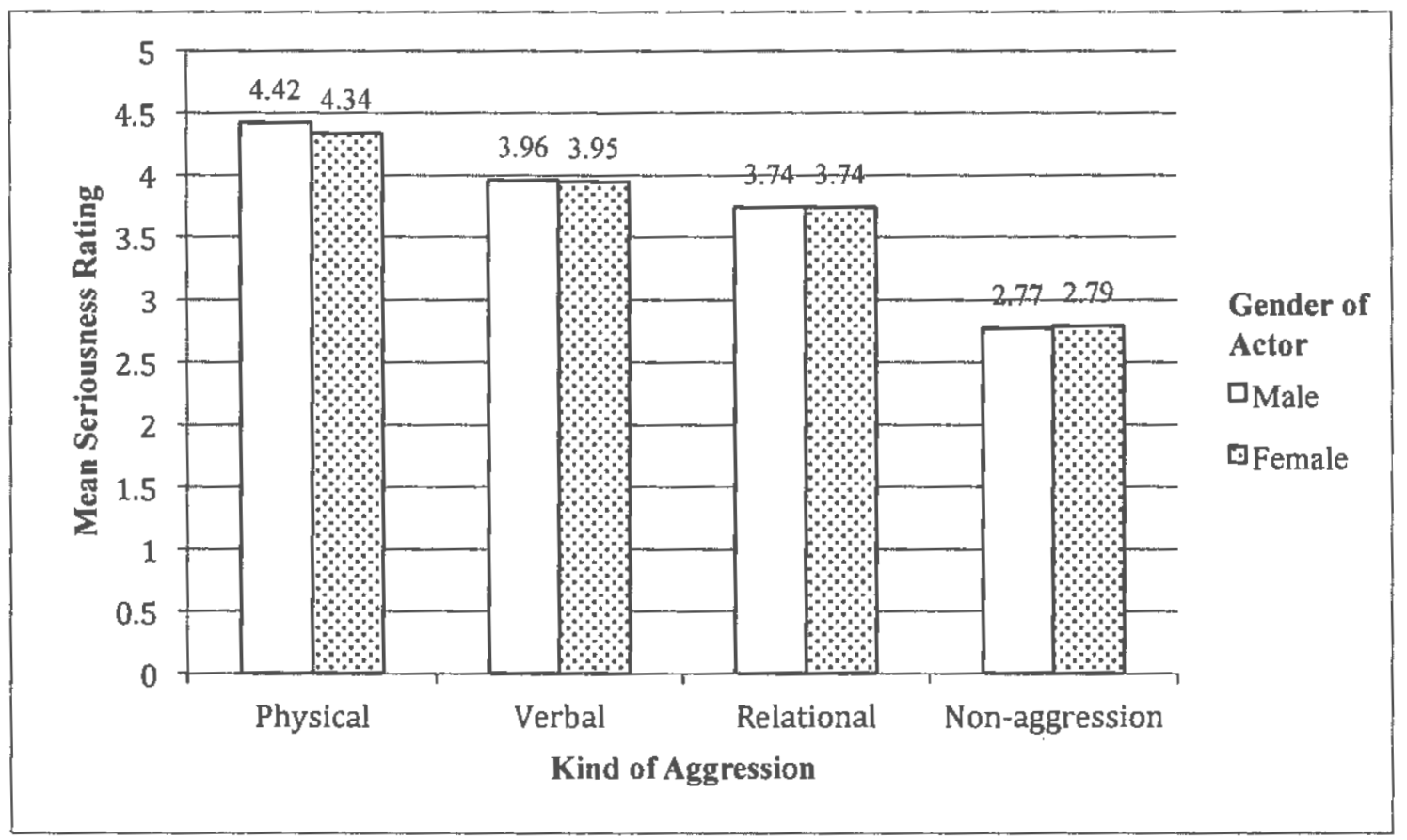

Figure 3. Marginal cell means of seriousness ratings for Kind of Aggression $x$ Gender of Actor interaction 
Results demonstrated that for male actors, teachers rated vignettes depicting physical aggression $(M=4.42)$ as more serious than vignettes depicting verbal $(M=$ 3.96), relational $(M=3.74)$, or non-aggression $(M=2.77 ; p s<.001)$. Teachers rated vignettes depicting verbal aggression as more serious than relational or non-aggression vignettes, and vignettes depicting relational aggression as more serious than nonaggression vignettes ( $p s<.001$ ). That is, for male actors, Physical $>$ Verbal $>$ Relational $>$ Non-aggression.

Again, despite the interaction, for female actors the pattern was the same. Teachers rated vignettes depicting physical aggression $(M=4.42)$ as more serious than vignettes depicting verbal $(M=3.96)$, relational $(M=3.74)$, or non-aggression $(M=2.77$; $p s<.001)$. Teachers rated vignettes depicting verbal aggression as more serious than relational or non-aggression vignettes, and vignettes depicting relational aggression as more serious than non-aggression vignettes $(p s<.001)$. That is, for female actors, Physical $>$ Verbal $>$ Relational $>$ Non-aggression .

Kind of Aggression $x$ Gender of Receiver Interaction

In order to analyze the Kind of Aggression $x$ Gender of Receiver interaction, the severity ratings across the four kinds of aggression (i.e., Physical, Verbal, Relational, Non-aggression) were examined separately for each gender of receiver (i.e., Male, Female). Marginal cell means for this interaction are presented in Table 9 and are graphically depicted in Figure 4. 
Table 9. Marginal cell means of seriousness ratings for Kind of Aggression x Gender of Receiver interaction

\begin{tabular}{lcc} 
& \multicolumn{2}{c}{ Gender of Receiver } \\
\cline { 2 - 3 } Kind of & Magression & Female \\
\cline { 2 - 3 } & 4.34 & 4.42 \\
\hline Physical & 3.95 & 3.96 \\
\hline Verbal & 3.73 & 3.74 \\
\hline Relational & 2.80 & 2.76
\end{tabular}

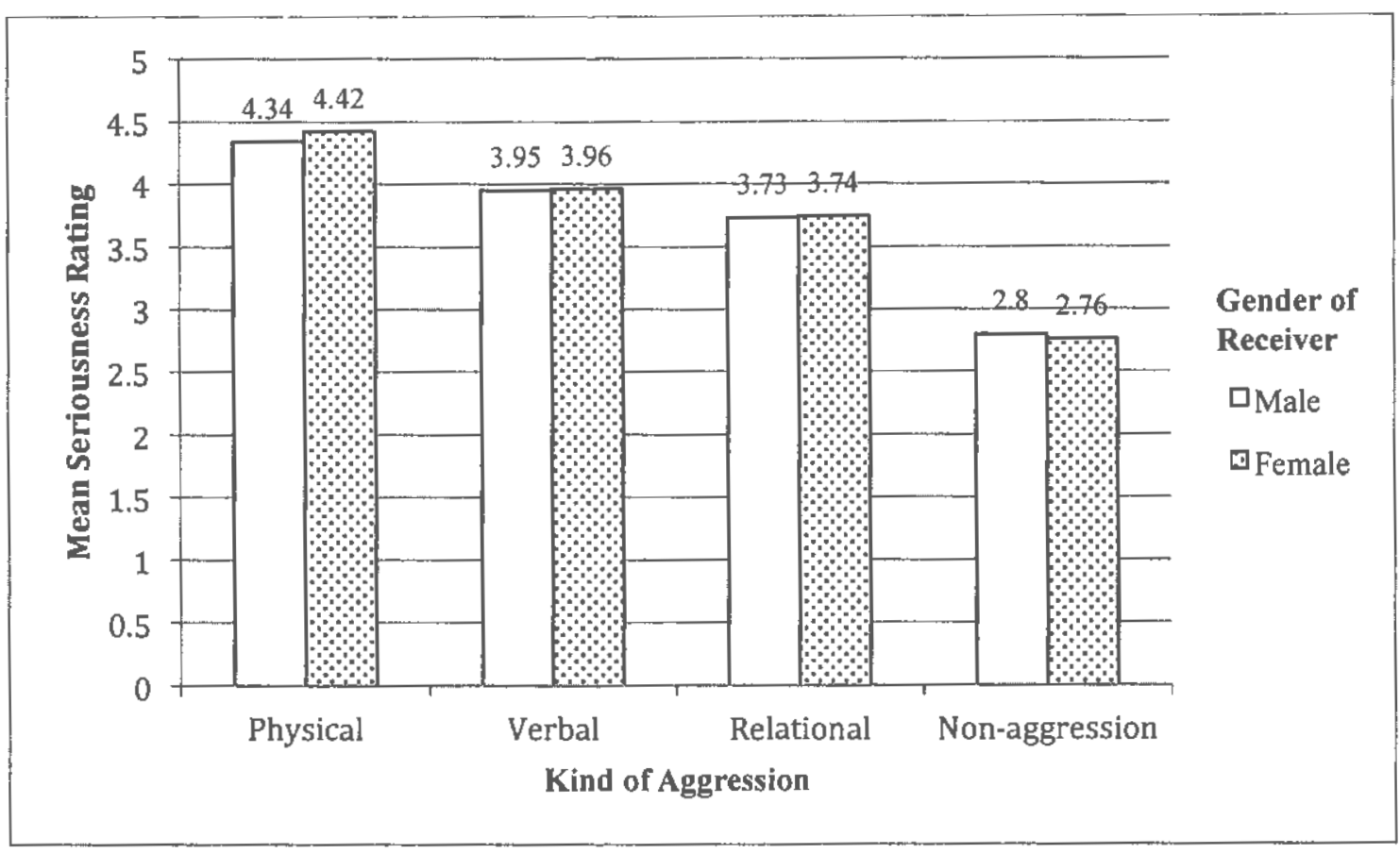

Figure 4. Marginal cell means of seriousness ratings for Kind of Aggression x Gender of Receiver interaction

Results demonstrated that for male receivers, teachers rated vignettes depicting physical aggression $(M=4.34)$ as more serious than vignettes depicting verbal $(M=$ 3.95), relational $(M=3.73)$, or non-aggression $(M=2.80 ; p s<.001)$. Teachers rated vignettes depicting verbal aggression as more serious than relational or non-aggression 
vignettes, and vignettes depicting relational aggression as more serious than nonaggression vignettes $(p s<.001)$. That is, for male receivers, Physical $>$ Verbal $>$ Relational > Non-aggression.

Again, despite the interaction, for female receivers the pattern was the same. Teachers rated vignettes depicting physical aggression $(M=4.42)$ as more serious than vignettes depicting verbal $(M=3.96)$, relational $(M=3.74)$, or non-aggression $(M=2.76$; $p s<.001$ ). Teachers rated vignettes depicting verbal aggression as more serious than relational or non-aggression vignettes, and vignettes depicting relational aggression as more serious than non-aggression vignettes ( $p s<.001)$. That is, for female receivers, Physical $>$ Verbal $>$ Relational $>$ Non-aggression.

Gender of Actor $x$ Gender of Receiver Interaction

In order to analyze the Gender of Actor x Gender of Receiver interaction, the severity ratings were examined separately for each gender of actor (i.e., Male, Female) and gender of receiver (i.e., Male, Female). Marginal cell means for this interaction are presented in Table 10 and are graphically depicted in Figure 5.

Table 10. Marginal cell means for seriousness ratings for

Gender of Actor x Gender of Receiver interaction

\begin{tabular}{lcc}
\hline \multirow{2}{*}{$\begin{array}{l}\text { Gender of } \\
\text { Receiver }\end{array}$} & \multicolumn{2}{c}{ Gender of Actor } \\
\cline { 2 - 3 } & Male & Female \\
\hline Male & 3.73 & 3.68 \\
Female & 3.71 & 3.73 \\
\hline
\end{tabular}




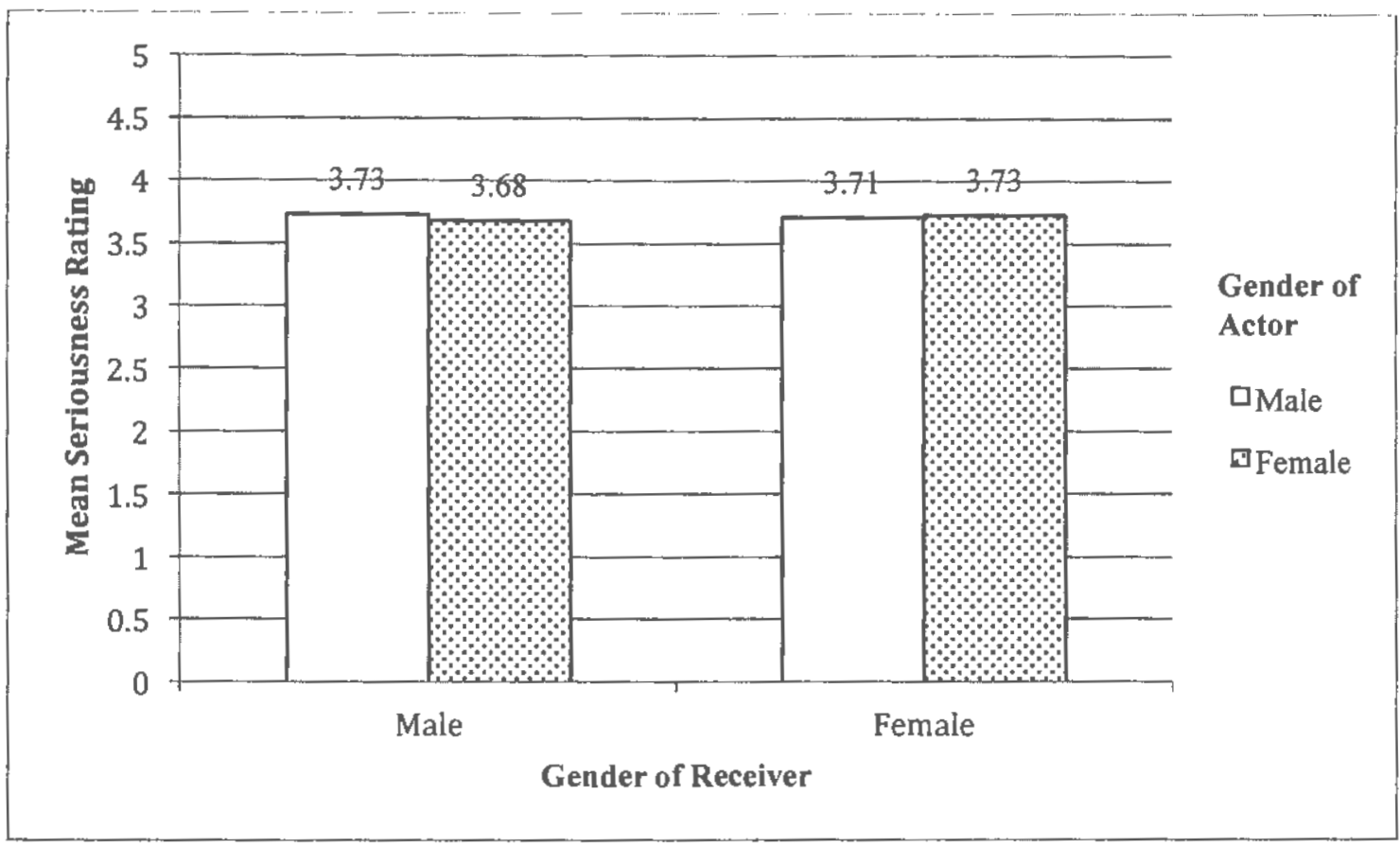

Figure 5. Marginal cell means for seriousness ratings for Gender of Actor $x$ Gender of Receiver interaction

Results demonstrated that, when the actor was depicted as male, there were no differences in how teachers rated the seriousness of both male $(M=3.73)$ and female receivers $(M=3.71)$. When the actor was depicted as female, however, then vignettes depicting male receivers $(M=3.68)$ were rated as less serious than vignettes depicting female receivers $(M=3.73 ; p<.03)$. When the receiver was depicted as male, vignettes depicting male actors were rated as more serious than vignettes depicting female actors ( $p$ $<.03)$. When the receiver was depicted as female, however, there was no difference between vignettes depicting either male or female actors.

\section{Hindsight Bias Study}

The hindsight bias study also was conceptualized as a $3 \times(2 \times 2 \times 4)$ factorial design with receiver reaction ( 3 ; Foresight-no reaction given, Hindsight: A -- aggressive reaction by the receiver given, Hindsight: $\mathrm{P}$ - passive reaction by the receiver) as a 
between-subjects independent variable, and gender of the actor (2; Male, Female), gender of the receiver (2; Male, Female), and kind of aggression (4; Physical, Verbal, Relational, Non-aggression) as within-subjects independent variables. Each of the 193 teachers provided probabilities (expressed as percents) that they would have predicted the (aggressive or passive) receiver outcome of each vignette, with the sum of these two predictions totaling $100 \%$. Because only one probability rating was needed for parametric statistical procedures, the probability that the receiver would respond aggressively was used as the dependent variable for this analysis. Table 11 presents the mean probabilities (expressed as percents) of an aggressive receiver reaction that teachers provided for each of the receiver-reaction conditions across each of the 16 vignettes.

Table 11. Mean Probabilities of Aggressive Receiver Reaction

\begin{tabular}{|c|c|c|c|c|c|}
\hline $\begin{array}{l}\text { Kind of } \\
\text { Aggression }\end{array}$ & $\begin{array}{l}\text { Gender } \\
\text { of Actor }\end{array}$ & $\begin{array}{l}\text { Gender of } \\
\text { Receiver }\end{array}$ & Foresight & $\begin{array}{l}\text { Hindsight- } \\
\text { Aggressive }\end{array}$ & $\begin{array}{l}\text { Hindsight- } \\
\text { Passive }\end{array}$ \\
\hline \multirow{4}{*}{ Physical } & \multirow{2}{*}{ Male } & Male & 55.00 & 61.75 & 52.54 \\
\hline & & Female & 31.39 & 51.42 & 33.25 \\
\hline & \multirow{2}{*}{ Female } & Male & 43.20 & 49.45 & 43.48 \\
\hline & & Female & 51.97 & 55.32 & 44.72 \\
\hline \multirow{4}{*}{ Verbal } & \multirow{2}{*}{ Male } & Male & 37.54 & 43.96 & 34.66 \\
\hline & & Female & 26.56 & 35.80 & 19.21 \\
\hline & \multirow{2}{*}{ Female } & Male & 23.00 & 38.32 & 23.02 \\
\hline & & Female & 25.61 & 38.44 & 24.89 \\
\hline \multirow{4}{*}{ Relational } & \multirow{2}{*}{ Male } & Male & 25.93 & 32.97 & 21.49 \\
\hline & & Female & 20.51 & 27.90 & 17.62 \\
\hline & \multirow{2}{*}{ Female } & Male & $19 . \overline{75}$ & 27.06 & 18.05 \\
\hline & & Female & 23.64 & 29.99 & 20.00 \\
\hline \multirow{4}{*}{$\begin{array}{l}\text { Non- } \\
\text { Aggression }\end{array}$} & \multirow{2}{*}{ Male } & Male & 14.30 & 17.13 & 12.34 \\
\hline & & Female & 10.41 & 14.16 & 11.38 \\
\hline & \multirow{2}{*}{ Female } & Male & 10.41 & 13.49 & 9.33 \\
\hline & & Female & 12.02 & 18.00 & 11.48 \\
\hline
\end{tabular}

Note. Values are expressed as percents. 
As in the vignette study, in order for the $F$-test to produce valid results, the sphericity assumption, assessed using Mauchly's $W$ (Mauchly, 1940) was considered. Estimates of Mauchly's $W$ are presented in Table 12 for all sources of variation in the hindsight bias study involving more than one pair of difference scores. Results indicated that the assumption of sphericity was violated for the Kind of Aggression $(\chi 2(5, N=193)$ $=47.87, p<.001, \varepsilon=.90)$, Kind of Aggression $\mathrm{x}$ Gender of Receiver interaction $(\chi<$ ( $5, N$ $=193)=28.23, p<.001, \varepsilon=.94)$, and the Kind of Aggression $\mathrm{x}$ Gender of Actor $\mathrm{x}$ Gender of Receiver interaction $(\chi(5, N=193)=31.58, p<.001, \varepsilon=.92)$. Thus, the Huynh-Feldt correction is reported for each interaction. It should be noted, however, that no decisions to reject null hypotheses (at $p<.05$ ) were affected by the type of correction applied.

Table 12. Mauchly's Test of Sphericity

\begin{tabular}{|c|c|c|c|c|c|c|c|}
\hline \multirow{2}{*}{$\begin{array}{l}\text { Within } \\
\text { Subjects Effect }\end{array}$} & \multirow{2}{*}{$\begin{array}{c}\text { Mauchly's } \\
\qquad W\end{array}$} & \multirow[b]{2}{*}{$x$} & \multirow[b]{2}{*}{$d f$} & \multirow[b]{2}{*}{$p$} & \multicolumn{3}{|c|}{$\varepsilon$} \\
\hline & & & & & $\begin{array}{l}\text { Greenhouse- } \\
\text { Geisser }\end{array}$ & $\begin{array}{l}\text { Huynh- } \\
\text { Feldt }\end{array}$ & $\begin{array}{l}\text { Lower- } \\
\text { bound }\end{array}$ \\
\hline $\begin{array}{l}\text { Kind of } \\
\text { Aggression }(\mathrm{K})\end{array}$ & .78 & 47.87 & 5 & .00 & .88 & .90 & .33 \\
\hline $\begin{array}{l}\mathrm{K} \times \text { Gender of } \\
\text { Actor }(\mathrm{A})\end{array}$ & .96 & 7.57 & 5 & .18 & .97 & 1.00 & .33 \\
\hline $\begin{array}{l}\mathrm{K} \times \text { Gender of } \\
\text { Receiver (R) }\end{array}$ & .86 & 28.23 & 5 & .00 & .91 & .94 & .33 \\
\hline $\mathrm{K} \times \mathrm{A} \times \mathrm{R}$ & .85 & 31.58 & 5 & .00 & .90 & .92 & .33 \\
\hline
\end{tabular}

The ANOVA table for the hindsight-bias study is presented in Table 13. Table 13. Hindsight Bias Study ANOVA Table

\begin{tabular}{lcccccc}
\hline Source of Variation & $\begin{array}{c}\text { Sum of } \\
\text { Squares }\end{array}$ & df & $\begin{array}{c}\text { Mean } \\
\text { Square }\end{array}$ & $F$ & $p$ & $\eta^{2}$ \\
\hline Kind of Aggression $(\mathrm{K})^{*}$ & 494994.46 & 2.70 & 183431.46 & 195.13 & .00 & .51
\end{tabular}




\begin{tabular}{|c|c|c|c|c|c|c|}
\hline Source of Vartation & $\begin{array}{l}\text { Sum of } \\
\text { Squares }\end{array}$ & $d f$ & $\begin{array}{c}\text { Mean } \\
\text { Square }\end{array}$ & $F$ & $p$ & $\eta^{2}$ \\
\hline Error: $\mathrm{K}^{*}$ & 481979.75 & 512.72 & 940.05 & & & \\
\hline K x Receiver Reaction (RR) & 6697.41 & 6 & 116.24 & 1.32 & .25 & .01 \\
\hline Gender of Actor (A) & 1596.73 & 1 & 1596.73 & 6.56 & .01 & .03 \\
\hline Error: A & 46277.94 & 190 & 243.57 & & & \\
\hline$A \times R R$ & 115.15 & 2 & 57.57 & .24 & .79 & .00 \\
\hline Gender of Receiver (R) & 7007.33 & 1 & 7007.33 & 33.02 & .00 & .15 \\
\hline Error: R & 40321.89 & 190 & 212.22 & & & \\
\hline $\mathrm{R} \times \mathrm{RR}$ & 826.90 & 2 & 413.45 & 1.95 & .15 & .02 \\
\hline $\mathrm{K} \times \mathrm{A}$ & 2104.86 & 3 & 701.62 & 3.96 & .01 & .02 \\
\hline Error: $\mathrm{K} \times \mathrm{A}$ & 101080.30 & 570 & 177.33 & & & \\
\hline $\mathrm{K} \times \mathrm{A} \times \mathrm{RR}$ & 3906.71 & 6 & 651.12 & 3.67 & .00 & .04 \\
\hline $\mathrm{K} \times \mathrm{R}^{*}$ & 5394.19 & 2.81 & 1919.79 & 9.23 & .00 & .05 \\
\hline Error: $\mathrm{K} \times \mathrm{R}^{*}$ & 111062.65 & 533.86 & 208.04 & & & \\
\hline $\mathrm{K} \times \mathrm{R} \times \mathrm{RR}$ & 1310.77 & 6 & 218.46 & 1.12 & .35 & .01 \\
\hline$A \times R$ & 29010.98 & 1 & 29010.98 & 95.11 & .00 & .33 \\
\hline Error; A x R & 57952.42 & 190 & 305.01 & & & \\
\hline$A \times R \times R R$ & 909.66 & 2 & 454.83 & 1.49 & .23 & .02 \\
\hline $\mathrm{K} \times \mathrm{A} \times \mathrm{R} *$ & 8884.92 & 2.75 & 3225.75 & 17.57 & .00 & .09 \\
\hline Error: $\mathrm{K} \times \mathrm{A} \times \mathrm{R}$ * & 96077.51 & 523.33 & 183.59 & & & \\
\hline $\mathrm{K} \times \mathrm{A} \times \mathrm{R} \times \mathrm{RR}$ & 2275.95 & 6 & 379.33 & 2.25 & .04 & .02 \\
\hline
\end{tabular}

*Huynh-Feldt correction.

Note: $\sum \eta^{2} \neq 1$ because separate error terms were used for each effect.

Results showed significant $(p<.01)$ main effects for Kind of Aggression, Gender of Actor, and Gender of Receiver, and significant $(p<.05)$ interactions for Kind of Aggression x Gender of Actor, Kind of Aggression x Gender of Receiver, Gender of Actor x Gender of Receiver, Kind of Aggression x Gender of Actor x Receiver Reaction, 
Kind of Aggression x Gender of Actor x Gender of Receiver, and Kind of Aggression x Gender of Actor x Gender of Receiver x Receiver Reaction.

Thus, potential hindsight-bias effects (i.e., Receiver Reaction effects) depended on combinations of Kind of Aggression, the Gender of the Actor, and the Gender of the Receiver. Therefore, simple-effect follow-up analyses were conducted to examine potential differences among foresight and hindsight groups for each of the 16 combinations of Kind of Aggression, Gender of Actor, and Gender of Receiver vignettes. Here, individual ANOVAs were conducted for each of the 16 vignettes. Results demonstrated that for each vignette where significant differences were found among receiver-reaction conditions, teachers in the Hindsight: A group always reported a higher likelihood of the receiver responding aggressively compared to those in the Hindsight: $\mathrm{P}$ or Foresight groups.

\section{Physical Aggression}

For vignettes depicting physical aggression, when the gender of the actor was male and the gender of the receiver was female, there was a significant difference between ratings of receiver response for teachers in the Hindsight: A condition versus those in the Foresight and the Hindsight: $\mathrm{P}$ conditions $(p s<.001)$; there were no differences between those in the Hindsight: $\mathrm{P}$ versus the Foresight conditions (H:A > F; $\mathrm{H}: \mathrm{A}>\mathrm{H}: \mathrm{P} ; \mathrm{H}: \mathrm{P}=\mathrm{F}$ ). Similarly, when the gender of both the actor and receiver was female, there was a significant difference between ratings for teachers in the Hindsight: A condition versus those in the Hindsight: $\mathrm{P}$ condition $(\mathrm{H}: \mathrm{A}>\mathrm{H}: \mathrm{P}, p<.02)$. There were no differences, however, between either of the hindsight conditions versus the Foresight condition for any of the vignettes depicting a female actor and female receiver $(\mathrm{H}: \mathrm{A}=\mathrm{F}$; 
$\mathrm{H}: \mathrm{P}=\mathrm{F})$. These results are illustrated in Figure 6.

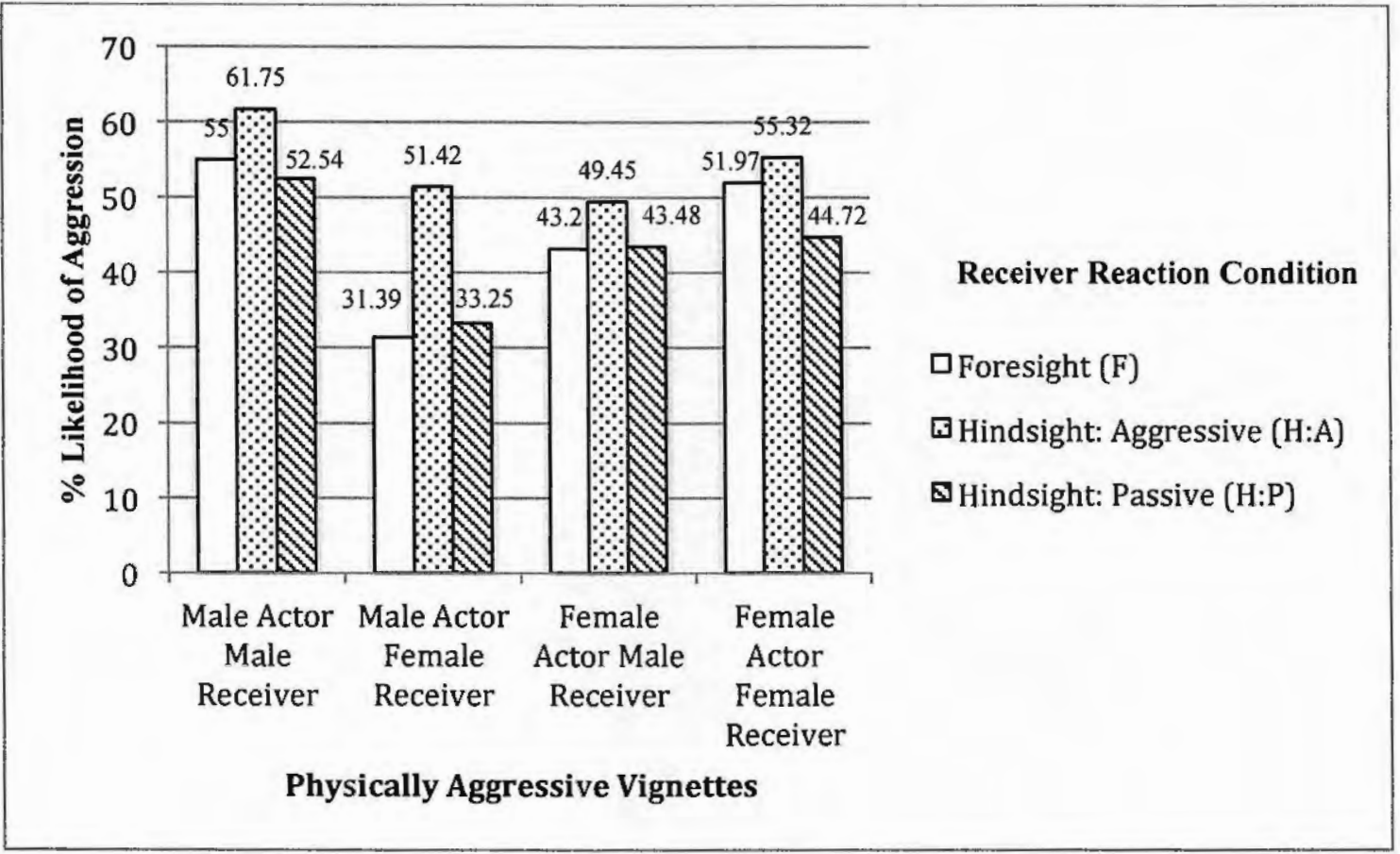

Figure 6. Percent Likelihood of Aggression for Physically Aggressive Vignettes

\section{Verbal Aggression}

For the vignettes depicting verbal aggression, when the gender of the actor was male and the gender of the receiver was female, and when the gender of the actor was female and the gender of the receiver was either male or female, there were significant differences between the Hindsight: A conditions and both the Foresight and Hindsight: $\mathrm{P}$ conditions (H:A > F; HA > H:P, ps <.05). There were no differences, however, between the Hindsight: P condition versus the Foresight condition for any of these vignettes (H:A $=F ; H: P=F)$. These results are illustrated in Figure 7. 


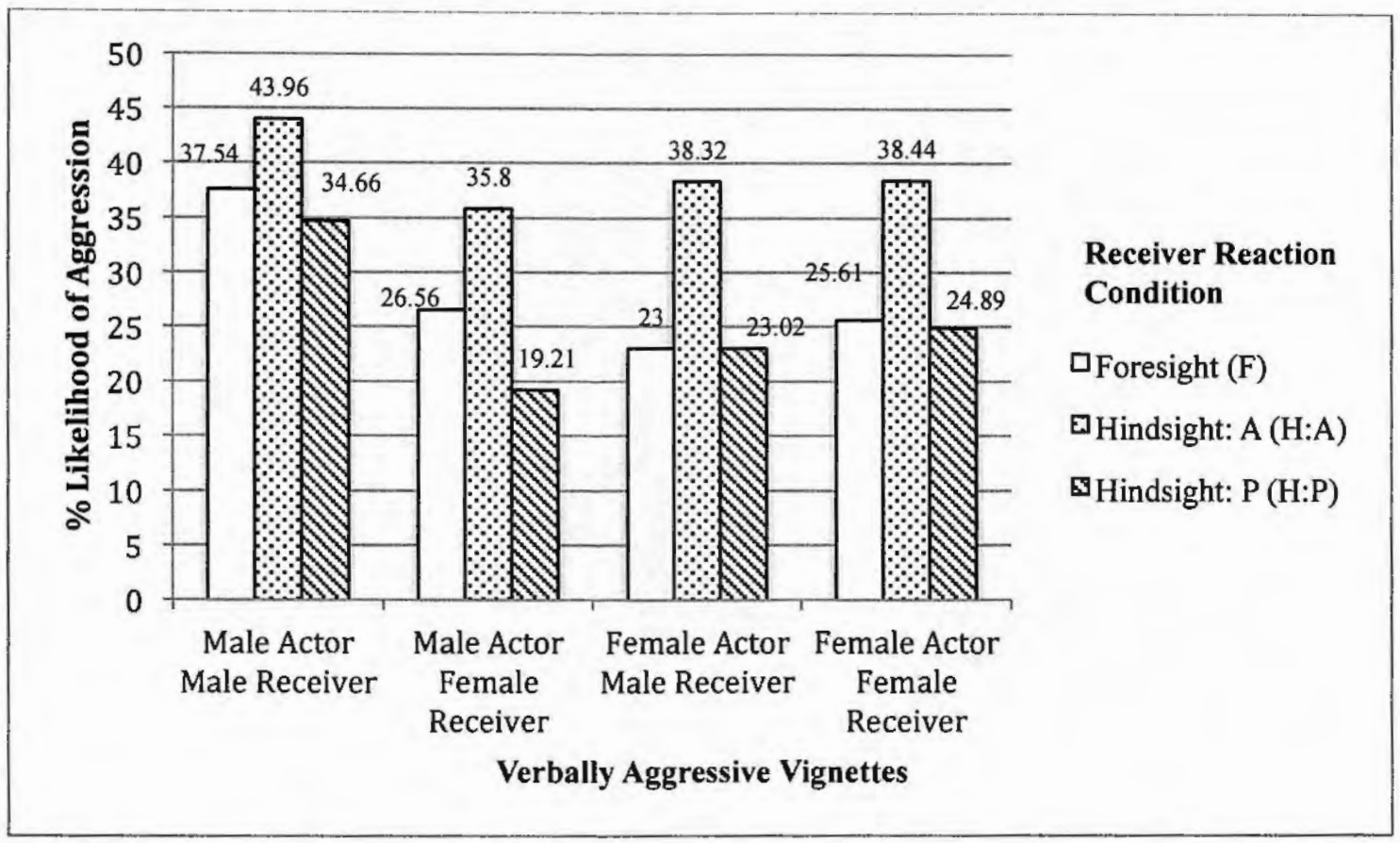

Figure 7. Percent Likelihood of Aggression for Verbally Aggressive Vignettes

\section{Relational Aggression}

For the vignettes depicting relational aggression, there were significant differences between all of the Hindsight: A versus Hindsight: $\mathrm{P}$ conditions $(\mathrm{H}: \mathrm{A}>\mathrm{H}: \mathrm{P}$, $p s<.05)$. There were no differences, however, between either of the hindsight conditions versus the Foresight conditions for any of these vignettes $(\mathrm{H}: \mathrm{A}=\mathrm{F} ; \mathrm{H}: \mathrm{P}=\mathrm{F})$. These results are illustrated in Figure 8. 


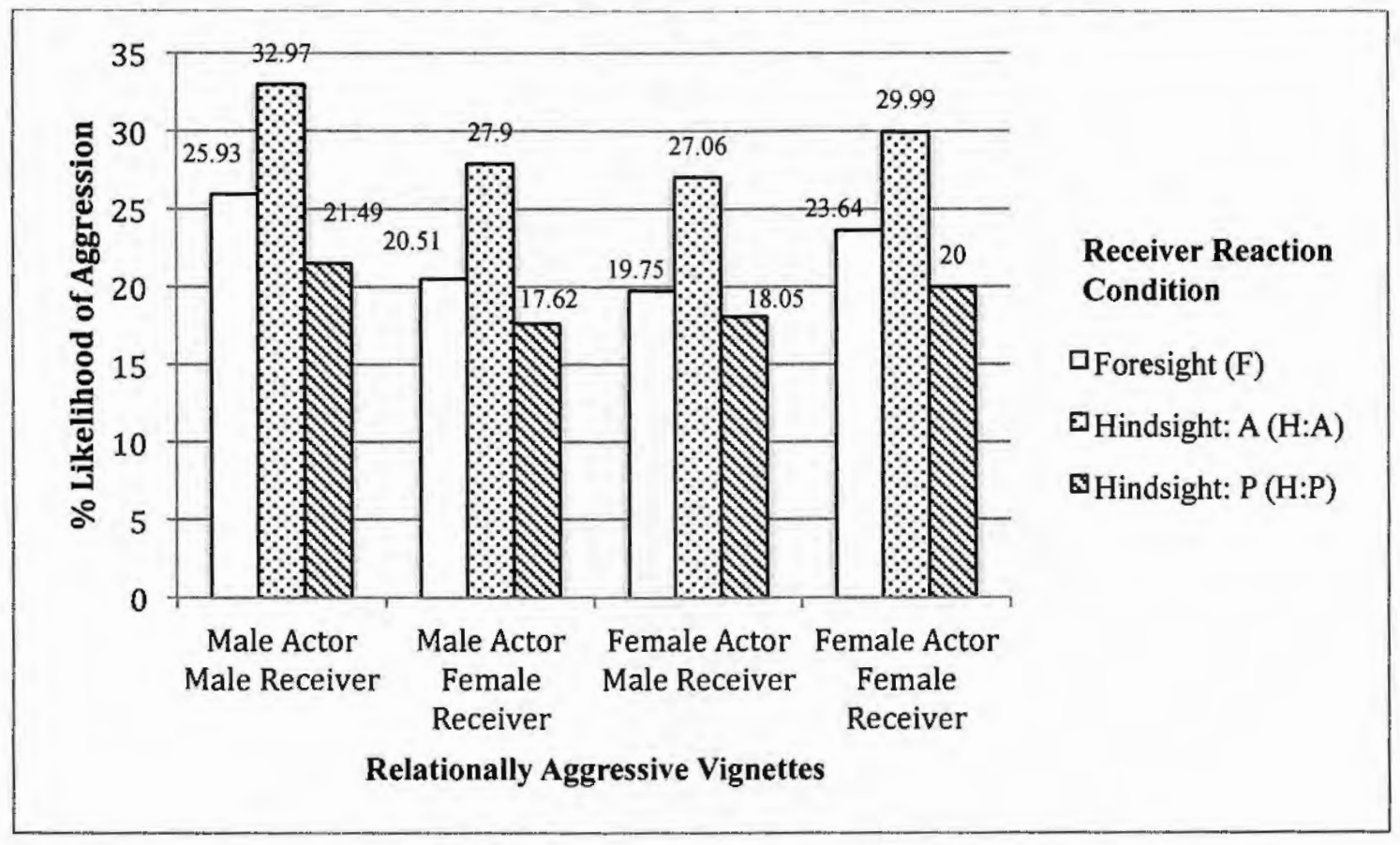

Figure 8. Percent Likelihood of Aggression for Relationally Aggressive Vignettes Non-aggression

Finally, there were no significant differences in ratings between any of the conditions for any of the non-aggressive vignettes $(\mathrm{H}: \mathrm{A}=\mathrm{H}: \mathrm{P}=\mathrm{F})$.

\section{Exploratory Qualitative Study}

The qualitative question asking if, and how, teachers would respond to each student depicted in the vignette was considered exploratory due to the lack of research data throughout the literature on this topic. The responses were coded for: intervene with actor (yes/no), intervene with receiver (yes/no), type of intervention with actor (categorical), type of intervention with receiver (categorical), and any additional interventions (categorical). After reading the responses, 18 intervention categories were delineated. Each of these variables was examined for differences based on the type of aggression depicted in the vignette and the gender of the actor or the gender of the receiver depicted in the vignette. 
The qualitative responses in the two hindsight conditions suggested that some teachers in those conditions considered the reaction of the receiver when responding to the open-ended questions. Due to the exploratory nature of the examination of the qualitative responses, and that the researcher could not know whether the teacher would have responded differently if they had, or had not, considered the reaction of the receiver, only qualitative responses from teachers in the Foresight condition $(N=61)$ were included in this examination of the data. Because the qualitative questions were optional, teachers could choose not to respond, or to enter one or multiple interventions. Frequencies for each of the 18 possible intervention categories for each question are presented in Table 14.

Table 14. Frequency of Responses for each Intervention Category

\begin{tabular}{lrrr}
\hline Intervention Categories & Actor & Receiver & Other \\
\hline No intervention & 54 & 64 & 46 \\
Administration for discussion/discipline & 142 & 40 & 95 \\
Counseling (advisor/counselor/psychologist) & 29 & 98 & 105 \\
Demand apology (or thank you) to other student & 23 & 28 & 12 \\
Disciplinary consequences & 99 & 6 & 20 \\
Incident report/referral & 70 & 16 & 33 \\
Increased supervision/monitoring & 15 & 23 & 70 \\
Mediate/peer resolution & 31 & 32 & 16 \\
No intervention & 54 & 64 & 46 \\
Parent involvement & 43 & 23 & 71 \\
Physical restraint/removal & 0 & 0 & 0 \\
Positive regard & 53 & 131 & 2 \\
Redirect to task & 4 & 9 & 0 \\
Separate students & 31 & 67 & 12 \\
Suggest avoidance & 0 & 27 & 1 \\
Suggest future help-seeking & 7 & 84 & 3 \\
Talk to student & 268 & 395 & 45 \\
Verbally reprimand/chastise student & 323 & 87 & 14 \\
\hline
\end{tabular}

As can be seen in Table 14., the most frequent intervention response for the actor was to verbally reprimand or to chastise the student. The most frequent intervention 
response for the receiver was to talk to the student, which was also the second most frequent intervention response for the actor. For the question regarding what other interventions teachers would use, the most frequent response was to suggest counseling by an advisor or school psychologist. No teachers reported that they would physically remove or restrain either the actor or the receiver across any of the scenarios. There were large differences (at least double the frequency) between responses regarding the actor and responses regarding the receiver in the frequencies that teachers reported they would separate the students $($ actor $=31$, receiver $=67)$, send them to administration $($ actor $=$ 142 , receiver $=40$ ), verbally reprimand the student (actor $=323$, receiver $=87$, discipline with consequences (actor $=99$, receiver $=6$ ), suggest avoidance $($ actor $=0$, receiver $=27$, , suggest counseling (actor $=29$, receiver $=98$ ), suggest future help-seeking $($ actor $=7$, receiver $=84)$, give positive regard $($ actor $=53$, receiver $=131)$, and document the incident with a referral $($ actor $=70$, receiver $=16)$.

To simplify the data when examining intervention offered by type of aggression depicted, gender of the actor, and gender of the receiver, the 18 intervention categories were further combined into four more general intervention categories: (a) No intervention, (b) Teach appropriate behavior, (c) Direct intervention, (d) Refer to other. Responses were included in the No intervention category if the teacher explicitly responded that they would not intervene (blank or missing responses were not included). The Teach appropriate behavior category included responses of talking to the student, mediating, discussing with the whole class, suggesting future help-seeking, and giving positive regard. Individual categories included in Direct intervention were separating the students, verbally reprimanding or chastising, physical removal, disciplining with 
consequences, suggesting avoidance, increasing supervision or monitoring, demanding an apology (or thank-you in the case of the non-aggressive scenarios), and redirecting to task. Finally, the Refer to other category included sending to administration, involving parents, sending to a counselor, and writing an incident report or referral. The frequency of responses to each of the four intervention categories were examined separately for each of the three questions (interventions for actor, interventions for receiver, and other interventions) by type of aggression, gender of the actor, and gender of the receiver. These data are presented in Tables 15-17.

Table 15. Sum of Intervention Categories for Actor

\begin{tabular}{|c|c|c|c|c|c|c|}
\hline $\begin{array}{l}\text { Kind of } \\
\text { Aggression }\end{array}$ & $\begin{array}{l}\text { Gender } \\
\text { of Actor }\end{array}$ & $\begin{array}{c}\text { Gender } \\
\text { of } \\
\text { Receiver }\end{array}$ & $\begin{array}{c}\text { No } \\
\text { Intervention }\end{array}$ & $\begin{array}{c}\text { Teach } \\
\text { Appropriate } \\
\text { Behavior }\end{array}$ & $\begin{array}{c}\text { Direct } \\
\text { Intervention }\end{array}$ & $\begin{array}{l}\text { Refer } \\
\text { to } \\
\text { Other }\end{array}$ \\
\hline \multirow{4}{*}{ Physical } & \multirow{2}{*}{ Male } & Male & 0 & 18 & 22 & 45 \\
\hline & & Female & 0 & 15 & 27 & 47 \\
\hline & \multirow{2}{*}{ Female } & Male & 0 & 20 & 27 & 39 \\
\hline & & Female & 0 & 19 & 28 & 46 \\
\hline \multirow{4}{*}{ Verbal } & \multirow{2}{*}{ Male } & Male & 0 & 22 & 50 & 20 \\
\hline & & Female & 0 & 10 & 53 & 16 \\
\hline & \multirow{2}{*}{ Female } & Male & 0 & 14 & 48 & 19 \\
\hline & & Female & 0 & 13 & 49 & 16 \\
\hline \multirow{4}{*}{ Relational } & \multirow{2}{*}{ Male } & Male & 2 & 22 & 42 & 6 \\
\hline & & Female & 1 & 23 & 44 & 8 \\
\hline & \multirow{2}{*}{ Female } & Male & 1 & 22 & 45 & 10 \\
\hline & & Female & 1 & 23 & 44 & 10 \\
\hline \multirow{4}{*}{$\begin{array}{l}\text { Non- } \\
\text { Aggressive }\end{array}$} & \multirow{2}{*}{ Male } & Male & 11 & 34 & 6 & 0 \\
\hline & & Female & 12 & 35 & 5 & 0 \\
\hline & \multirow{2}{*}{ Female } & Male & 13 & 40 & 3 & 1 \\
\hline & & Female & 13 & 33 & 2 & 1 \\
\hline
\end{tabular}

Table 16. Sum of Intervention Categories for Receiver

\begin{tabular}{ccccccc}
\hline $\begin{array}{c}\text { Kind of } \\
\text { Aggression }\end{array}$ & $\begin{array}{c}\text { Gender } \\
\text { of Actor }\end{array}$ & $\begin{array}{c}\text { Gender } \\
\text { of } \\
\text { Receiver }\end{array}$ & $\begin{array}{c}\text { No } \\
\text { Intervention }\end{array}$ & $\begin{array}{c}\text { Teach } \\
\text { Appropriate } \\
\text { Behavior }\end{array}$ & $\begin{array}{c}\text { Direct } \\
\text { Intervention }\end{array}$ & $\begin{array}{c}\text { Refer to } \\
\text { Other }\end{array}$ \\
\hline \multirow{2}{*}{ Physical } & Male & Male & 0 & 45 & 9 & 28 \\
\cline { 2 - 7 } & Female & 0 & 46 & 9 & 22 \\
\cline { 2 - 8 } & Female & Male & 2 & 41 & 6 & 23 \\
\hline
\end{tabular}




\begin{tabular}{|c|c|c|c|c|c|c|}
\hline & & Female & 0 & 47 & 8 & 30 \\
\hline \multirow{4}{*}{ Verbal } & \multirow{2}{*}{ Male } & Male & 3 & 56 & 14 & 14 \\
\hline & & Female & 3 & 51 & 11. & 13 \\
\hline & \multirow{2}{*}{ Female } & Male & 5 & 49 & 7 & 11 \\
\hline & & Female & 3 & $\overline{49}$ & 10 & 14 \\
\hline \multirow{4}{*}{ Relational } & \multirow{2}{*}{ Male } & Male & 3 & 46 & 13 & 4 \\
\hline & & Female & 0 & 49 & 21 & 5 \\
\hline & \multirow{2}{*}{ Female } & Male & 4 & 43 & 16 & 6 \\
\hline & & Female & 1 & 48 & 18 & 5 \\
\hline \multirow{4}{*}{$\begin{array}{l}\text { Non- } \\
\text { Aggressive }\end{array}$} & \multirow{2}{*}{ Male } & Male & 9 & 16 & 29 & 1 \\
\hline & & Female & 10 & 17 & 29 & 0 \\
\hline & \multirow{2}{*}{ Female } & Male & 11 & 27 & 18 & 1 \\
\hline & & Female & 10 & 16 & 29 & 0 \\
\hline
\end{tabular}

Table 17. Sum of Other Intervention Categories

\begin{tabular}{|c|c|c|c|c|c|c|}
\hline $\begin{array}{l}\text { Kind of } \\
\text { Aggression }\end{array}$ & $\begin{array}{l}\text { Gender } \\
\text { of Actor }\end{array}$ & $\begin{array}{c}\text { Gender } \\
\text { of } \\
\text { Receiver }\end{array}$ & $\begin{array}{c}\text { No } \\
\text { Intervention }\end{array}$ & $\begin{array}{c}\text { Teach } \\
\text { Appropriate } \\
\text { Behavior } \\
\end{array}$ & $\begin{array}{c}\text { Direct } \\
\text { Intervention }\end{array}$ & $\begin{array}{c}\text { Refer to } \\
\text { Other }\end{array}$ \\
\hline \multirow{4}{*}{ Physical } & \multirow{2}{*}{ Male } & Male & 1 & 3 & 11 & 24 \\
\hline & & Female & 1 & 3 & 7 & 34 \\
\hline & \multirow{2}{*}{ Female } & Male & 1 & 6 & 8 & 30 \\
\hline & & Female & 1 & 3 & 8 & 27 \\
\hline \multirow{4}{*}{ Verbal } & \multirow{2}{*}{ Male } & Male & 1 & 4 & 5 & 32 \\
\hline & & Female & 1 & 7 & 9 & 24 \\
\hline & \multirow{2}{*}{ Female } & Male & 1 & 6 & 8 & 25 \\
\hline & & Female & 3 & 9 & 10 & 30 \\
\hline \multirow{4}{*}{ Relational } & \multirow{2}{*}{ Male } & Male & 2 & 10 & 11 & 17 \\
\hline & & Female & 2 & 5 & 10 & 13 \\
\hline & \multirow{2}{*}{ Female } & Male & 3 & 8 & 7 & 18 \\
\hline & & Female & 3 & 5 & 11 & 15 \\
\hline \multirow{4}{*}{$\begin{array}{l}\text { Non- } \\
\text { Aggressive }\end{array}$} & \multirow{2}{*}{ Male } & Male & 5 & 4 & 7 & 5 \\
\hline & & Female & 6 & 7 & 8 & 3 \\
\hline & \multirow{2}{*}{ Female } & Male & 8 & 3 & 4 & 3 \\
\hline & & Female & 7 & 6 & 5 & 4 \\
\hline
\end{tabular}

Interventions for Actor

When responding to how they would intervene with the actor, there were no differences in frequency of each intervention type when the gender of the actor was male compared to when the gender of the actor was female across aggression type. There were, 
however, differences in interventions reported by type of aggression depicted. For physical scenarios, teachers most frequently responded that they would refer to others. For verbal and relational aggression scenarios, however, teachers most frequently responded they would use direct interventions. For non-aggressive scenarios, teachers most frequently reported that they would teach appropriate behavior. Teachers were more likely to report no intervention in response to non-aggressive scenarios compared to physical, verbal, or relational aggression scenarios.

Within each aggression type there was little difference in how the teachers reported they would respond to the actor based on gender of the actor or gender of the receiver. Within the physical aggression scenarios, however, they were slightly less likely to report they would refer to other when the gender of the actor was female and the receiver was male, compared to when the gender of the actor was female and the receiver was female, and when the gender of the actor was male and the receiver was either male or female. Within scenarios depicting verbal aggression, teachers were more likely to report they would teach appropriate behavior for scenarios with a male actor and male receiver, compared to those with a male actor and female receiver, and those with a female actor and either male or female receiver.

\section{Interventions for Receiver}

When responding to how they would intervene with the receiver, there were no differences in frequency of each intervention type when the gender of the receiver was male compared to when the gender of the receiver was female across aggression type. There were, however, differences in interventions reported by type of aggression depicted. For scenarios depicting physical, verbal, and relational aggression, teachers 
most frequently responded that they would teach appropriate behavior. For nonaggressive scenarios, teachers most frequently reported that they would use direct intervention. Teachers were more likely to report no intervention in response to nonaggression scenarios compared to physical, verbal, or relational aggression scenarios.

Within each aggression type there was little difference in how the teachers reported they would respond to the receiver based on gender of the actor or gender of the receiver. Within the physical aggression scenarios, however, they were slightly less likely to report they would refer to other in same-gender scenarios (male-male, female-female), compared to opposite-gender scenarios (male-female, female-male). Within scenarios depicting verbal aggression, teachers were half as likely to use direct interventions when the gender of the actor was female and gender of receiver was male, compared to when the gender of actor was male and gender of receiver was male. For scenarios depicting relational aggression, teachers were more likely to report no intervention when the gender of the receiver was male compared to when the gender of the receiver was female, independent of the gender of the actor. In response to the non-aggressive scenarios, when the gender of actor was female and the gender of receiver was male, teachers were more likely to report they would teach appropriate behavior and less likely to report they would use direct interventions compared to all other gender combinations.

\section{Other Interventions}

When responding to any additional interventions teachers would use, there were few differences in frequency of each intervention type by gender of the actor or gender of the receiver across aggression type. Teachers most frequently reported they would refer to other for physical, verbal, and relational aggression scenarios. They reported each 
intervention category with approximately equal frequency for non-aggressive scenarios. Within each aggression type there was little difference in how the teachers reported they would respond to the actor based on gender of the actor or gender of the receiver. 


\section{Chapter IV: Discussion}

Bullying is a pervasive problem throughout U.S. schools (Nansel et al., 2001). Research shows bullying can have detrimental effects on children's behavioral, emotional, psychosocial, and academic well-being (Nansel et al., 2001). This study examined teacher's perceptions of the severity of bullying scenarios based on type of bullying, gender of the bully and the victim, and the response of the victim. This research also examined the potential hindsight bias effects of knowing how a victim responded to a bullying scenario. Finally, an exploratory study was conducted to examine teachers' qualitative responses to how they would intervene in each of the bullying scenarios.

\section{Vignette Study}

The review of the literature on bullying presented in Chapter I revealed a paucity of research considering all kinds of contact (non-aggressive, physical, verbal, and relational), gender of the actor, and gender of the receiver. This study examined differences in how teachers perceived the bullying vignettes that were presented based on these variables.

Results showed that, given a scenario depicting physical bullying, teachers who did not know how the receiver responded perceived the vignette as more serious than teachers who were informed that the receiver reacted passively. This finding suggests that teachers may miss opportunities to intervene in physical bullying situations if the victim ignores the bullying. When the scenarios depicted verbal, relational, or non-aggression, however, teachers who were informed that the receiver reacted aggressively perceived vignettes as more serious compared to those teachers who either were informed that the receiver reacted passively or were not informed about the receiver's reaction. Similarly, 
regardless of the kind of bullying, teachers who were informed that the receiver reacted aggressively perceived the scenarios as more serious than those teachers who were informed the receiver reacted passively or were not informed about the receiver's reaction. This could suggest that teachers consider the aggressive reaction as a sign that the scenario is more serious than if the receiver reacted passively or when the teachers did not know how the receiver reacted. It could also suggest, however, that teachers are considering the aggressive reaction more so than the initial action, which potentially could lead to blaming of the victim.

Regardless of condition, gender of the actor, or gender of the receiver, teachers perceived vignettes depicting physical aggression as more serious than any other kind of social contact, verbal aggression as next serious, followed by relational aggression, and non-aggressive contact as least serious. A similar trend was found by Sherman (2009) using the measure that was adapted for the current research, in which results demonstrated a substantial difference between the non-aggressive and aggressive (i.e., verbal, relational, and physical) conditions. These findings attest to the construct validity of the scale. They also demonstrate potentially important differences in the seriousness teachers apply to different kinds of bullying situations. This suggests that, despite the detrimental consequences of both verbal and relational bullying, teachers perceive these situations as less serious than physical bullying, albeit still more serious than nonaggressive scenarios.

Finally, in examining how the gender of actor interacted with the gender of receiver across all kinds of contact and conditions, follow-up analyses revealed that, when the actor was male, there were no differences in the ratings of seriousness of the 
vignettes depicting male or female receivers. When the gender of the actor was female, however, the vignettes depicting female receivers were rated as more serious than those depicting male receivers. This demonstrates that when the actor was portrayed as male, teachers perceived situations in which the receiver was female as equally serious as situations in which the receiver was male. That is, for male actors, both same- and othergender interactions were perceived as equally serious. In contrast, when the actor was portrayed as female, teachers perceived other-gender interactions (i.e., female actormale receiver) as less serious than same-gender situations (i.e., female actor-female receiver). These findings are again consistent with those in prior research by Sherman (2009).

When considering gender of the receiver, teachers rated vignettes with male receivers and male actors as more serious than those with female actors. When the receiver was female, however, participants rated vignettes as equally serious regardless of the gender of the actor. These findings demonstrate that when the receiver was portrayed as male, teachers perceived same-gender social interactions (i.e., situations in which the actor is male) as more serious than other-gender-interactions (i.e., situations in which the actor is female). In contrast, for female receivers, both same- and other-gender interactions were perceived as equally serious. These differential perceptions potentially could lead to less reporting of or intervening in female bully - male victim interactions, despite literature that finds that relational bullying (which may occur more frequently among females than males) is as detrimental to males as it is to females (Hoglund, 2007; Prinstein, Boergers, \& Vernberg, 2001). Again, these findings replicate those in prior research by Sherman (2009). 


\section{Hindsight Bias Study}

Due to the detrimental consequences of bullying, it is important for teachers be able to assess the severity of different kinds of bullying situations accurately. Moreover, it is important to be able to consider potential outcomes or consequences of those situations because such perceptions are likely to affect responses. Unfortunately, discussing bullying situations with teachers after they occur and asking them to reflect on how they might have reacted or how serious they believed the situation might have been with knowledge of the outcome may result in what is known as hindsight bias. As discussed in the literature review in Chapter 1, an unfortunate outcome of hindsight bias is that because people overestimate the extent to which they would have predicted a given outcome, they have no need to learn from experience. It has been shown that teachers may respond differently to bullying scenarios based on the reaction of the victim (Yoon, 2004). For example, they may be more or less likely to consider the bullying to be serious or to intervene on the basis of their prediction of the response of the victim.

Results of this study demonstrated that for each vignette, when a significant difference was found between Hindsight: A, Hindsight: P, or Foresight conditions, teachers in the Hindsight: A condition always gave a higher prediction of the likelihood that the victim would respond aggressively. A hindsight bias effect, however, can only be determined if there is a significant difference between the group not receiving any additional outcome information (Foresight) and a group receiving additional outcome information but being asked to ignore it (Hindsight: A and Hindsight: P). Based on the results, a significant hindsight bias effect was seen in vignettes in which physical aggression was depicted and there was a male actor and a female receiver, and vignettes 
in which verbal aggression was depicted and there was a male actor and female receiver as well as when there was a female actor and either a male or female receiver. This is demonstrated by the significant difference between the prediction ratings of the teachers in the Hindsight: A condition and the Foresight condition. Since the Hindsight: P group never significantly differed from the Foresight group, there was not a hindsight bias affect for that group. This demonstrates that there was a stronger effect on inability to ignore information when being told the receiver reacted aggressively than when told the receiver reacted passively. The finding that a negative outcome is more prevalent in inducing a hindsight bias affect has been found in previous research as well (Guilbault, Bryant, Brockway, \& Posavac, 2004). Further, research has shown that given a negative victim response, people may tend to derogate the victim in reconstructing the event (Carli, 1999). Thus, the finding that teachers predicted that negative victim responses were more likely to occur in the Hindsight: A (vs. the Hindsight: P) group may indicate that in future situations teachers might be more likely to derogate or blame victims.

The results indicating a hindsight bias effect suggest that in those scenarios, teachers in the Hindsight: A condition were unable to ignore the information that the receiver reacted aggressively in their prediction of how the receiver would react. Teachers in the Hindsight: P group, however, were able to ignore information that the receiver reacted passively, and teachers in Foresight did not perceive aggressive responses as likely to occur as those in the Hindsight: A group. If a teacher witnesses a situation in which a male bully is physically aggressive toward a female victim, and the victim responds with physical aggression, the teacher may be more likely in later situations to assume that the female again will respond aggressively and therefore may 
intervene accordingly, regardless of how the victim in the later event actually responds. Again, this may lead to blaming the victim for the physically aggressive response, which may persist or generalize to other situations regardless of the victim's response.

\section{Exploratory Qualitative Study}

The qualitative question asking if, and how, teachers would respond to each student depicted in the vignette was considered exploratory due to the lack of research data throughout the literature on this topic. Based on the literature, as well as reviewing the qualitative comments themselves, 18 categories were delineated.

Examining the frequencies of these responses demonstrated that the most frequent intervention indicated by teachers in response to the actor was to verbally reprimand or to chastise the actor. The most frequent intervention response toward the receiver was to talk to the receiver, which was also the second most frequent intervention response for the actor. For the question regarding what other interventions teachers would use, the most frequent response was to suggest counseling by an advisor or a school psychologist. Further, when considering how they would respond to the actor, teachers reported with at least double the frequency compared to the receiver that they would refer them to administrative personnel, reprimand them verbally, give disciplinary consequences, or write an incident referral. When considering how they would respond to the receiver, teachers reported with at least double the frequency compared to the actors that they would separate the students, suggest avoidance, suggest counseling, suggest future helpseeking, give positive regard, and document the incident with a referral. It is clear from these preliminary data that teachers report using different intervention strategies with the actors versus the receivers. 
The data were then simplified to examine the frequencies of interventions by kind of aggression depicted, gender of the actor, and gender of the receiver. The 18 intervention categories were combined into four more general intervention categories: (a) no intervention, (b) teach appropriate behavior, (c) direct intervention, (d) refer to other.

When responding to how they would intervene with the actor, there were no major differences among the frequencies of each intervention category when the gender of the actor was male compared to when the gender of the actor was female across different kinds of aggression. This finding suggests that when teachers intervene with a bully, they indicate that they would use the same interventions for both males and females. There were, however, differences in interventions reported by different kinds of aggression. For physical aggression, teachers most frequently responded that they would refer to others. This is consistent with the previous finding that teachers rated physical scenarios the most serious, and therefore are more likely to request help from others, such as administrative personnel, when intervening. For verbal and relational aggression, teachers most frequently responded they would use direct interventions. This suggests that teachers are more likely to intervene themselves (e.g., talk to the student) in situations involving verbal or relational aggression, which they had rated less serious than physical aggression scenarios. For non-aggressive scenarios, teachers most frequently reported that they would teach appropriate behavior, and were more likely to report no intervention compared to physical, verbal, or relational aggression scenarios.

For the different kinds of aggression there were a few small differences in how the teachers reported they would respond to the bully based on gender of the bully or gender of the victim. For the physical-aggression scenarios, teachers seemed slightly less 
likely to report that they would refer to others when the gender of the bully was female and the victim was male, compared to when the gender of the bully was female and the victim also was female, and when the gender of the bully was male and the victim was either male or female. This finding is consistent with teachers' ratings of the severity of the scenarios, in which they rated the female bully-male victim scenarios the least serious compared to all other gender combinations. For the verbal-aggression scenarios, teachers seemed more likely to report that they would teach appropriate behavior in situation involving male bullies and male victims, compared to those with male bullies and female victims, and those with female bullies and either male or female victims.

When responding to how they would intervene with the victim, again teachers reported no differences in how they would respond to male versus female victims across the different kinds of aggression. There were differences in interventions reported by kind of aggression depicted. In responding to victims, for physical, verbal, and relational kinds of aggression, teachers most frequently responded that they would teach appropriate behavior, such as by mediating, by suggesting help-seeking, and by providing positive regard. For non-aggressive scenarios, teachers most frequently reported that they would use direct intervention, and often reported they would ask the receiver to thank the actor for loaning the pencil. Teachers were also more likely to report no intervention in response to non-aggressive scenarios compared to aggression scenarios.

Again, for the different kinds of aggression, there appeared to be a few small differences in how the teachers reported they would respond to the victim based on gender of the bully or gender of the victim. For the physical-aggression scenarios, teachers seemed slightly less likely to report that they would refer to others in same- 
gender scenarios (male-male, female-female), compared to different-gender scenarios (male-female, female-male). For example, for different-gender scenarios, teachers often speculated that the physical aggression might have been a result of a romantic relationship, which they indicated they would consider less serious than if the physical aggression was not thought to have a romantic or flirtatious underpinning. This finding is of particular interest in consideration of the possibility of hindsight bias. If teachers assume that physical aggression involving different-gender students is a result of a romantic relationship, they may miss opportunities to intervene with a bully as well as to protect a victim. For the verbal-aggression scenarios, teachers were only half as likely to use direct interventions when the gender of the bully was female and the gender of victim was male, compared to when the gender of bully was male and the gender of victim was male. This again supports the finding that teachers rated scenarios involving female bullies and male victims as less serious than those depicting male bullies and male victims. For the relational-aggression scenarios, teachers were more likely to report no intervention when the gender of the victim was male compared to when the gender of the victim was female, independent of the gender of the bully. This finding supports the theory by Crick (1997) that proposes that relational bullying is most hurtful to females because it damages their greatest peer value, as opposed to males who may be more hurt by physical bullying. This finding also suggests that teachers may be missing the opportunity to intervene in relational bullying toward males, despite the potential detrimental consequences that can result. In response to the non-aggressive scenarios, when the gender of actor was female and the gender of receiver was male, teachers were 
more likely to report they would teach appropriate behavior and less likely to report they would use direct interventions compared to all other gender combinations.

When responding to the item requesting information about any additional interventions, teachers most frequently reported that they would refer to others for physical, verbal, and relational aggression scenarios, regardless of gender of the bully or victim. They reported each intervention category with approximately equal frequency for non-aggressive scenarios.

\section{Implications}

The measure developed for this study could be used in a variety of ways. First, it could be used as a clinical tool to assess teachers' and preservice teachers' perceptions of different bullying situations. Second, it could be used within an educational institution to initiate class discussion on how teachers perceive different bullying situations, including kind of bullying and gender of the bully and victim, in an effort to raise awareness of possible biases. Third, it could be adapted and used in additional research to examine teachers' perceptions of bullying further.

This research illustrates how teachers perceive different kinds of bullying and victimization as well as how gender interacts with their perceptions. By examining how teachers perceive the different vignettes, this research extends the knowledge base about how teachers evaluate the severity of bullying, Thus, future research may consider these findings when assessing issues such as prevalence of bullying, teacher's reports of bullying, as well as their responses to individual bullying situations. By exploring how teacher's perceive different kinds of bullying situations and including perceptions based on gender of the bully and gender of the victim, as well as reaction of the victim, this 
research hopes to raise awareness of potential biases teachers may have in assessing different bullying situations. Considering the possible detrimental effects caused by bullying, it is hoped that by raising awareness and making it easier for teachers to recognize all bullying situations they will be better equipped to intervene and to prevent harmful consequences.

Results revealed that teachers rated the seriousness of the vignettes differently based on reaction of the receiver, kind of aggression depicted, as well as gender of the actor and gender of the receiver. Rating the physically aggressive scenarios when given no reaction by the receiver as more serious than when given a passive reaction by the receiver may indicate that teachers will be less likely to intervene when a student reacts passively. Therefore, teachers may inadvertently be less likely to protect passive victims from future bullying. By rating verbally and relationally aggression scenarios given an aggressive response of the receiver as more serious than no reaction or passive reaction of the receiver, there are two potential consequences each which may have negative implications for the receiver: teachers may blame the victim for responding aggressively, or they may interpret situations in which the victim reacts passively as less serious, and therefore be less likely to intervene. Teachers also rated vignettes depicting physical aggression as more serious than any other kind of social contact. This finding indicates that teachers may not take verbal or relational bullying as serious, despite the potential detrimental consequences of these forms of bullying. Finally, teachers rated female-male bullying as least serious regardless of kind of aggression. This may indicate that teachers are less likely to intervene in these situations, which may perpetuate the bullying as well as add to male victims of female bullies feeling of helplessness. Altogether, these 
differential perceptions of the seriousness of different bulling situations can increase the likelihood of blaming, or not supporting victims of bullying. This information could be used in schools to inform teachers of the seriousness of all types of bullying, and how to most effectively respond to both the bully and the victim.

For vignettes depicting physical aggression with a male actor and female receiver, and vignettes depicting verbal aggression with a male actor and female receiver or a female actor and female receiver, teachers were unable to ignore information about an aggressive response by the receiver in their predictions of how the receiver would respond. Implications of this hindsight bias effect may indicate that once a teacher has witnessed a victim responding aggressively they may be unable to ignore that information in future events, therefore potentially leading to derogating the victim or predicting an aggressive reaction will occur again and blaming the victim in future bullying occurrences. This may lead to teachers perceiving aggressive victims as bullies instead of as victims themselves, which could effect their intervention approaches and potentially leave the aggressive victims feeling helpless, unsupported, and without appropriate strategies to cope with future bullying events. Unfortunately talking to teachers about the hindsight bias is unlikely to change its effect. Teachers should be informed, however, of the differences in passive versus aggressive victims, and given intervention efforts that reduce the physically aggressive responses while supporting the aggressive victims, as well as given both types of victims more appropriate strategies to cope with bullying.

Teachers did indicate that they would respond differently to the actors than they would to the receivers in the scenarios. Frequencies of interventions revealed that teachers intervene to attempt to reduce the actor from engaging in bullying behavior by 
talking to the bully, and help the receiver feel supported and learn appropriate responses to bullying by offering support to the victim. Their responses to intervention efforts also differed based on kind of aggression. This finding is consistent with teachers' ratings of physical aggression as more serious than any other kind of aggression, when they reported being more likely to seek help from others (e.g., administrators) to intervene with the actor, compared to other kinds of aggression whereas teachers are more likely to intervene themselves. Differences in how teachers intervene in physical versus verbal or relational bullying may send the message to students that verbal and relational aggression are not as serious offenses, and may lead students to believe that they can continue to engage in these forms of bullying. Helping teachers to better understand the detrimental consequences of all kinds of bullying and differences in how they may perceive and respond to different instances in bullying may increase the likelihood of teachers considering all bullying as serious, as well as intervening consistently across all types of bullying.

\section{Limitations}

Although this study took several variables into consideration, there are several variables that were not considered due to response burden and the complexity of bullying situations in general. This study employed a series of vignettes, 48 in total, which were developed by the researcher after a thorough review of the bullying literature. Having either students, who are depicted as the actors in the vignettes, or teachers, who are witness to many kinds of aggressive and non-aggressive social contacts by students, review the vignettes and aid in their development could greatly enhance the authenticity of the vignettes. Also, only one behavior was used to symbolize each kind of contact. For 
example, the physical-aggression vignette depicted one student shoving another into a locker. Using only one example of each kind of aggressive or non-aggressive act is limiting in that we assume teachers would rate any of the possible examples of each kind of contact similarly to how they rated this one specific example. So, we are assuming, for example, that a teacher would rate one student shoving another student into a locker as severe as one student tripping another student or punching another student in the face. Measuring teachers' perceptions of multiple scenarios of each kind of aggression would make the results more generalizable to possible aggressive and non-aggressive situations.

When examining the data, the researcher noticed that the mean severity ratings for the non-aggressive vignettes were between 2.0 and 4.0 . This indicates that at least some participants found the situation of one student loaning another student a pencil, and having witnessed this more than once, as more concerning or problematic compared to a completely non-aggressive situation. It would have been beneficial to have several nonaggressive or even prosocial vignettes included to better understand what teachers considered non-aggressive, or prosocial, versus concerning.

The directions asked the participants to imagine that the vignettes occurred in a middle-class suburban middle school, which limits the generalizability of these results to other school levels and settings. Bullying that occurs in elementary versus middle versus high school may be perceived differently, by kind of contact and by gender. Also, each vignette may be perceived differently based on cultural factors, socioeconomic status of the school, and the frequency and severity of aggression typically seen within the particular school. It should be noted, however, that any bullying may be detrimental to the student, and therefore, whether the particular scenario is perceived as severe 
compared to other bullying at the school should not take precedence over the fact that all bullying is harmful. Teachers and other school personnel who perceive particular bullying scenarios as less serious because of the severity of other behaviors witnessed, such as weapon carrying, should be made aware of the possibly serious physical and psychosocial consequences of all kinds of bullying.

Finally, although the reliability of the measure developed for this study was evaluated in some detail in previous research (Sherman, 2009), issues of validity remain to be addressed. That the raters evaluated the seriousness of the non-aggressive versus the physical-, verbal-, and relational-aggression vignettes markedly differently is a promising indication of the construct validity of the measure. Further, several findings from the Sherman (2009) study which assessed preservice teachers were replicated here with current teachers, indicating the generalizability of the measure across these two populations. Future studies of validity remain to be conducted, however, in order to establish its value, particularly as it might apply to school settings.

\section{Future Directions}

The current study enhances the research in the area of bullying in several ways. The Vignette study revealed differences in how teachers perceive several kinds of bullying and whether they are perpetrated by a male versus a female and whether they are received by a male versus a female. The Hindsight bias study revealed the effects of how teachers perceive bullying situations based on knowledge of how a victim responded. Finally, an exploratory examination of qualitative data revealed differences in how teachers intervene with the bully or the victim in several kinds of bullying situations and whether the perpetrated and receiver were male or female. 
Additional analyses could be conducted to examine the results by gender of the reader, in order to assess whether male or female raters perceived the various bullying vignettes as relatively more or less serious. Further, the qualitative data could be recreated to include instructions to consider specific reactions of the victim, in order to examine potential differences among interventions recommended based on victim responses.

Future research could adapt the current study to include multiple scenarios depicting each kind of contact (non-aggressive, physical, verbal, and relational) as well as including prosocial acts. Future studies could also attempt to generalize the vignettes, and therefore the results, to different levels of school (i.e., elementary, middle, and high school) and different demographic settings (i.e., urban, suburban, and rural).

There is growing literature on bullying that describes different subtypes of victims; aggressive and nonaggressive victim profiles (Brockenbrough, Cornell, \& Loper, 2002; Olweus, 1993; Pellegrini, Bartini, \& Brooks, 1999; Toblin et al., 2005; Unnever, 2005). These subtypes have been seen in research that includes the victim's reactions to bullying, for example, where victims react to bullying in an aggressive versus passive manner, or where students both bully others and are themselves bullied as aggressive victims. Future research including victims' reactions to different bullying scenarios, in which the reaction of the victim is explicitly stated, could be conducted in order to assess whether or not teachers perceive bullying of aggressive versus non-aggressive victims as more or less severe, and if there are differences in the likelihood of intervening or interventions chosen given the reaction of the victin. Some literature suggests teachers may intervene less and be less concerned about bullying when the victim responds in an 
aggressive manner (Unnever, 2005), and this hypothesis could be tested through research that includes victim response as a separate variable.

The findings of this study could be used in a variety of ways in teaching and practice as well. In schools, the measure used here could be used as a clinical tool to assess teachers and preservice teachers' perceptions of different bullying situations in a particular school. This information could be used to attempt to counteract any biases, as well as educate teachers on the most appropriate interventions when bullying does occur at their school. Further, a uniform intervention strategy to be used when bullying does occur could be developed based on what the teachers report currently doing, as well as the practicality of responses for the school. These findings could also be used within an educational institution to initiate class discussion on how preservice teachers perceive different bullying situations, including kind of bullying, gender of the bully and victim, and victim reaction in an effort to raise awareness of possible biases.

\section{Summary and Conclusions}

This study furthered the current research on bullying to include data on teacher's perceptions of different bullying situations examining kind of aggression, gender of the bully, gender of the victim, and the reaction of the victim. Further, the effects of hindsight bias on teacher's predictions of the reaction of the victim were explored. Understanding how bullying affects youth, and particularly how different kinds of bullying (physical, verbal, or relational) affect boys versus girls is important for teachers to recognize bullying as well as considering when and how to intervene.

This study demonstrated that teachers perceive bullying scenarios differently based on the kind of aggression used, gender of the bully, gender of the victim, and the 
victim's response to the aggression. Hindsight bias effects were demonstrated in teachers' predictions of the victim's response. Finally, it was demonstrated that the kinds of interventions described by teachers in response to the scenarios differed based on whether they were intervening with the bully or victim and kind of aggression depicted.

Despite the detrimental consequences of both verbal and relational bullying, teachers perceived these situations as less serious than physical bullying, albeit still more serious than non-aggressive scenarios. In this way, teachers may be diminishing the effects of verbal and relational bullying, as well as missing potential opportunities to intervene in these situations. Moreover, teachers may miss opportunities to intervene in physical bullying situations if the victim ignores the bullying. When victims react aggressively, teachers may consider the aggressive reaction as a sign that the scenario is more serious. Teachers also may be giving more importance to the aggressive reaction than the initial bullying, which potentially could lead to blaming of the victim.

Finally, for male actors, both same- and other-gender interactions were perceived as equally serious. In contrast, however, when the actor was portrayed as female, teachers perceived other-gender interactions (i.e., female actor-male receiver) as less serious than same-gender situations (i,e., female actor-female receiver). These differential perceptions potentially could lead to less reporting of or intervening in female bullymale victim interactions, despite literature that finds that relational bullying (which may occur more frequently among females than males) is as detrimental to males as it is to females (Hoglund, 2007; Prinstein, Boergers, \& Vernberg, 2001).

Due to the detrimental consequences of bullying, it is important to be able to consider potential outcomes or consequences of bullying situations because such 
perceptions are likely to affect responses. Unfortunately, discussing bullying situations with teachers after they occur and asking them to reflect on how they might have reacted or how serious they believed the situation might have been without knowledge of the outcome may result in what is known as hindsight bias. This bias was demonstrated in the present study by the significant difference between the prediction ratings of the teachers in the Hindsight: A condition and the Foresight condition. There was a stronger effect on inability to ignore information when being told the receiver reacted aggressively than when told the receiver reacted passively. The finding that a negative outcome is more prevalent in inducing a hindsight bias affect has been found in previous research as well (Guilbault et al., 2004). Further, research has shown that given a negative victim response, people may tend to derogate the victim in reconstructing the event (Carli, 1999). Thus, the finding that teachers predicted that negative victim responses were more likely to occur in the Hindsight: A (vs. the Hindsight: P) group may indicate that in future situations teachers might be more likely to derogate or blame victims.

When responding to how they would intervene with the actor, there were no major differences among the frequencies of kinds of interventions when the gender of the actor was male compared to when the gender of the actor was female across different kinds of aggression. There were, however, differences in interventions reported by different kinds of aggression. For physical aggression, teachers most frequently responded that they would refer to others. For verbal and relational aggression, teachers most frequently responded they would use direct interventions (e.g., talk to the student). For non-aggressive scenarios, teachers most frequently reported that they would teach 
appropriate behavior, and were more likely to report no intervention compared to physical, verbal, or relational aggression scenarios.

When responding to how they would intervene with the victim, again teachers reported no differences in how they would respond to male versus female victims across the different kinds of aggression. For physical, verbal, and relational kinds of aggression, however, teachers most frequently responded that they would teach appropriate behavior, such as by mediating, by suggesting help-seeking, and by providing positive regard. For non-aggressive scenarios, teachers most frequently reported that they would use direct intervention, and often reported they would ask the receiver to thank the actor for loaning the pencil. Teachers were also more likely to report no intervention in response to nonaggressive scenarios compared to aggression scenarios.

When responding to the item requesting information about any additional interventions, teachers most frequently reported that they would refer to others for physical, verbal, and relational aggression scenarios, regardless of gender of the bully or victim. They reported each intervention category with approximately equal frequency for non-aggressive scenarios.

Finally, future research should seek to extend these findings to explore how best to counteract the potential biases found, as well as to assess the most effective intervention strategies for both the bully and the victim given each scenario. These results may be used to educate teachers about the detrimental effects of different kinds of bullying on both boys and girls to help them better prevent and intervene on bullying with youth. The measure employed here can potentially be used in future research as well as in schools to optimize the effectiveness and efficiency of the assessment of bullying 
and intervention responses in consideration of time, budget, and resource constraints in school systems. 
Appendix A: Directions, Demographic Questionnaire, Vignettes, and Items

Please answer all of the demographic questions on this screen.

What is your gender?

- Male

- Female

Are you Hispanic/Latino?

- Yes

- No

What is your race?

- White

- Black/African American

- American Indian/Alaskan Native

- Asian

- Native Hawaiian/Other Pacific Islander

- Two or more of the above

- Other

What is your age?

What is your highest level of education?

- High school

- Some college

- College

- Master's degree

- Other graduate degree

How many years have you been teaching?

What school level do you currently teach?

- Elementary school

- Middle school

- High school

What grade level do you currently teach?

What school levels have you taught previously? (check all that apply)

- Elementary school

- Middle school

- High school

In what U.S. State do you currently teach? 
I am going to ask you to read several brief descriptions of situations occurring in a suburban middle school. Please read each one carefully and then answer the questions that follow. First, you will be asked to provide probabilities of the two possible outcomes of the situation. Please make sure these ratings sum to $100 \%$. We recognize you may have less information than you usually would prefer, but please do your best with the information that has been provided. Give the best response for you for each question, even if it is hard to make up your mind. You are free to stop participation at any time. 
Please read the following scenario carefully. Then, answer each of the questions. While the class is working quietly at their desks, Matthew whispers to Christopher "You're such a loser!" You've heard Matthew saying things like this to Christopher before.

Assuming the situation resulted in one of the two outcomes listed below, how likely is it that you would have predicted each outcome? (Probabilities must add to equal $100 \%$ ).

Christopher would react by shoving Matthew hard

Christopher would react by ignoring Matthew $\%$

1. How serious is this situation?

\begin{tabular}{c|c|c|c|c}
1 & 2 & 3 & 4 & 5 \\
Not at all & A little & Moderately & Very & Extremely
\end{tabular}

2. How safe is this situation?

\begin{tabular}{c|c|c|c|c}
1 & 2 & 3 & 4 & 5 \\
Not at all & A little & Moderately & Very & Extremely
\end{tabular}

3. How concerned are you about this situation?

\begin{tabular}{c|c|c|c|c}
1 & 2 & 3 & 4 & 5 \\
Not at all & A little & Moderately & Very & Extremely
\end{tabular}

4. How likely are you to disregard this situation?

\begin{tabular}{c|c|c|c|c}
1 & 2 & 3 & 4 & 5 \\
Not at all & A little & Moderately & Very & Extremely
\end{tabular}

5. How harmful is this situation?

\begin{tabular}{c|c|c|c|c}
1 & 2 & 3 & 4 & 5 \\
Not at all & A little & Moderately & Very & Extremely
\end{tabular}

6. How likely are you to intervene in this situation?

\begin{tabular}{c|c|c|c|c}
1 & 2 & 3 & 4 & 5 \\
Not at all & A little & Moderately & Very & Extremely
\end{tabular}

7. How likely are you to label this situation as bullying?

\begin{tabular}{c|c|c|c|c}
1 & 2 & 3 & 4 & 5 \\
Not at all & A little & Moderately & Very & Extremely
\end{tabular}

As a teacher, if you would respond to this situation...

How would you respond to Matthew?

How would you respond to Christopher?

Is there anything else you would do in this situation? 
Please read the following scenario carefully. Then, answer each of the questions.

While the class is working quietly at their desks Matthew whispers to Christopher "You're such a loser!" You've heard Matthew saying things like this to Christopher before. Christopher reacts by ignoring Matthew.

Imagine you did not know how Christopher had reacted to the situation. Assuming the situation resulted in one of the two outcomes listed below, how likely is it that you would have predicted each outcome? (Probabilities must add to equal 100\%).

Christopher would react by shoving Matthew hard $\%$

Christopher would react by ignoring Matthew

$\%$

1. How serious is this situation?

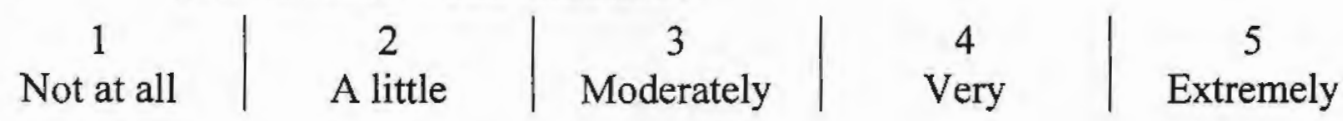

2. How safe is this situation?

\begin{tabular}{c|c|c|c|c}
1 & 2 & 3 & 4 & 5 \\
Not at all & A little & Moderately & Very & Extremely
\end{tabular}

3. How concerned are you about this situation?

\begin{tabular}{c|c|c|c|c}
1 & 2 & 3 & 4 & 5 \\
Not at all & A little & Moderately & Very & Extremely
\end{tabular}

4. How likely are you to disregard this situation?

\begin{tabular}{c|c|c|c|c}
1 & 2 & 3 & 4 & 5 \\
Not at all & A little & Moderately & Very & Extremely
\end{tabular}

5. How harmful is this situation?

\begin{tabular}{c|c|c|c|c}
1 & 2 & 3 & 4 & 5 \\
Not at all & A little & Moderately & Very & Extremely
\end{tabular}

6. How likely are you to intervene in this situation?
Not at all
\begin{tabular}{c|c}
2 & 3 \\
A little & Moderately
\end{tabular}
\begin{tabular}{c|}
4 \\
Very
\end{tabular}
5
Extremely

7. How likely are you to label this situation as bullying?

\begin{tabular}{c|c|c|c|c}
1 & 2 & 3 & 4 & 5 \\
Not at all & A little & Moderately & Very & Extremely
\end{tabular}

As a teacher, if you would respond to this situation...

How would you respond to Matthew?

How would you respond to Christopher?

Is there anything else you would do in this situation? 
Please read the following scenario carefully. Then, answer each of the questions.

While the class is working quietly at their desks Matthew whispers to Christopher "You're such a loser!" You've heard Matthew saying things like this to Christopher before. Christopher reacts by shoving Matthew hard.

Imagine you did not know how Christopher had reacted to the situation. Assuming the situation resulted in one of the two outcomes listed below, how likely is it that you would have predicted each outcome? (Probabilities must add to equal 100\%).

Christopher would react by shoving Matthew hard Christopher would react by ignoring Matthew $\%$

1. How serious is this situation?

\begin{tabular}{c|c|c|c|c}
1 & 2 & 3 & 4 & 5 \\
Not at all & A little & Moderately & Very & Extremely
\end{tabular}

2. How safe is this situation?
Not at all
\begin{tabular}{c|c}
2 & 3 \\
A little & Moderately
\end{tabular}
\begin{tabular}{c|c|c|c|}
4 \\
Very
\end{tabular}
$\stackrel{5}{\text { Extremely }}$

3. How concerned are you about this situation?
Not at all
A little
3
Moderately
4
Very
5
Extremely

4. How likely are you to disregard this situation?
1
Not at all
2
A little
3
Moderately
4
Very
Extremely

5. How harmful is this situation?
1
Not at all
A little
3
Moderately
4
Very
5
Extremely

6. How likely are you to intervene in this situation?
1
Not at all
$\stackrel{2}{\text { A little }}$
3
Moderately
4
Very
5
Extremely

7. How likely are you to label this situation as bullying?
1
Not at all
$\stackrel{2}{\text { A little }}$
3
Moderately
4
Very

As a teacher, if you would respond to this situation...

How would you respond to Matthew?

How would you respond to Christopher?

Is there anything else you would do in this situation? 
Please read the following scenario carefully. Then, answer each of the questions.

While the class is working quietly at their desks Joshua whispers to Ashley "You're such a loser?" You've heard Joshua saying things like this to Ashley before.

Assuming the situation resulted in one of the two outcomes listed below, how likely is it that you would have predicted each outcome? (Probabilities must add to equal $100 \%$ ).

Ashley would react by shoving Joshua hard

Ashley would react by ignoring Joshua $\%$

1. How serious is this situation?

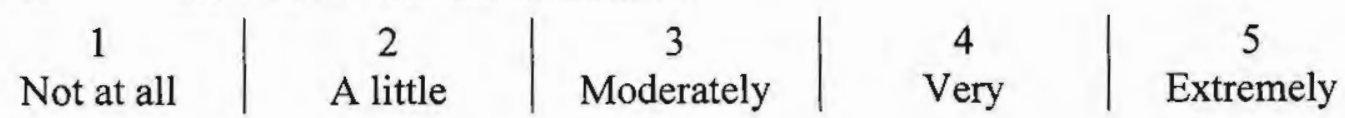

2. How safe is this situation?

\begin{tabular}{c|c|c|c|c}
1 & 2 & 3 & 4 & 5 \\
Not at all & A little & Moderately & Very & Extremely
\end{tabular}

3. How concerned are you about this situation?

\begin{tabular}{c|c|c|c|c}
1 & 2 & 3 & 4 & 5 \\
Not at all & A little & Moderately & Very & Extremely
\end{tabular}

4. How likely are you to disregard this situation?

\begin{tabular}{c|c|c|c|c}
1 & 2 & 3 & 4 & 5 \\
Not at all & A little & Moderately & Very & Extremely
\end{tabular}

5. How harmful is this situation?

\begin{tabular}{c|c|c|c|c}
1 & 2 & 3 & 4 & 5 \\
Not at all & A little & Moderately & Very & Extremely
\end{tabular}

6. How likely are you to intervene in this situation?

\begin{tabular}{c|c|c|c|c}
1 & 2 & 3 & 4 & 5 \\
Not at all & A little & Moderately & Very & Extremely
\end{tabular}

7. How likely are you to label this situation as bullying?

\begin{tabular}{c|c|c|c|c}
1 & 2 & 3 & 4 & 5 \\
Not at all & A little & Moderately & Very & Extremely
\end{tabular}

As a teacher, if you would respond to this situation...

How would you respond to Joshua?

How would you respond to Ashley?

Is there anything else you would do in this situation? 
Please read the following scenario carefully. Then, answer each of the questions. While the class is working quietly at their desks Joshua whispers to Ashley "You're such a loser!" You've heard Joshua saying things like this to Ashley before. Ashley reacts by ignoring Joshua.

Imagine you did not know how Ashley reacted to the situation. Assuming the situation resulted in one of the two outcomes listed below, how likely is it that you would have predicted each outcome? (Probabilities must add to equal 100\%).

Ashley would react by shoving Joshua hard

Ashley would react by ignoring Joshua

$\%$

1. How serious is this situation?

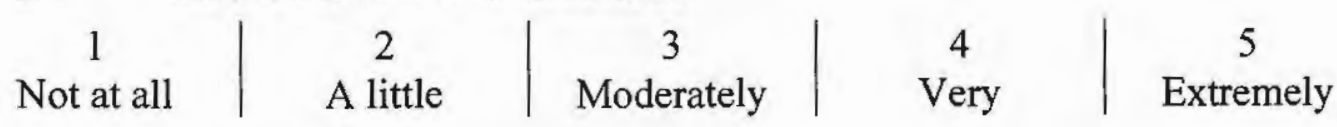

2. How safe is this situation?

\begin{tabular}{c|c|c|c|c}
1 & 2 & 3 & 4 & 5 \\
Not at all & A little & Moderately & Very & Extremely
\end{tabular}

3. How concerned are you about this situation?

\begin{tabular}{c|c|c|c|c}
1 & 2 & 3 & 4 & 5 \\
Not at all & A little & Moderately & Very & Extremely
\end{tabular}

4. How likely are you to disregard this situation?
1
Not at all
$\stackrel{2}{\text { A little }}$
3
Moderately
4
Very
5
Extremely

5. How harmful is this situation?
Not at all
\begin{tabular}{c|c}
2 & 3 \\
A little & Moderately
\end{tabular}
4
Very
5
Extremely

6. How likely are you to intervene in this situation?
\begin{tabular}{c|}
1 \\
Not at all
\end{tabular}
A little
3
Moderately
\begin{tabular}{c|}
4 \\
Very
\end{tabular}
5
Extremely

7. How likely are you to label this situation as bullying?
1
Not at all
A. little
3
Moderately
4
Very

As a teacher, if you would respond to this situation...

How would you respond to Joshua?

How would you respond to Ashley?

Is there anything else you would do in this situation? 
Please read the following scenario carefully. Then, answer each of the questions.

While the class is working quietly at their desks Joshua whispers to Ashley "You're such a loser!" You've heard Joshua saying things like this to Ashley before. Ashley reacts by shoving Joshua hard.

Imagine you did not know how Ashley reacted to the situation. Assuming the situation resulted in one of the two outcomes listed below, how likely is it that you would have predicted each outcome? (Probabilities must add to equal 100\%).

Ashley would react by shoving Joshua hard

Ashley would react by ignoring Joshua

$\%$

1. How serious is this situation?
Not at all
\begin{tabular}{c|c}
2 & 3 \\
A little & Moderately
\end{tabular} \mid
\begin{tabular}{c|c|c}
4 \\
Very
\end{tabular}
$\stackrel{5}{\text { Extremely }}$

2. How safe is this situation?

\begin{tabular}{c|c|c|c|c}
1 & 2 & 3 & 4 & 5 \\
Not at all & A little & Moderately & Very & Extremely
\end{tabular}

3. How concerned are you about this situation?

\begin{tabular}{c|c|c|c|c}
1 & 2 & 3 & 4 & 5 \\
Not at all & A little & Moderately & Very & Extremely
\end{tabular}

4. How likely are you to disregard this situation?
1
Not at all
\begin{tabular}{c|c|}
2 & 3 \\
A little & Moderately
\end{tabular}
4
Very
5
Extremely

5. How harmful is this situation?
1
Not at all
2
A little
3
Moderately
4
Very
5
Extremely

6. How likely are you to intervene in this situation?
1
Not at all
$\stackrel{2}{\text { A little }}$
$\left|\begin{array}{c}3 \\ \text { Moderately }\end{array}\right|$
4
Very
5
Extremely

7. How likely are you to label this situation as bullying?
1
Not at all
$\stackrel{2}{\text { A little }}$
$\left|\begin{array}{c}3 \\ \text { Moderately }\end{array}\right|$
4
Very
Extremely

As a teacher, if you would respond to this situation...

How would you respond to Joshua?

How would you respond to Ashley?

Is there anything else you would do in this situation? 
Please read the following scenario carefully. Then, answer each of the questions. While the class is working quietly at their desks Emily whispers to Samantha "You're such a loser!" You've heard Emily saying things like this to Samantha before.

Assuming the situation resulted in one of the two outcomes listed below, how likely is it that you would have predicted each outcome? (Probabilities must add to equal $100 \%$ ).

Samantha would react by shoving Emily hard

Samantha would react by ignoring Emily $\%$

1. How serious is this situation?
1
Not at all
\begin{tabular}{c|c}
2 & 3 \\
A little & Moderately
\end{tabular}
4
Very
5
Extremely

2. How safe is this situation?
1
Not at all
\begin{tabular}{c|c}
2 & 3 \\
A little & Moderately
\end{tabular}
4
Very
5
Extremely

3. How concerned are you about this situation?
1
Not at all
$\stackrel{2}{\text { A little }}$
3
Moderately
4
Very
5
Extremely

4. How likely are you to disregard this situation?
1
Not at all
\begin{tabular}{c|c}
2 & 3 \\
A little & Moderately
\end{tabular}
\begin{tabular}{c|}
4 \\
Very
\end{tabular}
Extremely

5. How harmful is this situation?
1
Not at all
\begin{tabular}{c|c}
2 & 3 \\
A little & Moderately
\end{tabular}
\begin{tabular}{c|}
4 \\
Very
\end{tabular}
5
Extremely

6. How likely are you to intervene in this situation?

\begin{tabular}{c|c|c|c|c}
1 & 2 & 3 & 4 & 5 \\
Not at all & A little & Moderately & Very & Extremely
\end{tabular}

7. How likely are you to label this situation as bullying?

\begin{tabular}{c|c|c|c|c}
1 & 2 & 3 & 4 & 5 \\
Not at all & A little & Moderately & Very & Extremely
\end{tabular}

As a teacher, if you would respond to this situation...

How would you respond to Emily?

How would you respond to Samantha?

Is there anything else you would do in this situation? 
Please read the following scenario carefully. Then, answer each of the questions. While the class is working quietly at their desks Emily whispers to Samantha "You're such a loser!" You've heard Emily saying things like this to Samantha before. Samantha reacts by ignoring Emily.

Imagine you did not know how Samantha reacted to the situation. Assuming the situation resulted in one of the two outcomes listed below, how likely is it that you would have predicted each outcome? (Probabilities must add to equal 100\%).

Samantha would react by shoving Emily hard

Samantha would react by ignoring Emily $\%$

1. How serious is this situation?

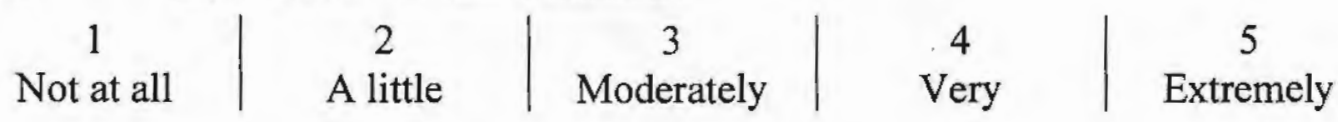

2. How safe is this situation?

\begin{tabular}{c|c|c|c|c}
1 & 2 & 3 & 4 & 5 \\
Not at all & A little & Moderately & Very & Extremely
\end{tabular}

3. How concerned are you about this situation?

\begin{tabular}{c|c|c|c|c}
1 & 2 & 3 & 4 & 5 \\
Not at all & A little & Moderately & Very & Extremely
\end{tabular}

4. How likely are you to disregard this situation?

\begin{tabular}{c|c|c|c|c}
1 & 2 & 3 & 4 & 5 \\
Not at all & A little & Moderately & Very & Extremely
\end{tabular}

5. How harmful is this situation?

\begin{tabular}{c|c|c|c|c}
1 & 2 & 3 & 4 & 5 \\
Not at all & A little & Moderately & Very & Extremely
\end{tabular}

6. How likely are you to intervene in this situation?

\begin{tabular}{c|c|c|c|c}
1 & 2 & 3 & 4 & 5 \\
Not at all & A little & Moderately & Very & Extremely
\end{tabular}

7. How likely are you to label this situation as bullying?

\begin{tabular}{c|c|c|c|c}
1 & 2 & 3 & 4 & 5 \\
Not at all & A little & Moderately & Very & Extremely
\end{tabular}

As a teacher, if you would respond to this situation...

How would you respond to Emily?

How would you respond to Samantha?

Is there anything else you would do in this situation? 
Please read the following scenario carefully. Then, answer each of the questions.

While the class is working quietly at their desks Emily whispers to Samantha "You're such a loser!" You've heard Emily saying things like this to Samantha before. Samantha reacts by shoving Emily hard.

Imagine you did not know how Samantha reacted to the situation. Assuming the situation resulted in one of the two outcomes listed below, how likely is it that you would have predicted each outcome? (Probabilities must add to equal 100\%).

Samantha would react by shoving Emily hard

Samantha would react by ignoring Emily $\%$

1. How serious is this situation?

\begin{tabular}{c|c|c|c|c}
1 & 2 & 3 & 4 & 5 \\
Not at all & A little & Moderately & Very & Extremely
\end{tabular}

2. How safe is this situation?

\begin{tabular}{c|c|c|c|c}
1 & 2 & 3 & 4 & 5 \\
Not at all & A little & Moderately & Very & Extremely
\end{tabular}

3. How concerned are you about this situation?
\begin{tabular}{c|}
1 \\
Not at all
\end{tabular}
A little
3
Moderately
4
Very
5
Extremely

4. How likely are you to disregard this situation?

\begin{tabular}{c|c|c|c|c}
1 & 2 & 3 & 4 & 5 \\
Not at all & A little & Moderately & Very & Extremely
\end{tabular}

5. How harmful is this situation?
1
Not at all
\begin{tabular}{c|c}
2 & 3 \\
A little & Moderately
\end{tabular}
\begin{tabular}{c|c|}
4 \\
Very
\end{tabular}
5
Extremely

6. How likely are you to intervene in this situation?
1
Not at all
$\stackrel{2}{\text { A little }}$
3
Moderately
4
Very
5
Extremely

7. How likely are you to label this situation as bullying?

\begin{tabular}{c|c|c|c|c}
1 & 2 & 3 & 4 & 5 \\
Not at all & A little & Moderately & Very & Extremely
\end{tabular}

As a teacher, if you would respond to this situation...

How would you respond to Emily?

How would you respond to Samantha?

Is there anything else you would do in this situation? 
Please read the following scenario carefully. Then, answer each of the questions.

While the class is working quietly at their desks Sarah whispers to Nicholas "You're such a loser!" You've heard Sarah saying things like this to Nicholas before.

Assuming the situation resulted in one of the two outcomes listed below, how likely is it that you would have predicted each outcome? (Probabilities must add to equal $100 \%$ ).

Nicholas would react by shoving Sarah hard

Nicholas would react by ignoring Sarah $\%$

1. How serious is this situation?
1
Not at all
\begin{tabular}{c|c}
2 & 3 \\
A little & Moderately
\end{tabular}
\begin{tabular}{c|c|c}
4 \\
Very
\end{tabular}
5
Extremely

2. How safe is this situation?

\begin{tabular}{c|c|c|c|c}
1 & 2 & 3 & 4 & 5 \\
Not at all & A little & Moderately & Very & Extremely
\end{tabular}

3. How concerned are you about this situation?

\begin{tabular}{c|c|c|c|c}
1 & 2 & 3 & 4 & 5 \\
Not at all & A little & Moderately & Very & Extremely
\end{tabular}

4. How likely are you to disregard this situation?

\begin{tabular}{c|c|c|c|c}
1 & 2 & 3 & 4 & 5 \\
Not at all & A little & Moderately & Very & Extremely
\end{tabular}

5. How harmful is this situation?
\begin{tabular}{c|}
1 \\
Not at all
\end{tabular}
\begin{tabular}{c|c}
2 & 3 \\
A little & Moderately
\end{tabular}
\begin{tabular}{c|c}
4 \\
Very
\end{tabular}
5
Extremely

6. How likely are you to intervene in this situation?
1
Not at all
\begin{tabular}{c|c}
2 & 3 \\
A little & Moderately
\end{tabular}
\begin{tabular}{c|}
4 \\
Very
\end{tabular}
5
Extremely

7. How likely are you to label this situation as bullying?
1
Not at all
2
A little

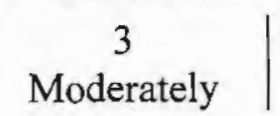
4
Very
Extremely

As a teacher, if you would respond to this situation...

How would you respond to Sarah?

How would you respond to Nicholas?

Is there anything else you would do in this situation? 
Please read the following scenario carefully. Then, answer each of the questions.

While the class is working quietly at their desks Sarah whispers to Nicholas "You're such a loser!" You've heard Sarah saying things like this to Nicholas before. Nicholas reacts by ignoring Sarah.

Imagine you did not know how Nicholas reacted to the situation. Assuming the situation resulted in one of the two outcomes listed below, how likely is it that you would have predicted each outcome? (Probabilities must add to equal 100\%).

Nicholas would react by shoving Sarah hard

Nicholas would react by ignoring Sarah $\%$

1. How serious is this situation?
Not at all
\begin{tabular}{c|c}
2 & 3 \\
A little & Moderately
\end{tabular}
\begin{tabular}{c|c|c}
4 \\
Very
\end{tabular}
$\stackrel{5}{\text { Extremely }}$

2. How safe is this situation?
Not at all
\begin{tabular}{c|c}
2 & 3 \\
A little & Moderately
\end{tabular}
\begin{tabular}{c|c|c}
4 \\
Very
\end{tabular}
$\stackrel{5}{\text { Extremely }}$

3. How concerned are you about this situation?

\begin{tabular}{c|c|c|c|c}
1 & 2 & 3 & 4 & 5 \\
Not at all & A little & Moderately & Very & Extremely
\end{tabular}

4. How likely are you to disregard this situation?

\begin{tabular}{c|c|c|c|c}
1 & 2 & 3 & 4 & 5 \\
Not at all & A little & Moderately & Very & Extremely
\end{tabular}

5. How harmful is this situation?
1
Not at all
\begin{tabular}{c|c}
2 & 3 \\
A little & Moderately
\end{tabular}
\begin{tabular}{c|c}
4 \\
Very
\end{tabular}
5
Extremely

6. How likely are you to intervene in this situation?
1
Not at all
A little
3
Moderately
\begin{tabular}{c|c|c|c|}
4 \\
Very
\end{tabular}
5
Extremely

7. How likely are you to label this situation as bullying?
1
Not at all
2
A little
3
Moderately
4
Very
Extremely

As a teacher, if you would respond to this situation...

How would you respond to Sarah?

How would you respond to Nicholas?

Is there anything else you would do in this situation? 
Please read the following scenario carefully. Then, answer each of the questions.

While the class is working quietly at their desks Sarah whispers to Nicholas "You're such a loser!" You've heard Sarah saying things like this to Nicholas before.

Nicholas reacts by shoving Sarah hard.

Imagine you did not know how Nicholas reacted to the situation. Assuming the situation resulted in one of the two outcomes listed below, how likely is it that you would have predicted each outcome? (Probabilities must add to equal 100\%).

Nicholas would react by shoving Sarah hard
Nicholas would react by ignoring Sarah

1. How serious is this situation?

\begin{tabular}{c|c|c|c|c}
1 & 2 & 3 & 4 & 5 \\
Not at all & A little & Moderately & Very & Extremely
\end{tabular}

2. How safe is this situation?

\begin{tabular}{c|c|c|c|c}
1 & 2 & 3 & 4 & 5 \\
Not at all & A little & Moderately & Very & Extremely
\end{tabular}

3. How concerned are you about this situation?

\begin{tabular}{c|c|c|c|c}
1 & 2 & 3 & 4 & 5 \\
Not at all & A little & Moderately & Very & Extremely
\end{tabular}

4. How likely are you to disregard this situation?

\begin{tabular}{c|c|c|c|c}
1 & 2 & 3 & 4 & 5 \\
Not at all & A little & Moderately & Very & Extremely
\end{tabular}

5. How harmful is this situation?
Not at all
\begin{tabular}{c|c}
2 & 3 \\
A little & Moderately
\end{tabular}
4
Very
5
Extremely

6. How likely are you to intervene in this situation?
1
Not at all
$\stackrel{2}{\text { A little }}$
3
Moderately
4
Very
5
Extremely

7. How likely are you to label this situation as bullying?
1
Not at all
2
A little
3
Moderately
4
Very
Extremely

As a teacher, if you would respond to this situation...

How would you respond to Sarah?

How would you respond to Nicholas?

Is there anything else you would do in this situation? 
Please read the following scenario carefully. Then, answer each of the questions.

The class is choosing teams to work on a group project. As Austin walks up to join Brandon's team, in front of everyone Brandon turns his back to close Austin out of the group, and begins delegating tasks to his group. You've seen Brandon doing things like this to Austin before.

Assuming the situation resulted in one of the two outcomes listed below, how likely is it that you would have predicted each outcome? (Probabilities must add to equal $100 \%$ ).

Austin would react by shoving Brandon hard

Austin would react by ignoring Brandon $\%$

1. How serious is this situation?

\begin{tabular}{c|c|c|c|c}
1 & 2 & 3 & 4 & 5 \\
Not at all & A little & Moderately & Very & Extremely
\end{tabular}

2. How safe is this situation?

\begin{tabular}{c|c|c|c|c}
1 & 2 & 3 & 4 & 5 \\
Not at all & A little & Moderately & Very & Extremely
\end{tabular}

3. How concerned are you about this situation?

\begin{tabular}{c|c|c|c|c}
1 & 2 & 3 & 4 & 5 \\
Not at all & A little & Moderately & Very & Extremely
\end{tabular}

4. How likely are you to disregard this situation?

\begin{tabular}{c|c|c|c|c}
1 & 2 & 3 & 4 & 5 \\
Not at all & A little & Moderately & Very & Extremely
\end{tabular}

5. How harmful is this situation?

\begin{tabular}{c|c|c|c|c}
1 & 2 & 3 & 4 & 5 \\
Not at all & A little & Moderately & Very & Extremely
\end{tabular}

6. How likely are you to intervene in this situation?

\begin{tabular}{c|c|c|c|c}
1 & 2 & 3 & 4 & 5 \\
Not at all & A little & Moderately & Very & Extremely
\end{tabular}

7. How likely are you to label this situation as bullying?

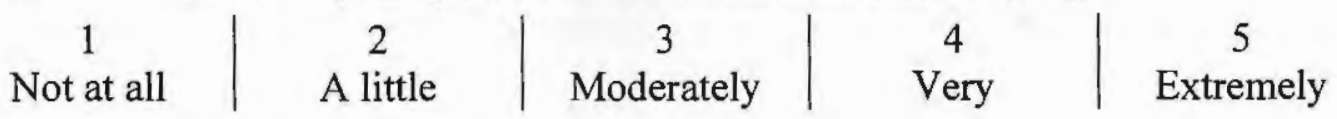

As a teacher, if you would respond to this situation...

How would you respond to Brandon?

How would you respond to Austin?

Is there anything else you would do in this situation? 
Please read the following scenario carefully. Then, answer each of the questions.

The class is choosing teams to work on a group project. As Austin walks up to join Brandon's team, in front of everyone Brandon turns his back to close Austin out of the group, and begins delegating tasks to his group. You've seen Brandon doing things like this to Austin before. Austin reacts by ignoring Brandon.

Imagine you did not know how Austin reacted to the situation. Assuming the situation resulted in one of the two outcomes listed below, how likely is it that you would have predicted each outcome? (Probabilities must add to equal 100\%).

Austin would react by shoving Brandon hard

Austin would react by ignoring Brandon

$\frac{}{\%} \%$

1. How serious is this situation?

\begin{tabular}{c|c|c|c|c}
1 & 2 & 3 & 4 & 5 \\
Not at all & A little & Moderately & Very & Extremely
\end{tabular}

2. How safe is this situation?

\begin{tabular}{c|c|c|c|c}
1 & 2 & 3 & 4 & 5 \\
Not at all & A little & Moderately & Very & Extremely
\end{tabular}

3. How concerned are you about this situation?

\begin{tabular}{c|c|c|c|c}
1 & 2 & 3 & 4 & 5 \\
Not at all & A little & Moderately & Very & Extremely
\end{tabular}

4. How likely are you to disregard this situation?

\begin{tabular}{c|c|c|c|c}
1 & 2 & 3 & 4 & 5 \\
Not at all & A little & Moderately & Very & Extremely
\end{tabular}

5. How harmful is this situation?

\begin{tabular}{c|c|c|c|c}
1 & 2 & 3 & 4 & 5 \\
Not at all & A little & Moderately & Very & Extremely
\end{tabular}

6. How likely are you to intervene in this situation?

\begin{tabular}{c|c|c|c|c}
1 & 2 & 3 & 4 & 5 \\
Not at all & A little & Moderately & Very & Extremely
\end{tabular}

7. How likely are you to label this situation as bullying?

\begin{tabular}{c|c|c|c|c}
1 & 2 & 3 & 4 & 5 \\
Not at all & A little & Moderately & Very & Extremely
\end{tabular}

As a teacher, if you would respond to this situation...

How would you respond to Brandon?

How would you respond to Austin?

Is there anything else you would do in tbis situation? 
Please read the following scenario carefully. Then, answer each of the questions.

The class is choosing teams to work on a group project. As Austin walks up to join Brandon's team, in front of everyone Brandon turns his back to close Austin out of the group, and begins delegating tasks to his group. You've seen Brandon doing things like this to Austin before. Austin reacts by shoving Brandon hard.

Imagine you did not know how Austin reacted to the situation. Assuming the situation resulted in one of the two outcomes listed below, how likely is it that you would have predicted each outcome? (Probabilities must add to equal 100\%).

Austin would react by shoving Brandon hard

Austin would react by ignoring Brandon $\%$

1. How serious is this situation?
Not at all
\begin{tabular}{c|c}
2 & 3 \\
A little & Moderately
\end{tabular}
\begin{tabular}{c|c}
4 & 5 \\
Very & Extremely
\end{tabular}

2. How safe is this situation?

\begin{tabular}{c|c|c|c|c}
1 & 2 & 3 & 4 & 5 \\
Not at all & A little & Moderately & Very & Extremely
\end{tabular}

3. How concerned are you about this situation?

\begin{tabular}{c|c|c|c|c}
1 & 2 & 3 & 4 & 5 \\
Not at all & A little & Moderately & Very & Extremely
\end{tabular}

4. How likely are you to disregard this situation?

\begin{tabular}{c|c|c|c|c}
1 & 2 & 3 & 4 & 5 \\
Not at all & A little & Moderately & Very & Extremely
\end{tabular}

5. How harmful is this situation?
1
Not at all
\begin{tabular}{c|c}
2 & 3 \\
A little & Moderately
\end{tabular}
\begin{tabular}{c|c}
4 \\
Very
\end{tabular}
5
Extremely

6. How likely are you to intervene in this situation?
1
Not at all
2
A little
3
Moderately
\begin{tabular}{c|}
4 \\
very
\end{tabular}
5
Extremely

7. How likely are you to label this situation as bullying?
1
Not at all
2
A little

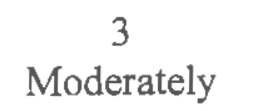
4
Very
Extremely

As a teacher, if you would respond to this situation...

How would you respond to Brandon?

How would you respond to Austin?

Is there anything else you would do in this situation? 
Please read the following scenario carefully. Then, answer each of the questions.

The class is choosing teams to work on a group project. As Hannah walks up to join Andrew's team, in front of everyone Andrew turns his back to close Hannah out of the group, and begins delegating tasks to his group. You've seen Andrew doing things like this to Hannah before.

Assuming the situation resulted in one of the two outcomes listed below, how likely is it that you would have predicted each outcome? (Probabilities must add to equal $100 \%$ ).

Hannah would react by shoving Andrew hard

Hannah would react by ignoring Andrew $\%$

1. How serious is this situation?

\begin{tabular}{c|c|c|c|c}
1 & 2 & 3 & 4 & 5 \\
Not at all & A little & Moderately & Very & Extremely
\end{tabular}

2. How safe is this situation?

\begin{tabular}{c|c|c|c|c}
1 & 2 & 3 & 4 & 5 \\
Not at all & A little & Moderately & Very & Extremely
\end{tabular}

3. How concerned are you about this situation?

\begin{tabular}{c|c|c|c|c}
1 & 2 & 3 & 4 & 5 \\
Not at all & A little & Moderately & Very & Extremely
\end{tabular}

4. How likely are you to disregard this situation?

\begin{tabular}{c|c|c|c|c}
1 & 2 & 3 & 4 & 5 \\
Not at all & A little & Moderately & Very & Extremely
\end{tabular}

5. How harmful is this situation?

\begin{tabular}{c|c|c|c|c}
1 & 2 & 3 & 4 & 5 \\
Not at all & A little & Moderately & Very & Extremely
\end{tabular}

6. How likely are you to intervene in this situation?

\begin{tabular}{c|c|c|c|c}
1 & 2 & 3 & 4 & 5 \\
Not at all & A little & Moderately & Very & Extremely
\end{tabular}

7. How likely are you to label this situation as bullying?

\begin{tabular}{c|c|c|c|c}
1 & 2 & 3 & 4 & 5 \\
Not at all & A little & Moderately & Very & Extremely
\end{tabular}

As a teacher, if you would respond to this situation...

How would you respond to Andrew?

How would you respond to Hannah?

Is there anything else you would do in this situation? 
Please read the following scenario carefully. Then, answer each of the questions.

The class is choosing teams to work on a group project. As Hannah walks up to join Andrew's team, in front of everyone Andrew turns his back to close Hannah out of the group, and begins delegating tasks to his group. You've seen Andrew doing things like this to Hannah before. Hannah reacts by ignoring Andrew.

Imagine you did not know how Hannah reacted to the situation. Assuming the situation resulted in one of the two outcomes listed below, how likely is it that you would have predicted each outcome? (Probabilities must add to equal 100\%).

Hannah would react by shoving Andrew hard $\%$

Hannah would react by ignoring Andrew

$\%$

1. How serious is this situation?
\begin{tabular}{c|}
1 \\
Not at all
\end{tabular}
\begin{tabular}{c|c}
2 & 3 \\
A little & Moderately
\end{tabular}
\begin{tabular}{c|c|c}
4 \\
Very
\end{tabular}
5
Extremely

2. How safe is this situation?

\begin{tabular}{c|c|c|c|c}
1 & 2 & 3 & 4 & 5 \\
Not at all & A little & Moderately & Very & Extremely
\end{tabular}

3. How concerned are you about this situation?

\begin{tabular}{c|c|c|c|c}
1 & 2 & 3 & 4 & 5 \\
Not at all & A little & Moderately & Very & Extremely
\end{tabular}

4. How likely are you to disregard this situation?

\begin{tabular}{c|c|c|c|c}
1 & 2 & 3 & 4 & 5 \\
Not at all & A little & Moderately & Very & Extremely
\end{tabular}

5. How harmful is this situation?
1
Not at all
2
$\stackrel{3}{\text { Moderately }}$
4
Very
5
Extremely

6. How likely are you to intervene in this situation?
Not at all
2
A little
3
Moderately
4
Very
Extremely

7. How likely are you to label this situation as bullying?
1
Not at all
$\stackrel{2}{\text { A little }}$
3
Moderately
4
Very

As a teacher, if you would respond to this situation...

How would you respond to Andrew?

How would you respond to Hannah?

Is there anything else you would do in this situation? 
Please read the following scenario carefully. Then, answer each of the questions.

The class is choosing teams to work on a group project. As Hannah walks up to join Andrew's team, in front of everyone Andrew turns his back to close Hannah out of the group, and begins delegating tasks to his group. You've seen Andrew doing things like this to Hannah before. Hannah reacts by shoving Andrew hard.

Imagine you did not know how Hannah reacted to the situation. Assuming the situation resulted in one of the two outcomes listed below, how likely is it that you would have predicted each outcome? (Probabilities must add to equal 100\%).

Hannah would react by shoving Andrew hard Hannah would react by ignoring Andrew $\%$

1. How serious is this situation?
1
Not at all
A little
3
Moderately
4
Very
Extremely

2. How safe is this situation?
1
Not at all
\begin{tabular}{c|c}
2 & 3 \\
A little & Moderately
\end{tabular}
4
Very
5
Extremely

3. How concerned are you about this situation?
1
Not at all
$\stackrel{2}{\text { A little }}$
3
Moderately
4
Very
5
Extremely

4. How likely are you to disregard this situation?

\begin{tabular}{c|c|c|c|c}
1 & 2 & 3 & 4 & 5 \\
Not at all & A little & Moderately & Very & Extremely
\end{tabular}

5. How harmful is this situation?
Not at all
$\stackrel{2}{2}$
$\left|\begin{array}{c}3 \\ \text { Moderately }\end{array}\right|$
4
Very
5
Extremely

6. How likely are you to intervene in this situation?
Not at all
A little
3
Moderately
4
Very
Extremely

7. How likely are you to label this situation as bullying?

\begin{tabular}{c|c|c|c|c}
1 & 2 & 3 & 4 & 5 \\
Not at all & A little & Moderately & Very & Extremely
\end{tabular}

As a teacher, if you would respond to this situation...

How would you respond to Andrew?

How would you respond to Hannah?

Is there anything else you would do in this situation? 
Please read the following scenario carefully. Then, answer each of the questions.

The class is choosing teams to work on a group project. As Brittany walks up to join Amanda's team, in front of everyone Amanda turns her back to close Brittany out of the group, and begins delegating tasks to her group. You've seen Amanda doing things like this to Brittany before.

Assuming the situation resulted in one of the two outcomes listed below, how likely is it that you would have predicted each outcome? (Probabilities must add to equal $100 \%$ ).

Brittany would react by shoving Amanda hard

Brittany would react by ignoring Amanda $\%$

1. How serious is this situation?

\begin{tabular}{c|c|c|c|c}
1 & 2 & 3 & 4 & 5 \\
Not at all & A little & Moderately & Very & Extremely
\end{tabular}

2. How safe is this situation?

\begin{tabular}{c|c|c|c|c}
1 & 2 & 3 & 4 & 5 \\
Not at all & A little & Moderately & Very & Extremely
\end{tabular}

3. How concerned are you about this situation?

\begin{tabular}{c|c|c|c|c}
1 & 2 & 3 & 4 & 5 \\
Not at all & A little & Moderately & Very & Extremely
\end{tabular}

4. How likely are you to disregard this situation?

\begin{tabular}{c|c|c|c|c}
1 & 2 & 3 & 4 & 5 \\
Not at all & A little & Moderately & Very & Extremely
\end{tabular}

5. How harmful is this situation?
Not at all
A little
$\stackrel{3}{\text { Moderately }}$
4
Very
5
Extremely

6. How likely are you to intervene in this situation?
Not at all
$\stackrel{2}{\text { A little }}$
3
Moderately
4
Very
5
Extremely

7. How likely are you to label this situation as bullying?
1
Not at all
2
A little

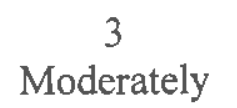
4
Very

As a teacher, if you would respond to this situation...

How would you respond to Amanda?

How would you respond to Brittany?

Is there anything else you would do in this situation? 
Please read the following scenario carefully. Then, answer each of the questions.

The class is choosing teams to work on a group project. As Brittany walks up to join Amanda's team, in front of everyone Amanda turns her back to close Brittany out of the group, and begins delegating tasks to her group. You've seen Amanda doing things like this to Brittany before. Brittany reacts by ignoring Amanda.

Imagine you did not know how Brittany reacted to the situation. Assuming the situation resulted in one of the two outcomes listed below, how likely is it that you would have predicted each outcome? (Probabilities must add to equal 100\%).

Brittany would react by shoving Amanda hard

Brittany would react by ignoring Amanda $\%$

1. How serious is this situation?

\begin{tabular}{c|c|c|c|c}
1 & 2 & 3 & 4 & 5 \\
Not at all & A little & Moderately & Very & Extremely
\end{tabular}

2. How safe is this situation?

\begin{tabular}{c|c|c|c|c}
1 & 2 & 3 & 4 & 5 \\
Not at all & A little & Moderately & Very & Extremely
\end{tabular}

3. How concerned are you about this situation?

\begin{tabular}{c|c|c|c|c}
1 & 2 & 3 & 4 & 5 \\
Not at all & A little & Moderately & Very & Extremely
\end{tabular}

4. How likely are you to disregard this situation?

\begin{tabular}{c|c|c|c|c}
1 & 2 & 3 & 4 & 5 \\
Not at all & A little & Moderately & Very & Extremely
\end{tabular}

5. How harmful is this situation?

\begin{tabular}{c|c|c|c|c}
1 & 2 & 3 & 4 & 5 \\
Not at all & A little & Moderately & Very & Extremely
\end{tabular}

6. How likely are you to intervene in this situation?

\begin{tabular}{c|c|c|c|c}
1 & 2 & 3 & 4 & 5 \\
Not at all & A little & Moderately & Very & Extremely
\end{tabular}

7. How likely are you to label this situation as bullying?

\begin{tabular}{c|c|c|c|c}
1 & 2 & 3 & 4 & 5 \\
Not at all & A little & Moderately & Very & Extremely
\end{tabular}

As a teacher, if you would respond to this situation...

How would you respond to Amanda?

How would you respond to Brittany?

Is there anything else you would do in this situation? 
Please read the following scenario carefully. Then, answer each of the questions.

The class is choosing teams to work on a group project. As Brittany walks up to join Amanda's team, in front of everyone Amanda turns her back to close Brittany out of the group, and begins delegating tasks to her group. You've seen Amanda doing things like this to Brittany before. Brittany reacts by shoving Amanda hard.

Imagine you did not know how Brittany reacted to the situation. Assuming the situation resulted in one of the two outcomes listed below, how likely is it that you would have predicted each outcome? (Probabilities must add to equal 100\%).

Brittany would react by shoving Amanda hard

Brittany would react by ignoring Amanda $\%$

1. How serious is this situation?
Not at all
\begin{tabular}{c|c}
2 & 3 \\
A little & Moderately
\end{tabular}
4
Very
5
Extremely

2. How safe is this situation?
1
Not at all
2
A little
$\left|\begin{array}{c}3 \\ \text { Moderately }\end{array}\right|$
4
Very
5
Extremely

3. How concerned are you about this situation?
1
Not at all
$\stackrel{2}{\text { A little }}$
3
Moderately
4
Very
5
Extremely

4. How likely are you to disregard this situation?
1
Not at all
$\stackrel{2}{\text { A little }}$
3
Moderately
4
Very
5
$\stackrel{5}{\text { Extremely }}$

5. How harmful is this situation?
1
Not at all
2
A little
3
Moderately
4
Very
5
Extremely

6. How likely are you to intervene in this situation?
Not at all
A little
3
Moderately
4
Very
5
Extremely

7. How likely are you to label this situation as bullying?
1
Not at all
$\stackrel{2}{\text { A little }}$
3
Moderately
4
Very
5
Extremely

As a teacher, if you would respond to this situation...

How would you respond to Amanda?

How would you respond to Brittany?

Is there anything else you would do in this situation? 
Please read the following scenario carefully. Then, answer each of the questions.

The class is choosing teams to work on a group project. As Ryan walks up to join Elizabeth's team, in front of everyone Elizabeth turns her back to close Ryan out of the group, and begins delegating tasks to her group. You've seen Elizabeth doing things like this to Ryan before.

Assuming the situation resulted in one of the two outcomes listed below, how likely is it that you would have predicted each outcome? (Probabilities must add to equal $100 \%$ ).

Ryan would react by shoving Elizabeth hard Ryan would react by ignoring Elizabeth $\%$

1. How serious is this situation?

\begin{tabular}{c|c|c|c|c}
1 & 2 & 3 & 4 & 5 \\
Not at all & A little & Moderately & Very & Extremely
\end{tabular}

2. How safe is this situation?

\begin{tabular}{c|c|c|c|c}
1 & 2 & 3 & 4 & 5 \\
Not at all & A little & Moderately & Very & Extremely
\end{tabular}

3. How concerned are you about this situation?

\begin{tabular}{c|c|c|c|c}
1 & 2 & 3 & 4 & 5 \\
Not at all & A little & Moderately & Very & Extremely
\end{tabular}

4. How likely are you to disregard this situation?

\begin{tabular}{c|c|c|c|c}
1 & 2 & 3 & 4 & 5 \\
Not at all & A little & Moderately & Very & Extremely
\end{tabular}

5. How harmful is this situation?

\begin{tabular}{c|c|c|c|c}
1 & 2 & 3 & 4 & 5 \\
Not at all & A little & Moderately & Very & Extremely
\end{tabular}

6. How likely are you to intervene in this situation?
1
Not at all
A little
3
Moderately
\begin{tabular}{c|c|c}
4 & \\
Very &
\end{tabular}
5
Extremely

7. How likely are you to label this situation as bullying?

\begin{tabular}{c|c|c|c|c}
1 & 2 & 3 & 4 & 5 \\
Not at all & A little & Moderately & Very & Extremely
\end{tabular}

As a teacher, if you would respond to this situation...

How would you respond to Elizabeth?

How would you respond to Ryan?

Is there anything else you would do in this situation? 
Please read the following scenario carefully. Then, answer each of the questions.

The class is choosing teams to work on a group project. As Ryan walks up to join Elizabeth's team, in front of everyone Elizabeth turns her back to close Ryan out of the group, and begins delegating tasks to her group. You've seen Elizabeth doing things like this to Ryan before. Ryan reacts by ignoring Elizabeth.

Imagine you did not know how Ryan reacted to the situation. Assuming the situation resulted in one of the two outcomes listed below, how likely is it that you would have predicted each outcome? (Probabilities must add to equal 100\%).

Ryan would react by shoving Elizabeth hard

Ryan would react by ignoring Elizabeth $\%$

1. How serious is this situation?
Not at all

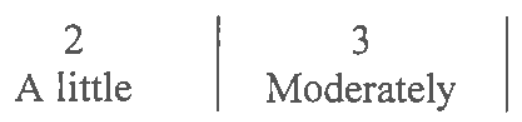
4
Very
5
Extremely

2. How safe is this situation?
Not at all
\begin{tabular}{c|c}
2 & 3 \\
A little & Moderately
\end{tabular}
4
Very
5
Extremely

3. How concerned are you about this situation?

\begin{tabular}{c|c|c|c|c}
1 & 2 & 3 & 4 & 5 \\
Not at all & A little & Moderately & Very & Extremely
\end{tabular}

4. How likely are you to disregard this situation?

\begin{tabular}{c|c|c|c|c}
1 & 2 & 3 & 4 & 5 \\
Not at all & A little & Moderately & Very & Extremely
\end{tabular}

5. How harmful is this situation?
\begin{tabular}{c|}
1 \\
Not at all
\end{tabular}
\begin{tabular}{c|c}
2 & 3 \\
A little & Moderately
\end{tabular}
\begin{tabular}{c|c|c}
4 \\
Very
\end{tabular}
5
Extremely

6. How likely are you to intervene in this situation?
1
Not at all
\begin{tabular}{c|c}
2 & 3 \\
A little & Moderately
\end{tabular}
\begin{tabular}{c|c|c|c|}
4 \\
Very
\end{tabular}
5
Extremely

7. How likely are you to label this situation as bullying?
Not at all
A little
$\left|\begin{array}{c}3 \\ \text { Moderately }\end{array}\right|$
4
Very
5
Extremely

As a teacher, if you would respond to this situation...

How would you respond to Elizabeth?

How would you respond to Ryan?

Is there anything else you would do in this situation? 
Please read the following scenario carefully. Then, answer each of the questions.

The class is choosing teams to work on a group project. As Ryan walks up to join Elizabeth's team, in front of everyone Elizabeth turns her back to close Ryan out of the group, and begins delegating tasks to her group. You've seen Elizabeth doing things like this to Ryan before. Ryan reacts by shoving Elizabeth hard.

Imagine you did not know how Ryan reacted to the situation. Assuming the situation resulted in one of the two outcomes listed below, how likely is it that you would have predicted each outcome? (Probabilities must add to equal 100\%).

Ryan would react by shoving Elizabeth hard

Ryan would react by ignoring Elizabeth $\%$

1. How serious is this situation?

\begin{tabular}{c|c|c|c|c}
1 & 2 & 3 & 4 & 5 \\
Not at all & A little & Moderately & Very & Extremely
\end{tabular}

2. How safe is this situation?

\begin{tabular}{c|c|c|c|c}
1 & 2 & 3 & 4 & 5 \\
Not at all & A little & Moderately & Very & Extremely
\end{tabular}

3. How concerned are you about this situation?

\begin{tabular}{c|c|c|c|c}
1 & 2 & 3 & 4 & 5 \\
Not at all & A little & Moderately & Very & Extremely
\end{tabular}

4. How likely are you to disregard this situation?

\begin{tabular}{c|c|c|c|c}
1 & 2 & 3 & 4 & 5 \\
Not at all & A little & Moderately & Very & Extremely
\end{tabular}

5. How harmful is this situation?

\begin{tabular}{c|c|c|c|c}
1 & 2 & 3 & 4 & 5 \\
Not at all & A little & Moderately & Very & Extremely
\end{tabular}

6. How likely are you to intervene in this situation?

\begin{tabular}{c|c|c|c|c}
1 & 2 & 3 & 4 & 5 \\
Not at all & A little & Moderately & Very & Extremely
\end{tabular}

7. How likely are you to label this situation as bullying?

\begin{tabular}{c|c|c|c|c}
1 & 2 & 3 & 4 & 5 \\
Not at all & A little & Moderately & Very & Extremely
\end{tabular}

As a teacher, if you would respond to this situation...

How would you respond to Elizabeth?

How would you respond to Ryan?

Is there anything else you would do in this situation? 
Please read the following scenario carefully. Then, answer each of the questions.

While in the hallway before school begins, John pushes Zachary into a locker. You've seen John doing things like this to Zachary before.

Assuming the situation resulted in one of the two outcomes listed below, how likely is it that you would have predicted each outcome? (Probabilities must add to equal 100\%).

Zachary would react by shoving John hard

Zachary would react by ignoring John $\%$

1. How serious is this situation?

\begin{tabular}{c|c|c|c|c}
1 & 2 & 3 & 4 & 5 \\
Not at all & A little & Moderately & Very & Extremely
\end{tabular}

2. How safe is this situation?

\begin{tabular}{c|c|c|c|c}
1 & 2 & 3 & 4 & 5 \\
Not at all & A little & Moderately & Very & Extremely
\end{tabular}

3. How concerned are you about this situation?

\begin{tabular}{c|c|c|c|c}
1 & 2 & 3 & 4 & 5 \\
Not at all & A little & Moderately & Very & Extremely
\end{tabular}

4. How likely are you to disregard this situation?

\begin{tabular}{c|c|c|c|c}
1 & 2 & 3 & 4 & 5 \\
Not at all & A little & Moderately & Very & Extremely
\end{tabular}

5. How harmful is this situation?

\begin{tabular}{c|c|c|c|c}
1 & 2 & 3 & 4 & 5 \\
Not at all & A little & Moderately & Very & Extremely
\end{tabular}

6. How likely are you to intervene in this situation?

\begin{tabular}{c|c|c|c|c}
1 & 2 & 3 & 4 & 5 \\
Not at all & A little & Moderately & Very & Extremely
\end{tabular}

7. How likely are you to label this situation as bullying?
Not at all
2
A little
3
Moderately
4
Very
5
Extremely

As a teacher, if you would respond to this situation...

How would you respond to John?

How would you respond to Zachary?

Is there anything else you would do in this situation? 
Please read the following scenario carefully. Then, answer each of the questions.

While in the hallway before school begins, John pushes Zachary into a locker. You've seen John doing things like this to Zachary before. Zachary reacts by ignoring John.

Imagine you did not know how Zachary reacted to the situation. Assuming the situation resulted in one of the two outcomes listed below, how likely is it that you would have predicted each outcome? (Probabilities must add to equal 100\%).

Zachary would react by shoving John hard

Zachary would react by ignoring John

$\%$

1. How serious is this situation?

\begin{tabular}{c|c|c|c|c}
1 & 2 & 3 & 4 & 5 \\
Not at all & A little & Moderately & Very & Extremely
\end{tabular}

2. How safe is this situation?

\begin{tabular}{c|c|c|c|c}
1 & 2 & 3 & 4 & 5 \\
Not at all & A little & Moderately & Very & Extremely
\end{tabular}

3. How concerned are you about this situation?
Not at all
A little
3
Moderately
4
Very
5
Extremely

4. How likely are you to disregard this situation?
Not at all
2
A little
3
Moderately
\begin{tabular}{c|c|}
4 \\
Very
\end{tabular}
5
Extremely

5. How harmful is this situation?
1
Not at all
\begin{tabular}{c|c}
2 & 3 \\
A little & Moderately
\end{tabular}
\begin{tabular}{c|c|}
4 & \\
Very
\end{tabular}
5
Extremely

6. How likely are you to intervene in this situation?
1
Not at all
2
A little
3
Moderately
4
Very
5
Extremely

7. How likely are you to label this situation as bullying?
1
Not at all
$\stackrel{2}{\text { A little }}$
3
Moderately
4
Very

As a teacher, if you would respond to this situation...

How would you respond to John?

How would you respond to Zachary?

Is there anything else you would do in this situation? 
Please read the following scenario carefully. Then, answer each of the questions.

While in the hallway before school begins, John pushes Zachary into a locker. You've seen John doing things like this to Zachary before. Zachary reacts by shoving John hard.

Imagine you did not know how Zachary reacted to the situation. Assuming the situation resulted in one of the two outcomes listed below, how likely is it that you would have predicted each outcome? (Probabilities must add to equal 100\%).

Zachary would react by shoving John hard

Zachary would react by ignoring John $\%$

1. How serious is this situation?
Not at all
\begin{tabular}{c|c}
2 & 3 \\
A little & Moderately
\end{tabular}
4
Very
5
Extremely

2. How safe is this situation?

\begin{tabular}{c|c|c|c|c} 
I & 2 & 3 & 4 & 5 \\
Not at all & A little & Moderately & Very & Extremely
\end{tabular}

3. How concerned are you about this situation?

\begin{tabular}{c|c|c|c|c}
1 & 2 & 3 & 4 & 5 \\
Not at all & A little & Moderately & Very & Extremely
\end{tabular}

4. How likely are you to disregard this situation?

\begin{tabular}{c|c|c|c|c}
1 & 2 & 3 & 4 & 5 \\
Not at all & A little & Moderately & Very & Extremely
\end{tabular}

5. How harmful is this situation?

\begin{tabular}{c|c|c|c|c}
1 & 2 & 3 & 4 & 5 \\
Not at all & A little & Moderately & Very & Extremely
\end{tabular}

6. How likely are you to intervene in this situation?

\begin{tabular}{c|c|c|c|c}
1 & 2 & 3 & 4 & 5 \\
Not at all & A little & Moderately & Very & Extremely
\end{tabular}

7. How likely are you to label this situation as bullying?

\begin{tabular}{c|c|c|c|c}
1 & 2 & 3 & 4 & 5 \\
Not at all & A little & Moderately & Very & Extremely
\end{tabular}

As a teacher, if you would respond to this situation...

How would you respond to John?

How would you respond to Zachary?

Is there anything else you would do in this situation? 
Please read the following scenario carefully. Then, answer each of the questions. While in the hallway before school begins, David pushes Kayla into a locker. You've seen David doing things like this to Kayla before.

Assuming the situation resulted in one of the two outcomes listed below, how likely is it that you would have predicted each outcome? (Probabilities must add to equal $100 \%$ ).

Kayla would react by shoving David hard

Kayla would react by ignoring David $\%$

1. How serious is this situation?

\begin{tabular}{c|c|c|c|c}
1 & 2 & 3 & 4 & 5 \\
Not at all & A little & Moderately & Very & Extremely
\end{tabular}

2. How safe is this situation?

\begin{tabular}{c|c|c|c|c}
1 & 2 & 3 & 4 & 5 \\
Not at all & A little & Moderately & Very & Extremely
\end{tabular}

3. How concerned are you about this situation?

\begin{tabular}{c|c|c|c|c}
1 & 2 & 3 & 4 & 5 \\
Not at all & A little & Moderately & Very & Extremely
\end{tabular}

4. How likely are you to disregard this situation?

\begin{tabular}{c|c|c|c|c}
1 & 2 & 3 & 4 & 5 \\
Not at all & A little & Moderately & Very & Extremely
\end{tabular}

5. How harmful is this situation?

\begin{tabular}{c|c|c|c|c}
1 & 2 & 3 & 4 & 5 \\
Not at all & A little & Moderately & Very & Extremely
\end{tabular}

6. How likely are you to intervene in this situation?

\begin{tabular}{c|c|c|c|c}
1 & 2 & 3 & 4 & 5 \\
Not at all & A little & Moderately & Very & Extremely
\end{tabular}

7. How likely are you to label this situation as bullying?

\begin{tabular}{c|c|c|c|c}
1 & 2 & 3 & 4 & 5 \\
Not at all & A little & Moderately & Very & Extremely
\end{tabular}

As a teacher, if you would respond to this situation...

How would you respond to David?

How would you respond to Kayla?

Is there anything else you would do in this situation? 
Please read the following scenario carefully. Then, answer each of the questions. While in the hallway before school begins, David pushes Kayla into a locker. You've seen David doing things like this to Kayla before. Kayla reacts by ignoring David. Imagine you did not know how Kayla reacted to the situation. Assuming the situation resulted in one of the two outcomes listed below, how likely is it that you would have predicted each outcome? (Probabilities must add to equal 100\%).

Kayla would react by shoving David hard

Kayla would react by ignoring David $\%$

1. How serious is this situation?

\begin{tabular}{c|c|c|c|c}
1 & 2 & 3 & 4 & 5 \\
Not at all & A little & Moderately & Very & Extremely
\end{tabular}

2. How safe is this situation?

\begin{tabular}{c|c|c|c|c}
1 & 2 & 3 & 4 & 5 \\
Not at all & A little & Moderately & Very & Extremely
\end{tabular}

3. How concerned are you about this situation?

\begin{tabular}{c|c|c|c|c}
1 & 2 & 3 & 4 & 5 \\
Not at all & A little & Moderately & Very & Extremely
\end{tabular}

4. How likely are you to disregard this situation?

\begin{tabular}{c|c|c|c|c}
1 & 2 & 3 & 4 & 5 \\
Not at all & A little & Moderately & Very & Extremely
\end{tabular}

5. How harmful is this situation?

\begin{tabular}{c|c|c|c|c}
1 & 2 & 3 & 4 & 5 \\
Not at all & A little & Moderately & Very & Extremely
\end{tabular}

6. How likely are you to intervene in this situation?

\begin{tabular}{c|c|c|c|c}
1 & 2 & 3 & 4 & 5 \\
Not at all & A little & Moderately & Very & Extremely
\end{tabular}

7. How likely are you to label this situation as bullying?

\begin{tabular}{c|c|c|c|c}
1 & 2 & 3 & 4 & 5 \\
Not at all & A little & Moderately & Very & Extremely
\end{tabular}

As a teacher, if you would respond to this situation...

How would you respond to David?

How would you respond to Kayla?

Is there anything else you would do in this situation? 
Please read the following scenario carefully. Then, answer each of the questions. While in the hallway before school begins, David pushes Kayla into a locker. You've seen David doing things like this to Kayla before. Kayla reacts by shoving David hard.

Imagine you did not know how Kayla reacted to the situation. Assuming the situation resulted in one of the two outcomes listed below, how likely is it that you would have predicted each outcome? (Probabilities must add to equal 100\%).

Kayla would react by shoving David hard Kayla would react by ignoring David $\%$

1. How serious is this situation?

\begin{tabular}{c|c|c|c|c}
1 & 2 & 3 & 4 & 5 \\
Not at all & A little & Moderately & Very & Extremely
\end{tabular}

2. How safe is this situation?

\begin{tabular}{c|c|c|c|c}
1 & 2 & 3 & 4 & 5 \\
Not at all & A little & Moderately & Very & Extremely
\end{tabular}

3. How concerned are you about this situation?

\begin{tabular}{c|c|c|c|c}
1 & 2 & 3 & 4 & 5 \\
Not at all & A little & Moderately & Very & Extremely
\end{tabular}

4. How likely are you to disregard this situation?

\begin{tabular}{c|c|c|c|c}
1 & 2 & 3 & 4 & 5 \\
Not at all & A little & Moderately & Very & Extremely
\end{tabular}

5. How harmful is this situation?
\begin{tabular}{c|}
1 \\
Not at all
\end{tabular}
\begin{tabular}{c|c}
2 & 3 \\
A little & Moderately
\end{tabular}
4
Very
5
Extremely

6. How likely are you to intervene in this situation?
\begin{tabular}{c|}
1 \\
Not at all
\end{tabular}
\begin{tabular}{c|c}
2 & 3 \\
A little & Moderately
\end{tabular}
4
Very
Extremely

7. How likely are you to label this situation as bullying?
1
Not at all
2
A little
3
Moderately
4
Very
5
Extremely

As a teacher, if you would respond to this situation...

How would you respond to David?

How would you respond to Kayla?

Is there anything else you would do in this situation? 
Please read the following scenario carefully. Then, answer each of the questions.

While in the hallway before school begins, Rachel pushes Megan into a locker. You've seen Rachel doing things like this to Megan before.

Assuming the situation resulted in one of the two outcomes listed below, how likely is it that you would have predicted each outcome? (Probabilities must add to equal 100\%).

Megan would react by shoving Rachel hard Megan would react by ignoring Rachel

$\%$

1. How serious is this situation?
1
Not at all
\begin{tabular}{c|c}
2 & 3 \\
A little & Moderately
\end{tabular}
4
Very
5
Extremely

2. How safe is this situation?
1
Not at all
\begin{tabular}{c|c|}
2 & 3 \\
A little & Moderately
\end{tabular}
4
Very
5
Extremely

3. How concerned are you about this situation?
1
Not at all
2
A little
3
Moderately
4
Very
5
Extremely

4. How likely are you to disregard this situation?
1
Not at all
$\stackrel{2}{\text { A little }}$
3
Moderately
4
Very
5
Extremely

5. How harmful is this situation?

\begin{tabular}{c|c|c|c|c}
1 & 2 & 3 & 4 & 5 \\
Not at all & A little & Moderately & Very & Extremely
\end{tabular}

6. How likely are you to intervene in this situation?

\begin{tabular}{c|c|c|c|c}
1 & 2 & 3 & 4 & 5 \\
Not at all & A little & Moderately & Very & Extremely
\end{tabular}

7. How likely are you to label this situation as bullying?

\begin{tabular}{c|c|c|c|c}
1 & 2 & 3 & 4 & 5 \\
Not at all & A little & Moderately & Very & Extremely
\end{tabular}

As a teacher, if you would respond to this situation...

How would you respond to Rachel?

How would you respond to Megan?

Is there anything else you would do in this situation? 
Please read the following scenario carefully. Then, answer each of the questions. While in the hallway before school begins, Rachel pushes Megan into a locker. You've seen Rachel doing things like this to Megan before. Megan reacts by ignoring Rachel.

Imagine you did not know how Megan reacted to the situation. Assuming the situation resulted in one of the two outcomes listed below, how likely is it that you would have predicted each outcome? (Probabilities must add to equal 100\%).

Megan would react by shoving Rachel hard

Megan would react by ignoring Rachel $\%$

$\%$

1. How serious is this situation?

\begin{tabular}{c|c|c|c|c}
1 & 2 & 3 & 4 & 5 \\
Not at all & A little & Moderately & Very & Extremely
\end{tabular}

2. How safe is this situation?

\begin{tabular}{c|c|c|c|c}
1 & 2 & 3 & 4 & 5 \\
Not at all & A little & Moderately & Very & Extremely
\end{tabular}

3. How concerned are you about this situation?

\begin{tabular}{c|c|c|c|c}
1 & 2 & 3 & 4 & 5 \\
Not at all & A little & Moderately & Very & Extremely
\end{tabular}

4. How likely are you to disregard this situation?

\begin{tabular}{c|c|c|c|c}
1 & 2 & 3 & 4 & 5 \\
Not at all & A little & Moderately & Very & Extremely
\end{tabular}

5. How harmful is this situation?

\begin{tabular}{c|c|c|c|c}
1 & 2 & 3 & 4 & 5 \\
Not at all & A little & Moderately & Very & Extremely
\end{tabular}

6. How likely are you to intervene in this situation?
Not at all
\begin{tabular}{c|c}
2 & 3 \\
A little & Moderately
\end{tabular}
4
Very
Extremely

7. How likely are you to label this situation as bullying?
1
Not at all
\begin{tabular}{c|c}
2 & 3 \\
A little & Moderately
\end{tabular}
4
Very
Extremely

As a teacher, if you would respond to this situation...

How would you respond to Rachel?

How would you respond to Megan?

Is there anything else you would do in this situation? 
Please read the following scenario carefully. Then, answer each of the questions.

While in the hallway before school begins, Rachel pushes Megán into a locker. You've seen Rachel doing things like this to Megan before. Megan reacts by shoving Rachel hard.

Imagine you did not know how Megan reacted to the situation. Assuming the situation resulted in one of the two outcomes listed below, how likely is it that you would have predicted each outcome? (Probabilities must add to equal 100\%).

Megan would react by shoving Rachel hard Megan would react by ignoring Rachel $\%$

1. How serious is this situation?

\begin{tabular}{c|c|c|c|c}
1 & 2 & 3 & 4 & 5 \\
Not at all & A little & Moderately & Very & Extremely
\end{tabular}

2. How safe is this situation?
Not at all
\begin{tabular}{c|c}
2 & 3 \\
A little & Moderately
\end{tabular}
\begin{tabular}{c|c}
4 \\
Very
\end{tabular}
5
Extremely

3. How concerned are you about this situation?
Not at all
2
A little
\begin{tabular}{c|}
3 \\
Moderately
\end{tabular}
\begin{tabular}{c|c|c|c|}
4 & 0 \\
Very &
\end{tabular}
5
Extremely

4. How likely are you to disregard this situation?
\begin{tabular}{c|}
1 \\
Not at all
\end{tabular}
$\stackrel{2}{\text { A little }}$
3
Moderately
\begin{tabular}{c|c|c|c|}
4 & \\
Very &
\end{tabular}
Extremely

5. How harmful is this situation?
Not at all
\begin{tabular}{c|c}
2 & 3 \\
A little & Moderately
\end{tabular}
\begin{tabular}{c|}
4 \\
Very
\end{tabular}
$\stackrel{5}{\text { Extremely }}$

6. How likely are you to intervene in this situation?
Not at all
$\stackrel{2}{\text { A little }}$
3
Moderately
4
Very
Extremely

7. How likely are you to label this situation as bullying?
Not at all
A little
3
Moderately
4
Very

As a teacher, if you would respond to this situation...

How would you respond to Rachel?

How would you respond to Megan?

Is there anything else you would do in this situation? 
Please read the following scenario carefully. Then, answer each of the questions.

While in the hallway before school begins, Lauren pushes James into a locker. You've seen Lauren doing things like this to James before.

Assuming the situation resulted in one of the two outcomes listed below, how likely is it that you would have predicted each outcome? (Probabilities must add to equal 100\%). James would react by shoving Lauren hard James would react by ignoring Lauren $\%$

\section{How serious is this situation?}
1
Not at all
A little
\begin{tabular}{c|c}
3 \\
Moderately
\end{tabular}
4
Very
5
Extremely

2. How safe is this situation?
1
Not at all
A little
\begin{tabular}{c|c|c|}
3 \\
Moderately
\end{tabular}
\begin{tabular}{c|c}
4 \\
Very
\end{tabular}
5
Extremely

3. How concerned are you about this situation?
1
Not at all
$\stackrel{2}{2}$ A little
$\stackrel{3}{\text { Moderately }}$
\begin{tabular}{c|c|c}
4 \\
Very
\end{tabular}
5
Extremely

4. How likely are you to disregard this situation?
\begin{tabular}{c|}
1 \\
Not at all
\end{tabular}
\begin{tabular}{c|c}
2 & 3 \\
A little & Moderately
\end{tabular}
\begin{tabular}{c|c|c}
4 & \\
Very
\end{tabular}
5
Extremely

5. How harmful is this situation?
\begin{tabular}{c|}
1 \\
Not at all
\end{tabular}
\begin{tabular}{c|c}
2 & 3 \\
A little & Moderately
\end{tabular}
\begin{tabular}{c|}
4 \\
Very
\end{tabular}
5
Extremely

6. How likely are you to intervene in this situation?
1
Not at all
\begin{tabular}{c|c}
2 & 3 \\
A little & Moderately
\end{tabular}
\begin{tabular}{c|c|c|c|}
4 & \\
Very &
\end{tabular}
5
Extremely

7. How likely are you to label this situation as bullying?
\begin{tabular}{c|}
1 \\
Not at all
\end{tabular}
A little
3
Moderately
4
Very
Extremely

As a teacher, if you would respond to this situation...

How would you respond to Lauren?

How would you respond to James?

Is there anything else you would do in this situation? 
Please read the following scenario carefully. Then, answer each of the questions. While in the hallway before school begins, Lauren pushes James into a locker. You've seen Lauren doing things like this to James before. James reacts by ignoring Lauren.

Imagine you did not know how James reacted to the situation. Assuming the situation resulted in one of the two outcomes listed below, how likely is it that you would have predicted each outcome? (Probabilities must add to equal 100\%).

James would react by shoving Lauren hard James would react by ignoring Lauren \%

$\%$

1. How serious is this situation?

\begin{tabular}{c|c|c|c|c}
1 & 2 & 3 & 4 & 5 \\
Not at all & A little & Moderately & Very & Extremely
\end{tabular}

2. How safe is this situation?

\begin{tabular}{c|c|c|c|c}
1 & 2 & 3 & 4 & 5 \\
Not at all & A little & Moderately & Very & Extremely
\end{tabular}

3. How concerned are you about this situation?

\begin{tabular}{c|c|c|c|c}
1 & 2 & 3 & 4 & 5 \\
Not at all & A little & Moderately & Very & Extremely
\end{tabular}

4. How likely are you to disregard this situation?

\begin{tabular}{c|c|c|c|c}
1 & 2 & 3 & 4 & 5 \\
Not at all & A little & Moderately & Very & Extremely
\end{tabular}

5. How harmful is this situation?

\begin{tabular}{c|c|c|c|c}
1 & 2 & 3 & 4 & 5 \\
Not at all & A little & Moderately & Very & Extremely
\end{tabular}

6. How likely are you to intervene in this situation?

\begin{tabular}{c|c|c|c|c}
1 & 2 & 3 & 4 & 5 \\
Not at all & A little & Moderately & Very & Extremely
\end{tabular}

7. How likely are you to label this situation as bullying?

\begin{tabular}{c|c|c|c|c} 
I & 2 & 3 & 4 & 5 \\
Not at all & A little & Moderately & Very & Extremely
\end{tabular}

As a teacher, if you would respond to this situation...

How would you respond to Lauren?

How would you respond to James?

Is there anything else you would do in this situation? 
Please read the following scenario carefully. Then, answer each of the questions. While in the hallway before school begins, Lauren pushes James into a locker. You've seen Lauren doing things like this to James before. James reacts by shoving Lauren hard.

Imagine you did not know how James reacted to the situation. Assuming the situation resulted in one of the two outcomes listed below, how likely is it that you would have predicted each outcome? (Probabilities must add to equal 100\%).

James would react by shoving Lauren hard James would react by ignoring Lauren $\%$

1. How serious is this situation?
\begin{tabular}{c|}
1 \\
Not at all
\end{tabular}
\begin{tabular}{c|c}
2 & 3 \\
A little & Moderately
\end{tabular}
4
Very
5
Extremely

2. How safe is this situation?
1
Not at all
\begin{tabular}{c|c}
2 & 3 \\
A little & Moderately
\end{tabular}
4
Very
5
Extremely

3. How concerned are you about this situation?
Not at all
2
A little
3
Moderately
4
Very
5
Extremely

4. How likely are you to disregard this situation?
Not at all
A little
\begin{tabular}{c|}
3 \\
Moderately
\end{tabular}
$\stackrel{4}{\text { Very }}$
5
Extremely

5. How harmful is this situation?
Not at all
$\stackrel{2}{\text { A little }}$
3
Moderately
\begin{tabular}{c|c}
4 \\
Very
\end{tabular}
5
Extremely

6. How likely are you to intervene in this situation?
Not at all
A little
3
Moderately
4
Very
5
Extremely

7. How likely are you to label this situation as bullying?
\begin{tabular}{c|}
1 \\
Not at all
\end{tabular}
\begin{tabular}{c|c|}
2 & 3 \\
A little & Moderately
\end{tabular}
4
Very
Extremely

As a teacher, if you would respond to this situation...

How would you respond to Lauren?

How would you respond to James?

Is there anything else you would do in this situation? 
Please read the following scenario carefully. Then, answer each of the questions. During a classroom assignment, Justin loans a pencil to Anthony. You've seen Justin loaning things to Anthony before.

Assuming the situation resulted in one of the two outcomes listed below, how likely is it that you would have predicted each outcome? (Probabilities must add to equal $100 \%$ ).

Anthony would react by shoving Justin hard

Anthony would react by ignoring Justin $\%$

1. How serious is this situation?

\begin{tabular}{c|c|c|c|c}
1 & 2 & 3 & 4 & 5 \\
Not at all & A little & Moderately & Very & Extremely
\end{tabular}

2. How safe is this situation?

\begin{tabular}{c|c|c|c|c}
1 & 2 & 3 & 4 & 5 \\
Not at all & A little & Moderately & Very & Extremely
\end{tabular}

3. How concerned are you about this situation?

\begin{tabular}{c|c|c|c|c}
1 & 2 & 3 & 4 & 5 \\
Not at all & A little & Moderately & Very & Extremely
\end{tabular}

4. How likely are you to disregard this situation?

\begin{tabular}{c|c|c|c|c}
1 & 2 & 3 & 4 & 5 \\
Not at all & A little & Moderately & Very & Extremely
\end{tabular}

5. How harmful is this situation?

\begin{tabular}{c|c|c|c|c}
1 & 2 & 3 & 4 & 5 \\
Not at all & A little & Moderately & Very & Extremely
\end{tabular}

6. How likely are you to intervene in this situation?

\begin{tabular}{c|c|c|c|c}
1 & 2 & 3 & 4 & 5 \\
Not at all & A little & Moderately & Very & Extremely
\end{tabular}

7. How likely are you to label this situation as bullying?

\begin{tabular}{c|c|c|c|c}
1 & 2 & 3 & 4 & 5 \\
Not at all & A little & Moderately & Very & Extremely
\end{tabular}

As a teacher, if you would respond to this situation...

How would you respond to Justin?

How would you respond to Anthony?

Is there anything else you would do in this situation? 
Please read the following scenario carefully. Then, answer each of the questions. During a classroom assignment, Justin loans a pencil to Anthony. You've seen Justin loaning things to Anthony before. Anthony reacts by ignoring Justin. Imagine you did not know how Anthony reacted to the situation. Assuming the situation resulted in one of the two outcomes listed below, how likely is it that you would have predicted each outcome? (Probabilities must add to equal 100\%).

Anthony would react by shoving Justin hard

Anthony would react by ignoring Justin $\%$ $\%$

1. How serious is this situation?
\begin{tabular}{c|}
1 \\
Not at all
\end{tabular}
A little
\begin{tabular}{l|l}
3 \\
Moderately
\end{tabular}
4
Very
5
Extremely

2. How safe is this situation?

\begin{tabular}{c|c|c|c|c}
1 & 2 & 3 & 4 & 5 \\
Not at all & A little & Moderately & Very & Extremely
\end{tabular}

3. How concerned are you about this situation?

\begin{tabular}{c|c|c|c|c}
1 & 2 & 3 & 4 & 5 \\
Not at all & A little & Moderately & Very & Extremely
\end{tabular}

4. How likely are you to disregard this situation?

\begin{tabular}{c|c|c|c|c}
1 & 2 & 3 & 4 & 5 \\
Not at all & A little & Moderately & Very & Extremely
\end{tabular}

5. How harmful is this situation?

\begin{tabular}{c|c|c|c|c}
1 & 2 & 3 & 4 & 5 \\
Not at all & A little & Moderately & Very & Extremely
\end{tabular}

6. How likely are you to intervene in this situation?

\begin{tabular}{c|c|c|c|c}
1 & 2 & 3 & 4 & 5 \\
Not at all & A little & Moderately & Very & Extremely
\end{tabular}

7. How likely are you to label this situation as bullying?

\begin{tabular}{c|c|c|c|c}
1 & 2 & 3 & 4 & 5 \\
Not at all & A little & Moderately & Very & Extremely
\end{tabular}

As a teacher, if you would respond to this situation...

How would you respond to Justin?

How would you respond to Anthony?

Is there anything else you would do in this situation? 
Please read the following scenario carefully. Then, answer each of the questions. During a classroom assignment, Justin loans a pencil to Anthony. You've seen Justin loaning things to Anthony before. Anthony reacts by shoving Justin hard. Imagine you did not know how Anthony reacted to the situation. Assuming the situation resulted in one of the two outcomes listed below, how likely is it that you would have predicted each outcome? (Probabilities must add to equal 100\%).

Anthony would react by shoving Justin hard

Anthony would react by ignoring Justin $\%$

1. How serious is this situation?
Not at all
A little
$\stackrel{3}{\text { Moderately }}$
4
Very
5
Extremely

2. How safe is this situation?

\begin{tabular}{c|c|c|c|c}
1 & 2 & 3 & 4 & 5 \\
Not at all & A little & Moderately & Very & Extremely
\end{tabular}

3. How concerned are you about this situation?
Not at all
A little
3
Moderately
4
Very
5

4. How likely are you to disregard this situation?

\begin{tabular}{c|c|c|c|c}
1 & 2 & 3 & 4 & 5 \\
Not at all & A little & Moderately & Very & Extremely
\end{tabular}

5. How harmful is this situation?

\begin{tabular}{c|c|c|c|c}
1 & 2 & 3 & 4 & 5 \\
Not at all & A little & Moderately & Very & Extremely
\end{tabular}

6. How likely are you to intervene in this situation?

\begin{tabular}{c|c|c|c|c}
1 & 2 & 3 & 4 & 5 \\
Not at all & A little & Moderately & Very & Extremely
\end{tabular}

7. How likely are you to label this situation as bullying?

\begin{tabular}{c|c|c|c|c}
1 & 2 & 3 & 4 & 5 \\
Not at all & A little & Moderately & Very & Extremely
\end{tabular}

As a teacher, if you would respond to this situation...

How would you respond to Justin?

How would you respond to Anthony?

Is there anything else you would do in this situation? 
Please read the following scenario carefully. Then, answer each of the questions.

During a classroom assignment, William loans a pencil to Jessica. You've seen William loaning things to Jessica before.

Assuming the situation resulted in one of the two outcomes listed below, how likely is it that you would have predicted each outcome? (Probabilities must add to equal 100\%).

Jessica would react by shoving William hard

Jessica would react by ignoring William $\%$ $\%$

1. How serious is this situation?
Not at all
\begin{tabular}{c|c}
2 & 3 \\
A little & Moderately
\end{tabular}
4
Very
5
Extremely

2. How safe is this situation?
\begin{tabular}{c|}
1 \\
Not at all
\end{tabular}
\begin{tabular}{c|c}
2 & 3 \\
A little & Moderately
\end{tabular}
4
Very
5

3. How concerned are you about this situation?
1
Not at all
A little
3
Moderately
4
Very
5
Extremely

4. How likely are you to disregard this situation?
\begin{tabular}{c|}
1 \\
Not at all
\end{tabular}
A little
$\stackrel{3}{\text { Moderately }}$
4
Very
5

5. How harmful is this situation?

\begin{tabular}{c|c|c|c|c}
1 & 2 & 3 & 4 & 5 \\
Not at all & A little & Moderately & Very & Extremely
\end{tabular}

6. How likely are you to intervene in this situation?

\begin{tabular}{c|c|c|c|c}
1 & 2 & 3 & 4 & 5 \\
Not at all & A little & Moderately & Very & Extremely
\end{tabular}

7. How likely are you to label this situation as bullying?

\begin{tabular}{c|c|c|c|c}
1 & 2 & 3 & 4 & 5 \\
Not at all & A little & Moderately & Very & Extremely
\end{tabular}

As a teacher, if you would respond to this situation...

How would you respond to William?

How would you respond to Jessica?

Is there anything else you would do in this situation? 
Please read the following scenario carefully. Then, answer each of the questions. During a classroom assignment, William loans a pencil to Jessica. You've seen William loaning things to Jessica before. Jessica reacts by ignoring William.

Imagine you did not know how Jessica reacted to the situation. Assuming the situation resulted in one of the two outcomes listed below, how likely is it that you would have predicted each outcome? (Probabilities must add to equal 100\%).

Jessica would react by shoving William hard

Jessica would react by ignoring William $\%$ $\%$

1. How serious is this situation?
1
Not at all
$\stackrel{2}{\text { A little }}$
3
Moderately
4
Very
5
Extremely

2. How safe is this situation?
1
Not at all
2
A little
$\stackrel{3}{\text { Moderately }}$
4
Very
5
Extremely

3. How concerned are you about this situation?
1
Not at all
2
A little
3
Moderately
4
Very
5
Extremely

4. How likely are you to disregard this situation?

\begin{tabular}{c|c|c|c|c}
1 & 2 & 3 & 4 & 5 \\
Not at all & A little & Moderately & Very & Extremely
\end{tabular}

5. How harmful is this situation?
Not at all
A little
$\stackrel{3}{\text { Moderately }}$
\begin{tabular}{c|c}
4 \\
Very
\end{tabular}
5
Extremely

6. How likely are you to intervene in this situation?
Not at all
$\stackrel{2}{\text { A little }}$
\begin{tabular}{c|c}
3 \\
Moderately
\end{tabular}
4
Very
Extremely

7. How likely are you to label this situation as bullying?

\begin{tabular}{c|c|c|c|c}
1 & 2 & 3 & 4 & 5 \\
Not at all & A little & Moderately & Very & Extremely
\end{tabular}

As a teacher, if you would respond to this situation...

How would you respond to William?

How would you respond to Jessica?

Is there anything else you would do in this situation? 
Please read the following scenario carefully. Then, answer each of the questions. During a classroom assignment, William loans a pencil to Jessica. You've seen William loaning things to Jessica before. Jessica reacts by shoving William hard. Imagine you did not know how Jessica reacted to the situation. Assuming the situation resulted in one of the two outcomes listed below, how likely is it that you would have predicted each outcome? (Probabilities must add to equal 100\%).

Jessica would react by shoving William hard

Jessica would react by ignoring William $\%$ $\%$

1. How serious is this situation?
\begin{tabular}{c|}
1 \\
Not at all
\end{tabular}
\begin{tabular}{c|c}
2 & 3 \\
A little & Moderately
\end{tabular}
\begin{tabular}{c|c}
4 \\
Very
\end{tabular}
5
Extremely

2. How safe is this situation?
\begin{tabular}{c|}
1 \\
Not at all
\end{tabular}
\begin{tabular}{c|c}
2 & 3 \\
A little & Moderately
\end{tabular}
$\stackrel{4}{\text { Very }}$
5
Extremely

3. How concerned are you about this situation?
Not at all
\begin{tabular}{c|c}
2 & 3 \\
A little & Moderately
\end{tabular}
\begin{tabular}{c|c|c}
4 \\
Very
\end{tabular}
5
Extremely

4. How likely are you to disregard this situation?
1
Not at all
\begin{tabular}{c|c|}
2 & 3 \\
A little & Moderately
\end{tabular}
4
Very
Extremely

5. How harmful is this situation?
\begin{tabular}{c|}
1 \\
Not at all
\end{tabular}
\begin{tabular}{c|c}
2 & 3 \\
A little & Moderately
\end{tabular}
\begin{tabular}{c|c}
4 \\
Very
\end{tabular}
5
Extremely

6. How likely are you to intervene in this situation?
Not at all
\begin{tabular}{c|c}
2 & 3 \\
A little & Moderately
\end{tabular}
\begin{tabular}{c|c|c}
4 & \\
Very
\end{tabular}
5
Extremely

7. How likely are you to label this situation as bullying?

\begin{tabular}{c|c|c|c|c}
1 & 2 & 3 & 4 & 5 \\
Not at all & A little & Moderately & Very & Extremely
\end{tabular}

As a teacher, if you would respond to this situation...

How would you respond to William?

How would you respond to Jessica?

Is there anything else you would do in this situation? 
Please read the following scenario carefully. Then, answer each of the questions. During a classroom assignment, Jennifer loans a pencil to Alyssa. You've seen Jennifer loaning things to Alyssa before.

Assuming the situation resulted in one of the two outcomes listed below, how likely is it that you would have predicted each outcome? (Probabilities must add to equal $100 \%$ ).

Alyssa would react by shoving Jennifer hard

Alyssa would react by ignoring Jennifer $\%$

1. How serious is this situation?

\begin{tabular}{c|c|c|c|c}
1 & 2 & 3 & 4 & 5 \\
Not at all & A little & Moderately & Very & Extremely
\end{tabular}

2. How safe is this situation?

\begin{tabular}{c|c|c|c|c}
1 & 2 & 3 & 4 & 5 \\
Not at all & A little & Moderately & Very & Extremely
\end{tabular}

3. How concerned are you about this situation?

\begin{tabular}{c|c|c|c|c}
1 & 2 & 3 & 4 & 5 \\
Not at all & A little & Moderately & Very & Extremely
\end{tabular}

4. How likely are you to disregard this situation?

\begin{tabular}{c|c|c|c|c}
1 & 2 & 3 & 4 & 5 \\
Not at all & A little & Moderately & Very & Extremely
\end{tabular}

5. How harmful is this situation?

\begin{tabular}{c|c|c|c|c}
1 & 2 & 3 & 4 & 5 \\
Not at all & A little & Moderately & Very & Extremely
\end{tabular}

6. How likely are you to intervene in this situation?

\begin{tabular}{c|c|c|c|c}
1 & 2 & 3 & 4 & 5 \\
Not at all & A little & Moderately & Very & Extremely
\end{tabular}

7. How likely are you to label this situation as bullying?

\begin{tabular}{c|c|c|c|c}
1 & 2 & 3 & 4 & 5 \\
Not at all & A little & Moderately & Very & Extremely
\end{tabular}

As a teacher, if you would respond to this situation...

How would you respond to Jennifer?

How would you respond to Alyssa?

Is there anything else you would do in this situation? 
Please read the following scenario carefully. Then, answer each of the questions. During a classroom assignment, Jennifer loans a pencil to Alyssa. You've seen Jennifer loaning things to Alyssa before. Alyssa reacts by ignoring Jennifer.

Imagine you did not know how Alyssa reacted to the situation. Assuming the situation resulted in one of the two outcomes listed below, how likely is it that you would have predicted each outcome? (Probabilities must add to equal 100\%).

Alyssa would react by shoving Jennifer hard

Alyssa would react by ignoring Jennifer $\%$

1. How serious is this situation?

\begin{tabular}{c|c|c|c|c}
1 & 2 & 3 & 4 & 5 \\
Not at all & A little & Moderately & Very & Extremely
\end{tabular}

2. How safe is this situation?

\begin{tabular}{c|c|c|c|c}
1 & 2 & 3 & 4 & 5 \\
Not at all & A little & Moderately & Very & Extremely
\end{tabular}

3. How concerned are you about this situation?

\begin{tabular}{c|c|c|c|c}
1 & 2 & 3 & 4 & 5 \\
Not at all & A little & Moderately & Very & Extremely
\end{tabular}

4. How likely are you to disregard this situation?

\begin{tabular}{c|c|c|c|c}
1 & 2 & 3 & 4 & 5 \\
Not at all & A little & Moderately & Very & Extremely
\end{tabular}

5. How harmful is this situation?

\begin{tabular}{c|c|c|c|c}
1 & 2 & 3 & 4 & 5 \\
Not at all & A little & Moderately & Very & Extremely
\end{tabular}

6. How likely are you to intervene in this situation?

\begin{tabular}{c|c|c|c|c}
1 & 2 & 3 & 4 & 5 \\
Not at all & A little & Moderately & Very & Extremely
\end{tabular}

7. How likely are you to label this situation as bullying?

\begin{tabular}{c|c|c|c|c}
1 & 2 & 3 & 4 & 5 \\
Not at all & A little & Moderately & Very & Extremely
\end{tabular}

As a teacher, if you would respond to this situation...

How would you respond to Jennifer?

How would you respond to Alyssa?

Is there anything else you would do in this situation? 
Please read the following scenario carefully. Then, answer each of the questions. During a classroom assignment, Jennifer loans a pencil to Alyssa. You've seen Jennifer loaning things to Alyssa before. Alyssa reacts by shoving Jennifer hard. Imagine you did not know how Alyssa reacted to the situation. Assuming the situation resulted in one of the two outcomes listed below, how likely is it that you would have predicted each outcome? (Probabilities must add to equal 100\%).

Alyssa would react by shoving Jennifer hard

Alyssa would react by ignoring Jennifer $\%$

1. How serious is this situation?

\begin{tabular}{c|c|c|c|c}
1 & 2 & 3 & 4 & 5 \\
Not at all & A little & Moderately & Very & Extremely
\end{tabular}

2. How safe is this situation?

\begin{tabular}{c|c|c|c|c}
1 & 2 & 3 & 4 & 5 \\
Not at all & A little & Moderately & Very & Extremely
\end{tabular}

3. How concerned are you about this situation?

\begin{tabular}{c|c|c|c|c}
1 & 2 & 3 & 4 & 5 \\
Not at all & A little & Moderately & Very & Extremely
\end{tabular}

4. How likely are you to disregard this situation?

\begin{tabular}{c|c|c|c|c}
1 & 2 & 3 & 4 & 5 \\
Not at all & A little & Moderately & Very & Extremely
\end{tabular}

5. How harmful is this situation?
Not at all
\begin{tabular}{c|c}
2 & 3 \\
A little & Moderately
\end{tabular}
4
Very
5
Extremely

6. How likely are you to intervene in this situation?
Not at all
A little
3
Moderately
4
Very
Extremely

7. How likely are you to label this situation as bullying?

\begin{tabular}{c|c|c|c|c}
1 & 2 & 3 & 4 & 5 \\
Not at all & A little & Moderately & Very & Extremely
\end{tabular}

As a teacher, if you would respond to this situation...

How would you respond to Jennifer?

How would you respond to Alyssa?

Is there anything else you would do in this situation? 
Please read the following scenario carefully. Then, answer each of the questions.

During a classroom assignment, Madison loans a pencil to Robert. You've seen Madison loaning things to Robert before.

Assuming the situation resulted in one of the two outcomes listed below, how likely is it that you would have predicted each outcome? (Probabilities must add to equal $100 \%$ ).

Robert would react by shoving Madison hard

Robert would react by ignoring Madison $\%$

$\%$

1. How serious is this situation?

\begin{tabular}{c|c|c|c|c}
1 & 2 & 3 & 4 & 5 \\
Not at all & A little & Moderately & Very & Extremely
\end{tabular}

2. How safe is this situation?

\begin{tabular}{c|c|c|c|c}
1 & 2 & 3 & 4 & 5 \\
Not at all & A little & Moderately & Very & Extremely
\end{tabular}

3. How concerned are you about this situation?

\begin{tabular}{c|c|c|c|c}
1 & 2 & 3 & 4 & 5 \\
Not at all & A little & Moderately & Very & Extremely
\end{tabular}

4. How likely are you to disregard this situation?

\begin{tabular}{c|c|c|c|c}
1 & 2 & 3 & 4 & 5 \\
Not at all & A little & Moderately & Very & Extremely
\end{tabular}

5. How harmful is this situation?

\begin{tabular}{c|c|c|c|c}
1 & 2 & 3 & 4 & 5 \\
Not at all & A little & Moderately & Very & Extremely
\end{tabular}

6. How likely are you to intervene in this situation?

\begin{tabular}{c|c|c|c|c}
1 & 2 & 3 & 4 & 5 \\
Not at all & A little & Moderately & Very & Extremely
\end{tabular}

7. How likely are you to label this situation as bullying?

\begin{tabular}{c|c|c|c|c}
1 & 2 & 3 & 4 & 5 \\
Not at all & A little & Moderately & Very & Extremely
\end{tabular}

As a teacher, if you would respond to this situation...

How would you respond to Madison?

How would you respond to Robert?

Is there anything else you would do in this situation? 
Please read the following scenario carefully. Then, answer each of the questions. During a classroom assignment, Madison loans a pencil to Robert. You've seen Madison loaning things to Robert before. Robert reacts by ignoring Madison.

Imagine you did not know how Robert reacted to the situation. Assuming the situation resulted in one of the two outcomes listed below, how likely is it that you would have predicted each outcome? (Probabilities must add to equal 100\%).

Robert would react by shoving Madison hard

Robert would react by ignoring Madison $\%$

1. How serious is this situation?

\begin{tabular}{c|c|c|c|c}
1 & 2 & 3 & 4 & 5 \\
Not at all & A little & Moderately & Very & Extremely
\end{tabular}

2. How safe is this situation?

\begin{tabular}{c|c|c|c|c}
1 & 2 & 3 & 4 & 5 \\
Not at all & A little & Moderately & Very & Extremely
\end{tabular}

3. How concerned are you about this situation?

\begin{tabular}{c|c|c|c|c}
1 & 2 & 3 & 4 & 5 \\
Not at all & A little & Moderately & Very & Extremely
\end{tabular}

4. How likely are you to disregard this situation?

\begin{tabular}{c|c|c|c|c}
1 & 2 & 3 & 4 & 5 \\
Not at all & A little & Moderately & Very & Extremely
\end{tabular}

5. How harmful is this situation?

\begin{tabular}{c|c|c|c|c}
1 & 2 & 3 & 4 & 5 \\
Not at all & A little & Moderately & Very & Extremely
\end{tabular}

6. How likely are you to intervene in this situation?

\begin{tabular}{c|c|c|c|c}
1 & 2 & 3 & 4 & 5 \\
Not at all & A little & Moderately & Very & Extremely
\end{tabular}

7. How likely are you to label this situation as bullying?

\begin{tabular}{c|c|c|c|c}
1 & 2 & 3 & 4 & 5 \\
Not at all & A little & Moderately & Very & Extremely
\end{tabular}

As a teacher, if you would respond to this situation...

How would you respond to Madison?

How would you respond to Robert?

Is there anything else you would do in this situation? 
Please read the following scenario carefully. Then, answer each of the questions. During a classroom assignment, Madison loans a pencil to Robert. You've seen Madison loaning things to Robert before. Robert reacts by shoving Madison hard. Imagine you did not know how Robert reacted to the situation. Assuming the situation resulted in one of the two outcomes listed below, how likely is it that you would have predicted each outcome? (Probabilities must add to equal 100\%).

Robert would react by shoving Madison hard

Robert would react by ignoring Madison $\%$

1. How serious is this situation?
\begin{tabular}{c|}
1 \\
Not at all
\end{tabular}
A little
$\stackrel{3}{\text { Moderately }}$
4
Very
5
Extremely

2. How safe is this situation?
\begin{tabular}{c|}
1 \\
Not at all
\end{tabular}
2
A little
$\stackrel{3}{\text { Moderately }}$
4
Very
5
Extremely

3. How concerned are you about this situation?

\begin{tabular}{c|c|c|c|c}
1 & 2 & 3 & 4 & 5 \\
Not at all & A little & Moderately & Very & Extremely
\end{tabular}

4. How likely are you to disregard this situation?

\begin{tabular}{c|c|c|c|c}
1 & 2 & 3 & 4 & 5 \\
Not at all & A little & Moderately & Very & Extremely
\end{tabular}

5. How harmful is this situation?

\begin{tabular}{c|c|c|c|c}
1 & 2 & 3 & 4 & 5 \\
Not at all & A little & Moderately & Very & Extremely
\end{tabular}

6. How likely are you to intervene in this situation?

\begin{tabular}{c|c|c|c|c}
1 & 2 & 3 & 4 & 5 \\
Not at all & A little & Moderately & Very & Extremely
\end{tabular}

7. How likely are you to label this situation as bullying?
1
Not at all

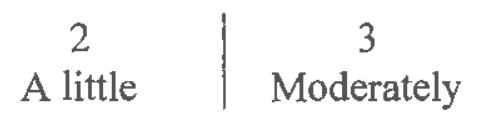
4
Very
Extremely

As a teacher, if you would respond to this situation...

How would you respond to Madison?

How would you respond to Robert?

Is there anything else you would do in this situation? 


\section{Appendix B: \\ Email Invitation to Participate}

Hello,

My name is Karen Sherman, and I am a graduate student in the School Psychology Ph.D. program at the University of Rhode Island. I am currently conducting research for my dissertation. The purpose of this project is to investigate teachers' perceptions of bullying among youth. You are one of about 144 teachers across the Unites Sates being invited to participate in this research. The survey will only take 20-30 minutes of your time, and you will be contributing to valuable research as well as helping me, as a student, complete my degree. To participate, you must be at least I 8 years old and currently working as a teacher. This research is completely confidential, and your name will never be used, released to anyone else, or connected with the data in any way. If you would like to participate, simply click the link below or copy and paste it into your web browser, and you will be directed to the online survey site where you will receive more information regarding this research. Please forward this invitation to any colleagues or friends that may also be eligible to participate.

Thank you in advance, Karen

Link to survey appeared here.

Karen J. Sherman, M.A.

School Psychology

University of Rhode Island

karenjean.sherman @agmail.con 
Appendix C:

Informed Consent Form

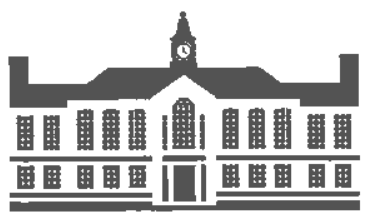

UN I VER S I T Y OF

Rhode Island

\section{INFORMED CONSENT FORM}

Title of Research Project: $\quad$ Teachers' Perceptions of Bullying Among Youth: Hindsight bias in relation to victim responses.

Principal Investigator:

Karen J. Sherman, M.A. $\quad 401-699-1220$

Major Professor:

W. Grant Willis, Ph.D. $\quad$ 401-874-4245

DESCRIPTION OF THE RESEARCH AND THE RIGHTS OF PARTICIPANTS You have been asked to take part in a study described below. If you have more questions later, call 401-699-1220, and Karen J. Sherman, the person mainly responsible for this study will discuss them with you.

1. Purpose of Study: The purpose of this project is to investigate teachers' perceptions of bullying among youth.

2. Procedures: You are one of about 144 teachers who will be asked to respond to questions about attitudes and behaviors related to bullying among youth. There are no right or wrong answers, just answer what is true for you. To participate, you must be 18 years of age and be able to read English. Your participation should last about 20-30 minutes.

3. Risks: There are minimal risks associated with participating in this research. If the survey raises any issues, concerns, or distress, we urge you to contact the University of Rhode Island Counseling Center at 401-874-5010.

4. Benefits: You may not receive any direct benefit from taking part in this study. Taking part in the study may help others in the future. This is why your ideas are so important. Some people may find participation in this research informative and personally beneficial.

5. Costs/Payment: This project is being funded by Karen J. Sherman and the University of Rhode Island. There will be no costs to you, except your time spent taking the survey. 
6. Confidentiality: Participation in this project is confidential and anonymous. Your information will not be shared with any organizations. Your name will never be collected and therefore cannot be connected with your data. Research summaries will combine all the information collected. No individual information will be reported. Data will be stored in statistical analysis software (SPSS), on a computer that is password protected. Only the principal investigator will have access to this computer and the data.

7. Right to Refuse to Participate: The decision whether or not to take part in this study is up to you. If you decide not to participate, simply do not complete the survey.

8. Questions/Concerns: This study is being conducted by Karen J. Sherman under the direction of W. Grant Willis at the University of Rhode Island. If you have any questions or concerns about this study, please contact Ms. Sherman at 401-699-1220 or Dr. Willis at 401-874-4245.

If you have questions or concerns about your rights as a participant, if this study causes you any harm, or if you feel you are receiving pressure to continue in this study against your wishes, you may also contact the University of Rhode Island's Vice President for Research, 70 Lower College Road, Suite 2, URI, Kingston, RI, (401) 8744328.

You understand that you may ask any additional questions at any time, that your participation in this project is voluntary, and that you may withdraw from this project at any time. Your decision to complete a survey means that you understand the information provided and you agree to participate in this project.

Karen J. Sherman, M.A.

Principal Investigator's Name

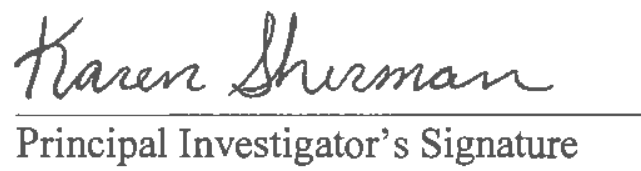




\section{Appendix D: Debriefing Form}

About This Research

The survey you have just completed was developed by Karen J. Sherman, a school-psychology graduate student at the University of Rhode Island. This research, titled "Teachers' Perceptions of Bullying Among Youth: Hindsight Bias in Relation to Victim Responses." is being conducted in order to fulfill requirements for a doctoral degree in Psychology. You are one of approximately 144 teachers who volunteered to participate in this research.

As a common, persistent, and detrimental occurrence in schools, bullying has significant potential to undermine the social, emotional, behavioral, and psychological well being of children and youth. This research seeks to assess the perceived severity of different kinds of bullying situations. For example, three kinds of bullying are physical (i.e., behaviors that harm others through physical damage or through the threat of physical or property damage), verbal (i.e., making mean comments or calling names with the intention of harm), and relational (i.e., manipulation or control of social relationships such as threatening to end a friendship, social exclusion, or rumor spreading). Bullies and their victims can be either of the same or different genders. Victims of bullying may also react to these provocations in difference manners, specifically by becoming physically aggressive themselves, or being passive. These outcomes may affect the way the situations are perceived by teachers who are likely to witness the bullying. By investigating teachers' perceptions of and reactions to bullying, it is hoped that the phenomenon can be better described and explained and that well informed interventions might be developed to address this problem in schools.

If you have any questions or concerns about this study, please contact Karen Sherman at 401-699-1220. I appreciate your participation very much. 
Appendix E: Sources of Variation in Research Designs

Table 18. Sources of Variation in Research Designs

\begin{tabular}{|c|c|}
\hline Source of Variation & $d f \begin{array}{cc}\text { Sum of } & \text { Mean } \\
\text { Squares } & \text { Square }\end{array}$ \\
\hline Condition & 2 \\
\hline Kind of Aggression & 3 \\
\hline Gender of Actor & 1 \\
\hline Gender of Receiver & 1 \\
\hline Kind of Aggression $\mathrm{x}$ Actor & 3 \\
\hline Kind of Aggression $\mathrm{x}$ Receiver & 3 \\
\hline Kind of Aggression $x$ Condition & 6 \\
\hline Actor $\mathrm{x}$ Receiver & 1 \\
\hline Actor $\mathrm{x}$ Condition & 2 \\
\hline Receiver $\mathrm{x}$ Condition & 2 \\
\hline Kind of Aggression $\mathrm{x}$ Actor $\mathrm{x}$ Receiver & 3 \\
\hline Kind of Aggression $\mathrm{x}$ Actor $\mathrm{x}$ Condition & 6 \\
\hline Kind of Aggression $x$ Receiver $x$ Condition & 6 \\
\hline Actor $\mathrm{x}$ Receiver $\mathrm{x}$ Condition & 2 \\
\hline $\begin{array}{l}\text { Kind of Aggression x Actor } \mathrm{x} \text { Receiver } \mathrm{x} \\
\text { Condition }\end{array}$ & 6 \\
\hline
\end{tabular}




\section{Bibliography}

American Psychological Association. (2002). Ethical principles of psychologists and code of conduct. American Psychologist, 57, 1060-1073.

Arkes, H.R., Faust, D., Guilmette, T.J., \& Hart, K. (1988). Eliminating the hindsight bias. Journal of Applied Psychology, 73, 305-307.

Bauman, S. \& Del Rio, A. (2006). Preservice teachers' response to bullying scenarios: Comparing physical, verbal, and relational bullying. Journal of Educational Psychology, 98, 219-231.

Blank, H., Musch, J., \& Pohl, R.F. (2007). Hindsight bias: On being wise after the event. Social Cognition, 25, 1-9.

Brockenbrough, K.K., Cornell, D.G., \& Loper, A.B. (2002). Aggressive attitudes among victims of violence at school. Education and Treatment of Children, 25, 273-287.

Cairns, R.B., Cairns, B.D., Neckerman, H.J., Ferguson, L.L., \& Gariepy, J.L. (1989). Growth and aggression: 1. Childhood to early adolescence. Developmental Psychology, 25, 320-330.

Carli, L.L. (1999). Cognitive reconstruction, hindsight, and reactions to victims and perpetrators. Personality and Social Psychology Bulletin, 25, 966-979.

Cohen, J. (1988). Statistical power analysis for the behavioral sciences (2nd edition). Hillsdale, NJ: Erlbaum.

Coie, J.D. \& Dodge, K.A. (1983). Continuities and changes in children's social status: A five-year longitudinal study. Merrill-Palmer Quarterly, 29, 261-282.

Craig, W.M., Henderson, K., \& Murphy, J.G. (2000). Prospective teachers' attitudes toward bullying and victimization. School Psychology International, 2I(5).

Crick, N.R. (1997). Engagement in gender normative versus non-normative forms of aggression: Links to social-psychological adjustment. Developmental $P_{\text {sychology, }}$ $33,610-617$.

Crick, N.R., \& Bigbee, M.A. (1998). Relational and physical forms of peer victimization: A multiinformant approach. Journal of Consulting and Clinical Psychology, 66, 337-347.

Crick, N.R., \& Grotpeter, J.K. (1995). Relational aggression, gender, and socialpsychological adjustment. Child Development, 66, 710-722. 
Cronbach, L.J., Gleser, G.C., Nanda, H., \& Ragaratnam, N. (1972). The dependability of behavioral measurements theory of generalizability for scores and profiles. New York: John Wiley \& Sons, Inc.

Cullerton-Sen, C. \& Crick, N.R. (2005). Understanding the effects of physical and relational victimization: The utility of multiple perspectives in predicting socialemotional adjustment. School Psychology Review, 34, 147-160.

Dake, J.A., Price, J.H., Telljohann, S.K., \& Funk, J.B. (2003). Teacher perceptions and practices regarding school bullying prevention. Journal of School Health, 73, 347-355.

Dodge, K.A., \& Coie, J.D. (1987). Social-information-processing factors in reactive and proactive aggression in children's peer groups. Journal of Personality and Social Psychology, 53, 1146-1158.

Fekkes, M., Pijpers, F.I.M., \& Verloove-Vanhorick, S.P. (2005). Bullying: who does what, when and where? Involvement of children, teachers and parents in bullying behavior. Health Education Research, 20, 81-91.

Fischhoff, B. (1975). Hindsight unequal to Foresight: The effect of outcome knowledge on judgment under uncertainty. Journal of Experimental Psychology: Human Perception and Performance, 1, 288-299.

Fischhoff, B. (1977). Perceived informativeness of facts. Journal of Experimental Psychology: Human Perception and Performance, 3, 349-358.

Fischhoff, B. \& Beyth, R. (1975) "I knew it would happen" Remembered probabilities of once-future things. Organizational Behavior and Human Performance, 13, 116.

Forero, R., McLellan, L., Rissel, C., \& Bauman, A. (1999). Bullying behavior and psychological health among school students in New South Wales, Australia: cross sectional survey. British Medical Journal, 319, 344-348.

Galen, B.R. \& Underwood, M.K. (1997). A developmental investigation of social aggression among children. Developmental Psychology, 33, 589-600.

Girden, E. R. (1992). ANOVA: Repeated Measures. Thousand Oaks, CA: Sage.

Granello, D.H. \& Wheaton, J.E. (2004). Online data collection: Strategies for research. Journal of Counseling \& Development, 82, 387-393.

Greenhouse, S.W. \& Geisser, S. (1959). On methods in the analysis of profile data. Psychometrika, 24, 95-112. 
Guilbault, R.L., Bryant, F.R., Brockway, J.H., \& Posavac, E.J. (2004). A metaanalysis of research on hindsight bias. Basic and Applied Social Psychology, 26, 103-117.

Hoglund, W.L.G. (2007). School functioning in early adolescence: Linked-responses to peer victimization. Journal of Educational Psychology, 99, 683-699.

Huynh, H. \& Feldt, L.S. (1976). Estimation of the Box correction for degrees of freedom from sample data in randomized block and split-plot designs. Journal of Educational Statistics, $1,69-82$.

Juvonen, J., \& Graham, S. (Eds.). (2001). Peer harassment in school: The plight of the vulnerable and victimized. New York, NY: The Guilford Press.

Juvonen, J., Nishina, A., \& Graham, S. (2001). Self-views versus peer perceptions of victim status among early adolescents. In: Juvonen, J. \& Graham, S (Eds.). Peer harassment in school: The plight of the vulnerable and victimized. New York, NY: The Guilford Press.

Koriat, A., Lichtenstein, S., \& Fischhoff, B. (1980). Reasons for confidence. Journal of Experimental Psychology: Human Learning and Memory, 6(2).

Kumpulainen, K., Rasanen, E., \& Henttonen, I. (1998). Bullying and psychiatric symptoms among elementary school children. Child Abuse \& Neglect, 22, 705717.

Lagerspetz, K.M.J., Bjorkqvist, K., \& Peltonen, T. (1988). Is indirect aggression typical of females? Gender differences in aggressiveness in 11- to 12-year-old children. Aggressive Behavior, 14, 403-414.

Mauchly, J.W. (1940). Significance Test for Sphericity of a Normal n-Variate Distribution. The Annals of Mathematical Statistics, 11, 204-209.

Nansel, T.R., Overpeck, M., Pilla, R.S., Ruan, W.J., Simons-Morton, B., \& Scheidt, P. (2001). Bullying behaviors among U.S. youth. Journal of the American Medical Association, 285, 2094-2100.

National Association of School Psychologists. (2010). Principles for Professional Ethics. Retrieved on August 20, 2010, from:

http://www.nasponline.org/standards/2010standards/1_\%20Ethical\%20Principles. pdf

Naylor, P., Cowie, H., Cossin, F., de Bettencourt, R., \& Lemme, F. (2006). Teachers' and pupils' definitions of bullying. British Journal of Educational Psychology, 76, 553-576.

Olweus, D. (1991) Bully/victim problems among schoolchildren: Basic facts and effects of a school based intervention program. In Pepler, D.J. and Rubin, K.H. 
(eds), The Development and Treatment of Childhood Aggression. Lawrence Erlbaum, Hillsdale, NJ, pp. 411-448.

Olweus, D. (1993). Bullying at school: What we know and what we can do. Oxford, UK, and Cambridge, MA: Blackwell.

Olweus, D. (2001). General information about the Revised Olweus Bully/Victim Questionnaire, PC Program and Teacher handbook. Personal communication received from Dan Olweus on August 22, 2008.

Paquette, J.A. \& Underwood, M.K. (1999). Gender differences in young adolescents' experiences of peer victimization: Social and physical aggression. Merrill-Palmer Quarterly, 45, 242-266.

Pellegrini, A.D. (1998). Bullies and victims in school: A review and call for research. Journal of Applied Developmental Psychology, 19, 165-176.

Pellegrini, A.D., Bartini, M., \& Brooks, F. (1999). School bullies, victims, and aggressive victims: Factors relating to group affiliation and victimization in early adolescence. Journal of Educational Psychology, 91, 216-224.

Prinstein, M.J., Boergers, J., \& Vernberg, E.M. (2001). Physical and relational aggression in adolescents: Social-psychological adjustment of aggressors and victims. Journal of Clinical Child Psychology, 30, 479-491.

Qualtrics (2010). Qualtrics. Retrieved from http://www.qualtrics.com.

Sawyer, A., Bradshaw, C., \& O'Brennan, L. (2008). Examining ethnic, gender, and developmental differences in the way children report being a victim of "bullying" on self-report measures. Journal of Adolescent Health, 43, 106-114.

Schwartz, D., Dodge, K.A., Petit, G.S., \& Bates, J.E. (1997). The early socialization and adjustment of aggressive victims of bullying. Child Development, 68, 885675 .

Sherman, K. (2009). Pre-service teachers' perceptions of bullying among youth: $A$ Generalizability Theory analysis. (Unpublished doctoral dissertation). University of Rhode Island, Kingston RI.

Smith, P.K., Cowie, H., Olafsson, R.F., \& Liefooghe, A.P.D. (2002). Definitions of bullying: A comparison of terms used, and age and gender differences, in a fourteen-country international comparison. Child Development, 73(4).

Smorti, A., Menesini, E., \& Smith, P.K. (2003). Parents' definitions of children's bullying in a five-country comparison. Journal of Cross-Cultural Psychology, 34, 417. 
Social Security Administration. (2010). Popular Baby Names. Retrieved from: http://www.ssa.gov/OACT/babynames on 12/15/2008.

Solberg, M.E., \& Olweus, D. (2003). Prevalence estimation of school bullying with the Olweus Bully/Victim Questionnaire. Aggressive Behavior, 29, 239-268.

Sourander, A., \& Helstela, L. (2000). Persistence of bullying from childhood to adolescence - A longitudinal 8-year follow-up study. Child Abuse \& Neglect, 24, 873-881.

Toblin, R.L., Schwartz, D., Gorman, A.H., \& Abou-esseddine, T. (2005). Socialcognitive and behavioral attributes of aggressive victims of bullying. Applied Developmental Psychology, 26, 329-346.

Tritt, C., \& Duncan, R. (1997). The relationship between childhood bullying and young adult self-esteem and loneliness. Journal of Humanistic Education and Development, 36, 35-45.

Troop-Gordon, W., \& Ladd, G.W. (2005). Trajectories of peer victimization and perceptions of the self and schoolmates: Precursors to internalizing and externalizing problems. Child Development, 76, 1072-1091.

University of Rhode Island (2010). Institutional Review Board Protection of Human Subjects: Policies and Procedures. Retrieved on August 20, 2010 from: http://www.uri.edu/research/tro/about/IRB/index.html.

Unnever, J.D. (2005). Bullies, aggressive victims, and victims: Are they distinct groups? Aggressive Behavior, 31, 153-171.

United States Census Bureau Regions (2012, January 2012). Census Bureau Regions and Divisions with State FIPS. Retrieved from

www.census.gov/geo/www/us_regdiv.pdf.

van der Wal, M.F., de Wit, C.A.M., \& Hirasing, R.A. (2003). Psychosocial health among young victims and offenders of physical and relational bullying. Pediatrics, $111,1312-1317$.

Weinke Tortura, C.M., Green, A.E., Karver, M.S., \& Gesten, E.L. (2009). Multiple informants in the assessment of psychological, behavioral, and academic correlates of bullying and victimization in middle school. Journal of Adolescence, 32, 193211.

Williams, E. J. (1949): Experimental designs balanced for the estimation of residual effects of treatments. Australian Journal of Scientific Research, A2, 149-168.

Wong, L.Y. (1995). Research on teaching: Process-product research findings and the feeling of obviousness. Journal of Educational Psychology, 87, 504-511. 
Yates, G.C.R. (2005). "How Obvious": Personal reflections on the database of educational psychology and effective teaching research. Educational Psychology, $25,681-700$.

Yoon, J.S. (2004). Predicting teacher interventions in bullying situations. Education and Treatment of Children, 27, 37-45.

Yoon, J.S. \& Kerber, K. (2003). Bullying Elementary teachers' attitudes and intervention strategies. Research in Education, 69. 